Um modelo arquitetural para captura e uso de informações de contexto em sistemas de anotações de vídeo

\author{
Roberto Fagá Júnior
}





\title{
Um modelo arquitetural para captura e uso de informações de contexto em sistemas de anotações de vídeo
}

\author{
Roberto Fagá Júnior
}

Orientadora: Profa. Dra. Maria da Graça Campos Pimentel

Dissertação apresentada ao Instituto de Ciências Matemáticas e de Computação - ICMC-USP, como parte dos requisitos para obtenção do título de Mestre em Ciências - Ciências de Computação e Matemática Computacional.

USP - São Carlos

Maio/2010 



\section{Agradecimentos}

À minha orientadora, profa. Dra Maria da Graça Campos Pimentel, por todo o apoio e amparo dados a minha pesquisa, pela autonomia oferecida, pela amizade e pela confiança.

Aos professores Rudinei e Junia por terem participado da minha banca de qualificação e contribuído com sugestões essenciais para minha pesquisa.

Aos colegas do laboratório Intermidia da USP, que me ajudaram a desenvolver o trabalho desta dissertação, além da amizade e companheirismo em todos os momentos.

Aos envolvidos com projetos de TV Digital do laboratório LINCE da UFSCar e também do Intermidia da USP, por possibilitaram discussões e ideias à minha pesquisa.

A todos os participantes das avaliações de meus protótipos, em especial aos alunos de graduação da disciplina de Interação Usuário-Computador de 2009 que participaram do estudo de caso.

Aos professores e funcionários do ICMC, que me ajudaram na graduação e no mestrado para concretizar minha formação.

À minha família, por sempre terem acreditado em mim e sempre estarem ao meu lado, aos quais devo tudo que consegui.

À minha noiva Isa, pelo apoio e carinho incondicionais e pelo companheirismo em todos os momentos de minha vida.

À FAPESP, pelo auxílio financeiro concedido para minha dedicação à pesquisa.

A Deus, por tudo. 


\section{Resumo}

Diversos pesquisadores vêm investigando métodos e técnicas para tornar possível às pessoas anotarem vídeos de modo transparente. A anotação pode ser realizada com a fala, com o uso de tinta digital ou algum outro meio que possa ser capturado enquanto a pessoa assiste ao vídeo. Tais anotações podem ser compartilhadas com outras pessoas, que podem estar assistindo ao mesmo vídeo em um mesmo instante ou em momentos diferentes, sendo interessante ainda que as anotações possam ser realizadas por várias pessoas de modo colaborativo. O paradigma Watch-and-Comment (WaC) propõe a captura transparente de anotações multimodais de usuários enquanto os mesmos assistem e comentam um vídeo. Como resultado desse processo, é gerado um vídeo digital interativo integrando o conteúdo original às anotações realizadas. Esta dissertação tem por objetivo explorar conceitos de computação ubíqua, redes sociais, redes peer-to-peer e TV interativa na proposta de um modelo arquitetural de ciência de informações de contexto para aplicações definidas segundo o paradigma WaC. O modelo explora a integração de um serviço ao paradigma, que auxilie ou forneça alternativas para que aplicações, do momento da captura ao acesso das anotações, utilizem informações de contexto do usuário, do vídeo e das anotações. O modelo também auxilia no estudo de colaboração entre usuários que realizam anotações em vídeos. Outra contribuição da dissertação é a prototipação de aplicações para avaliar e refinar o modelo proposto. São apresentadas extensões para a aplicação WaCTool, considerando o uso de redes sociais e de alternativas para a anotação em vídeos. 


\section{Abstract}

Researchers have been investigating methods and techniques to allow people to annotate videos ubiquitously. Annotations can be made using voice, digital ink or some other media that can be captured while a person watches a video. These annotations can be shared with other people, who can be watching a video on the same time or at a different one. Also, these annotations can be made by many people collaboratively. The Watch-and-Comment (WaC) paradigm aims at capturing multimodal annotations in an ubiquitous way, while users watch and comment some video. As a result, an interactive digital video is generated combining the original content and the annotations. The work reported on this thesis explores concepts such as ubiquitous computing, social networks, peer-to-peer networks and interactive digital TV, to propose an architectural context-aware model to the applications defined by WaC paradigm. The model proposes the integration of a new service to the paradigm, supporting applications on the annotation process by offering capture alternatives and using context information from user, video and annotations. Also, the model provides a study in collaborative annotation process. Another contribution of this thesis is the prototypes built to evaluate and upgrade the proposed model. The prototypes are extensions from WaCTool, considering the use of social networks and alternatives to annotate in videos. 


\section{Lista de Figuras}

3.1 Interação de um Context Broker no modelo CoBrA, adquirindo informações de contexto de dispositivos, agentes e sensores no ambiente. As informações são unidas em um modelo compartilhado com os dispositivos e agentes (Chen, 2004). . . . . . . . . 22

3.2 Visão geral do modelo de informações de contexto SeCoM (Bulcão Neto; Pimentel, 2006). . . . . . . . . . . . . . . . . . . . . . 24

3.3 Estrutura do framework SenSee, exibindo como é realizada a interação entre os componentes principais e os usuários (Aroyo et al., 2007a).

3.4 Estrutura do sistema Tribler, exibindo como é realizada a interação entre os usuários e a rede P2P. . . . . . . . . . . . . . . 27

3.5 Arquitetura proposta por Manzato et al. (2009). . . . . . . . . . 28

3.6 Parte da tela que o usuário visualiza enquanto assiste uma aplicação no CollaboraTV. Cada usuário é representado por um avatar contendo a expressão capturada do usuário correspondente. O usuário da esquerda apresenta o texto com uma mensagem de texto enviada. . . . . . . . . . . . . . . . 30

3.7 Exemplo de uso do sistema Telebuddies (Luyten et al., 2006). Uma questão é exibida em um televisor, em que a entrada do usuário é limitada a responder a questão entre as alternativas A, B, C e D. . . . . . . . . . . . . . . . 32

3.8 Ontologias diferentes em bases de dados P2P distribuídas (Skoutas et al., 2008). 
4.1 Arquitetura da ferramenta WaCTool com seus componentes Adaptado de Cattelan (2009, p.36) e Cattelan et al. (2008a). . . .

4.2 Ferramenta Watch-and-Comment Tool (WaCTool). O canto superior esquerdo mostra o vídeo em reprodução, que permite anotações de texto e áudio além de permitir captura de tela com um clique do quadro. Quando há a captura de tela, o quadro de vídeo atual aparece na região superior direita. Nessa janela é possível realizar anotações de tinta eletrônica e inserção de textos. No canto inferior esquerdo há uma janela de bate papo entre usuários que estão visualizando o mesmo vídeo, e na parte inferior direita uma janela com as sessões anotadas do vídeo (Cattelan et al., 2008a). . . . . . . . . . . . . . . . . . . .

4.3 Janela da ferramenta WaCTool que mostra os comandos de edição de vídeo que o usuário pode inserir (Cattelan et al., 2008a). .

4.4 Janela de compartilhamento das anotações, em que a raiz é o arquivo de vídeo e os nós são as anotações, que ficam internas aos usuários, associando-os diretamente (Cattelan et al., 2008a).

5.1 Construção em etapas do modelo. . . . . . . . . . . . . . . 46

5.2 Arquitetura do modelo Context Aware Peer-to-Peer Architecture (CAPPA). . . . . . . . . . . . . . . . . . . . . 49

5.3 Fluxo de informações do modelo CAPPA. . . . . . . . . . 50

5.4 Ontologias utilizadas no modelo CAPPA. . . . . . . . . . . 62

6.1 Diagrama com o fluxo das informações no processo de anotação da CWaCTool vl sobre um mesmo programa de TV (Motti et al., 2009). . . . . . . . . . . . . . . . . . . 75

6.2 Collaborative Watch-and-Comment Tool (CWaCTool) v1: ferramenta em funcionamento realizando anotação colaborativa (Motti et al., 2009). . . . . . . . . . . . . . . . . . . 75

6.3 CWaCTool v2: usuário realizando anotação de tinta enquanto assiste ao vídeo correspondente em (A) (Fagá Jr. et al., 2009a). . . 77

6.4 CWaCTool v2: janela de bate-papo sobreposta ao vídeo em reprodução. . . . . . . . . . . . . . . . . . 77

6.5 CWaCTool v2: durante a realização de uma anotação de texto, um possível modo de sugerir uma anotação auto-completando o texto digitado pelo usuário. . . . . . . . . . . . 78 
6.6 Arquitetura da CWaCTool. . . . . . . . . . . . . . . . . 78

6.7 Fluxo de informações na arquitetura da CWaCTool. . . . . . . . . 82

6.8 Tela de abertura para a CWaCTool, requisitando um nome de usuário. . . . . . . . . . . . . . . . . . . . 84

6.9 Tela inicial da CWaCTool, mostrando os diferentes elementos presentes na ferramenta. . . . . . . . . . . . . . . . 84

6.10Diagrama de sequência sobre um usuário utilizando a CWaCTool para anotação. . . . . . . . . . . . . . . 86

6.11 Aplicação no Orkut exibindo o código UID do usuário. . . . . . . . 88

6.12 Captura de tela da caixa de seleção do Orkut UID, código fornecido quando instalado a aplicação na Web. . . . . . . . . . . . 89

6.13Usuário realizando uma busca na CWaCTool, com capturas de tela em etapas: do início da busca em (A) a reprodução final em (G) . . . . . . . . . . . . . . . . . . 9 90

6.14 Parte da CWaCTool exibindo o painel inferior com os comentários do atual vídeo em reprodução e uma janela pop-up com uma anotação sendo realizada. . . . . . . . . . . . . . 91

6.15Site do Youtube com o novo comentário inserido pela CWaCTool, referenciando o tempo da anotação para o vídeo saltar ao ponto correspondente no vídeo. . . . . . . . . . . . . . . . . 92

6.16 Anotação de tinta, em que o usuário compartilha um vídeo (A) ou aceita um convite (B) e realiza anotações de tinta em (D). . . . . . 93

6.17 Anotação de texto, em que o usuário digitou apenas as duas primeiras letras e o restante é sugerido de acordo com o trecho do vídeo e anotações de outros usuários (C). Uma seta, na direita do campo de texto, permite selecionar outras sugestões (D) e ainda ver na linha do tempo (A) o vídeo (B). . . . . . . . . . . . . . . 94

6.18 Chat da ferramenta, com um usuário compartilhando um vídeo e em seguida compartilhando uma sessão de anotação de tinta. 96

6.19Seleção e gerenciamento dos grupos participantes pelo usuário. 96

6.20 Médias das pontuações relativas a avaliação Likert com 10 usuá-

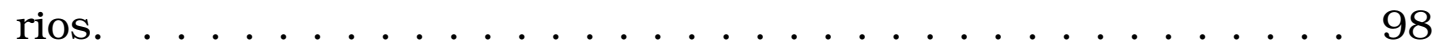

6.21 Médias das pontuações relativas a avaliação Likert com 22 usuários na CWaCToolv1. . . . . . . . . . . . . . . . . . . 99 
6.22 Anotações realizadas classificadas por tipo (voz, texto e tinta) e se foi colaborativa ou individual. . . . . . . . . . . . . 101 


\section{Lista de Tabelas}

2.1 Dados de domicílios particulares permanentes, por existência de alguns bens duráveis da população brasileira referente ao censo do IBGE (2008). . . . . . . . . . . . . . . . . . 16

3.1 Categorias de modelos de contexto seguindo classificação de Strang e Popien (2004). . . . . . . . . . . . . . . . . . . . . 20

5.1 Diferentes fontes de informações para o modelo CAPPA. . . . . . . 51

6.1 Ações dos usuários realizadas no estudo de caso da CWaCTool. . 100

A. 1 Itens para usuário avaliar a ferramenta CWaCTool em cinco diferentes questões. . . . . . . . . . . . . . . 126 


\section{Lista de Acrônimos}

APIs Application Programming Interfaces

ARFF Attribute-Relation File Format

ATSC Advanced Television System Committee

CAPPA Context Aware Peer-to-Peer Architecture

CAPPAS Context Aware Peer-to-Peer Architecture Service

CPU Central Processing Unit

CSCW Computer Supported Cooperative Work

CWaCTool Collaborative Watch-and-Comment Tool

DTV TV Digital

DVB-T Digital Video Broadcasting-Terrestrial

EMMA Extensible MultiModal Annotation markup language

FCA Formal Concept Analysis

GPS Global Positioning System

HDTV High Definition TV, ou TV de Alta Definição

iDTV interactive Digital TV, ou TV Digital interativa

IPTV Internet Protocol TV, ou TV por IP

ISDB-T Integrated Services Digital Broadcasting Terrestrial

ISDTV International System for Digital Television

iTV TV Interativa 
M4Note MultiMedia MultiModal Annotation Tool

MHP Multimedia Home Platform

NCL Ginga Nested Context Language

OWL Web Ontology Language

P2P Peer-to-Peer

PC Computador Pessoal

PDA Personal Digital Assistant

PDAs Personal Digital Assistants

RDF Resource Description Framework

RFID Radio-Frequency Identification

SAX Simple API for XML

SBTVD Sistema Brasileiro de TV Digital

SeCoM Semantic Context Model

SMIL Synchronized Multimedia Integration Language

SVG Scalable Vector Graphics

Tidia Tecnologia da Informação no Desenvolvimento da Internet Avançada

Tidia-Ae Tecnologia da Informação no Desenvolvimento da Internet Avançada - Aprendizado Eletrônico

TVDI Televisão Digital Interativa

URL Uniform Resource Locator

W3C World Wide Web Consortium

WaC Watch-and-Comment

WaCTool Watch-and-Comment Tool

XML Extensible Markup Language

XSLT XML Stylesheets 


\section{Sumário}

1 Introdução 1

1.1 Contextualização e Motivação . . . . . . . . . . . . . . . 1

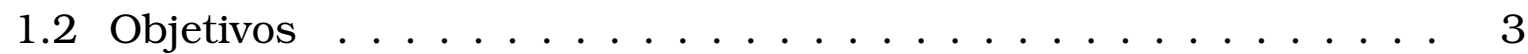

1.3 Metodologia de Construção do Modelo . . . . . . . . . . . . 4

1.4 Definição do Modelo . . . . . . . . . . . . . . 5

1.5 Organização da Dissertação . . . . . . . . . . . . . 6

2 Fundamentação Teórica $\quad 7$

2.1 Computação Ubíqua . . . . . . . . . . . . . . . 7

2.1.1 Captura Automática e Acesso . . . . . . . . . . . . 8

2.1.2 Computação Ciente de Informações de Contexto . . . . . . 9

2.2 Sistemas de Recomendação . . . . . . . . . . . . . . . 11

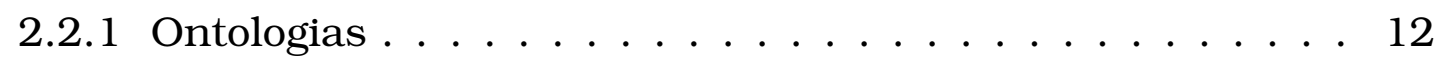

2.2.2 Extração de Conhecimento . . . . . . . . . . . . . 13

2.3 Colaboração e Aspectos Sociais . . . . . . . . . . . . 13

2.3.1 Social TV ................... 14

2.3.2 Redes P2P ..................... 14

2.4 TV Digital Interativa . . . . . . . . . . . . . . 15

2.5 Considerações Finais . . . . . . . . . . . . . . 17

3 Trabalhos Relacionados $\quad 19$

xix 
3.1 Sistemas e Modelos Cientes de Contexto . . . . . . . . . . . . . 19

3.1 .1 Context Toolkit . . . . . . . . . . . . . . 20

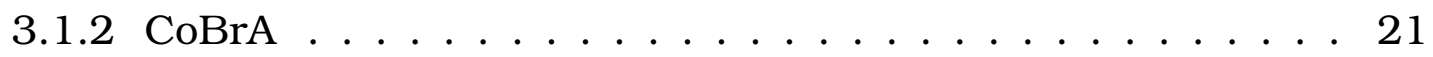

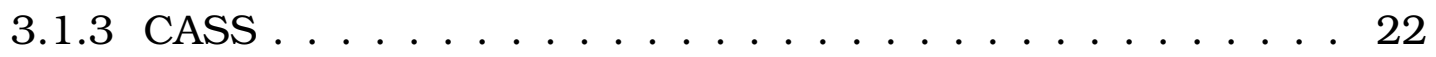

3.1 .4 IM4Sports . . . . . . . . . . . . . . . 23

$3.1 .5 \mathrm{SeCoM} \ldots \ldots \ldots \ldots \ldots \ldots \ldots$

3.2 Sistemas de Recomendação Multimídia . . . . . . . . . . . . . . 24

3.2 .1 SenSee . . . . . . . . . . . . . . . . . . 25

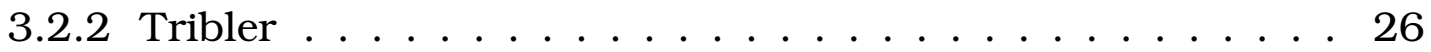

3.2 .3 M4Note . . . . . . . . . . . . . . 27

3.2 .4 Social $\mathrm{CAB} \ldots \ldots \ldots \ldots \ldots \ldots \ldots$

3.3 Sistemas Colaborativos de Vídeo _ . . . . . . . . . . . . . 29

3.3 .1 AmigoTV . . . . . . . . . . . . . . . . . . 29

3.3 .2 CollaboraTV . . . . . . . . . . . . . . . . 30

3.3 .3 Telebuddies . . . . . . . . . . . . . . . . . . . 31

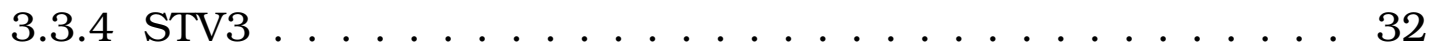

3.3 .5 PersonalTV . . . . . . . . . . . . . . 33

3.3.6 Outros Trabalhos Relevantes . . . . . . . . . . . . . . 33

3.4 Sistemas Peer-to-Peer . . . . . . . . . . . . . . . . . . 34

3.5 Considerações Finais $\ldots \ldots \ldots \ldots$

4 Paradigma Watch-and-Comment $\quad 37$

4.1 Proposta Watch-and-Comment . . . . . . . . . . . . . 38

4.2 Protótipo WaCTool . . . . . . . . . . . . . . . . 40

4.3 Considerações Finais . . . . . . . . . . . . . . . . . 44

5 Modelo Arquitetural CAPPA $\quad 45$

5.1 Construção do Modelo CAPPA . . . . . . . . . . . . . . 46

5.2 Requisitos para o Modelo . . . . . . . . . . . . . . . . . . 48

5.3 Arquitetura do Modelo CAPPA . . . . . . . . . . . . . . 49 
5.4 Fontes de Informações e Dados . . . . . . . . . . . . . . . 51

5.5 Informações sobre o Usuário . . . . . . . . . . . . . . . . 52

5.5 .1 Elemento user . . . . . . . . . . . . . . . . . . . 53

5.5 .2 Elemento location . . . . . . . . . . . . . . . . . . 55

5.5 .3 Elemento media . . . . . . . . . . . . . . . . . . . 56

5.5 .4 Elemento device . . . . . . . . . . . . . . . . . . . 57

5.5 .5 Elemento interaction . . . . . . . . . . . . . . . 58

5.6 Ontologias . . . . . . . . . . . . . . . . . 61

5.7 Raciocínio . . . . . . . . . . . . . . . . . . . . . 64

5.7 .1 Plataforma WEKA . . . . . . . . . . . . . . 65

5.7 .2 Máquina de Inferência . . . . . . . . . . . . . . 67

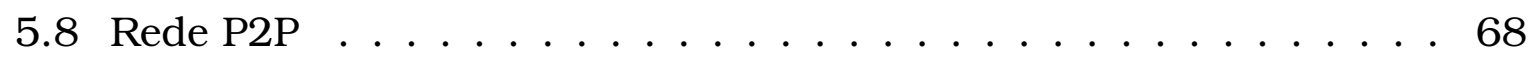

5.9 Considerações Finais ． . . . . . . . . . . . . . . . . . . 69

6 Protótipos CWaCTool 71

6.1 Serviço CAPPAS . . . . . . . . . . . . . . 72

6.1 .1 Recurso Jena . . . . . . . . . . . . . . . . . . . . 72

6.1 .2 Recurso Weka . . . . . . . . . . . . . . . . . 73

6.1 .3 Análise do Serviço CAPPAS . . . . . . . . . . . 73

6.2 Versões Iniciais da CWaCTool $\ldots \ldots$. . . . . . . . . . . . 74

6.2 .1 CWaCToolv1 . . . . . . . . . . . . . . . 74

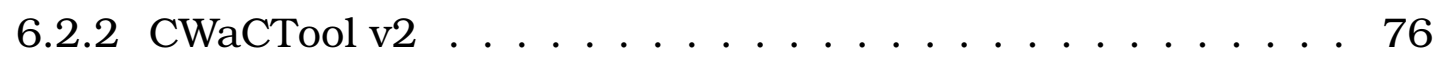

6.3 Arquitetura CWaCTool . . . . . . . . . . . . . . 78

6.3 .1 Módulos . . . . . . . . . . . . . . . . . 78

6.3.1.1 Módulos de Anotação . . . . . . . . . . . . . . 79

6.3.1.2 Módulos de Colaboração e Contexto . . . . . . . . 80

6.3 .2 Fluxo de Informações . . . . . . . . . . . . . . . . . 82

6.4 CWaCTool em Uso . . . . . . . . . . . . . . . . . . . . . 83

6.4.1 Sequência de Interação para Anotações . . . . . . . . . . . 85

6.4 .2 Integração com Redes Sociais . . . . . . . . . . . . 87 
6.4.2.1 Integração com Orkut . . . . . . . . . . . 87

6.4.2.2 Integração com Youtube . . . . . . . . . 88

6.4 .3 Anotações . . . . . . . . . . . . . . . 91

6.4.3.1 Anotações de Tinta . . . . . . . . . . . . . 92

6.4.3.2 Anotações de Texto . . . . . . . . . . . . . 93

6.4 .4 Conexão de Rede . . . . . . . . . . . . . . . . . 95

6.5 Avaliação CWaCTool . . . . . . . . . . . . . . . . 97

6.5.1 Avaliações com Usuários . . . . . . . . . . . . . 98

6.5.2 Estudo de Caso . . . . . . . . . . . . . . . 99

6.6 Considerações Finais . . . . . . . . . . . . . . 103

7 Conclusões 105

7.1 Resultados e Contribuições . . . . . . . . . . . 106

7.2 Limitações . . . . . . . . . . . . . . . . . 107

7.3 Trabalhos Futuros .................... 107

$\begin{array}{ll}\text { Referências } & 109\end{array}$

A Avaliações realizadas $\quad 125$

A. 1 Formulário de Percurso Cognitivo CWaCTool . . . . . . . . . 125

A.2 Formulário Likert CWaCTool . . . . . . . . . . . . . . . . 126 


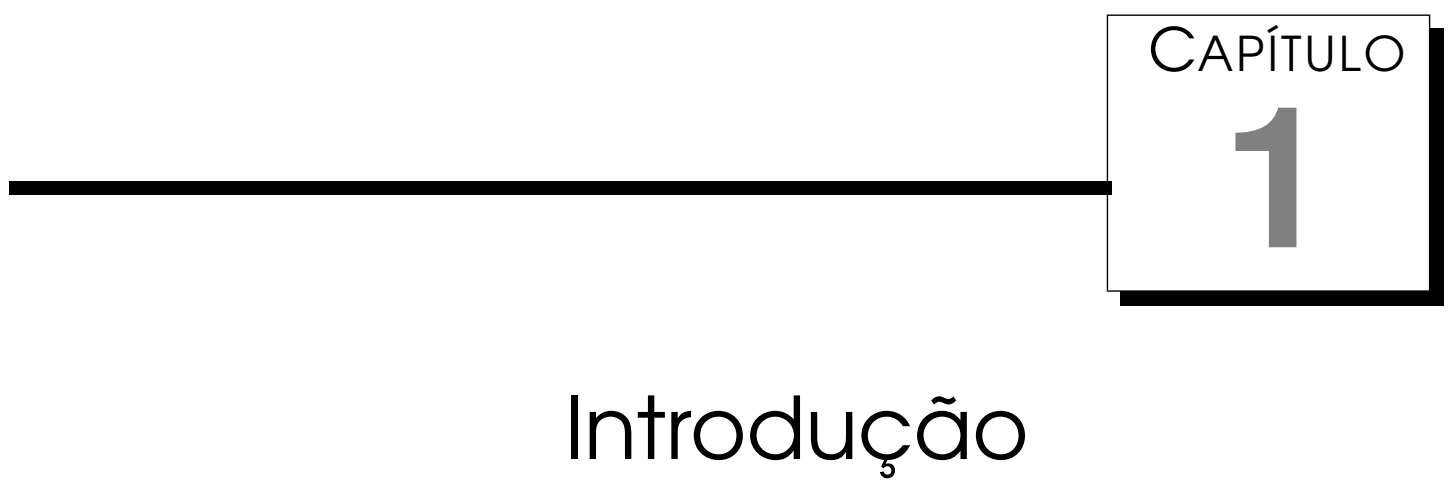

\subsection{Contextualização e Motivação}

Diversas mídias estão cada vez mais presentes no dia-a-dia dos indivíduos, dentre elas imagens, áudio e vídeo capturados por câmeras digitais e celulares. Essas tecnologias contribuem para a produção de mídias, como vídeos, fotos, sons, textos e animações, tornando difíceis tarefas como coletar, organizar e até mesmo identificar os novos artefatos adquiridos (Kientz; Abowd, 2009).

A área de Computação Ubíqua investiga alternativas para prover serviços a usuários de modo transparente, ou seja, sem desviar a atenção do usuário da tarefa principal (Weiser, 1991). Diversas técnicas e métodos vêm sendo apresentados com o intuito de possibilitar pessoas a anotarem comentários em vídeos (Bocconi et al., 2008; Geng et al., 2008; Manzato et al., 2009). Tais comentários podem ser realizados por tinta eletrônica, voz, texto ou algum outro meio.

Diante da necessidade de organização e identificação de anotações e da área de Computação Ubíqua, o paradigma Watch-and-Comment (WaC) propõe a captura transparente de comentários dos usuários enquanto assistem a um vídeo, auxiliando na identificação dos vídeos bem como na comunicação com outros usuários. O resultado das anotações é transformado automaticamente em documentos multimídia interativos, especificando o vídeo original e as anotações dos usuários. 
Explorando extensões do paradigma WaC reportado por Pimentel et al. (2007), Cattelan et al. (2008a) e Cattelan (2009), esta dissertação propõe o modelo arquitetural Context Aware Peer-to-Peer Architecture (CAPPA), que possibilita o uso de informações de contexto no processo de captura de anotações. Tal uso é realizado pela captura e utilização de informações de contexto provenientes do usuário (como de redes sociais) e das anotações criadas pelo usuário (ou por outros usuários). O modelo também propõe abordagens alternativas ao paradigma para possibilitar maior colaboração no processo de anotação.

O modelo CAPPA permite que aplicações do paradigma WaC possam ser cientes de informações de contexto, tanto do contexto do usuário que realiza as anotações, como de outras fontes, como por exemplo informações presentes em um vídeo ou em uma rede Peer-to-Peer (P2P). O modelo CAPPA envolve também a produção de uma ferramenta funcional que atua como prova de conceito, a Collaborative Watch-and-Comment Tool (CWaCTool). O trabalho envolve várias áreas de Computação como Interação Usuário-Computador, Computação Ubíqua e Multimídia.

Um dos temas de pesquisa na área de Computação Ubíqua é o da construção de aplicações de captura automática e acesso, nas quais se explora a oportunidade de capturar automaticamente informações no ambiente natural do usuário de modo transparente, para permitir acesso posterior à informação capturada (Abowd et al., 2002). Outro tema é o de construção de aplicações cientes de informações de contexto, tema esse que se refere a aplicações que conseguem se adaptar dinamicamente às condições de informações de contexto (também dinâmicas) de seus usuários (Schilit et al., 1994). Essa é uma característica considerada essencial em diversas aplicações de Computação Ubíqua (Coutaz et al., 2005).

Também como tema de pesquisa da área de Computação Ubíqua, o conceito de ciência de informações de contexto é utilizado por aplicações que permitem a coleta de informação de contexto e a mudança de comportamento com base nas informações de contexto coletadas. Ainda, uma aplicação ciente de informações de contexto deve poder associar significado aos eventos do mundo exterior e usar essa informação de maneira efetiva (Abowd et al., 2002).

A utilização de ciência de informações de contexto em aplicações que manipulam vídeos tem sido abordada, por exemplo, em aplicações para Televisão Digital Interativa (TVDI), considerando a personalização de programação. Alguns trabalhos, como o SenSee (Aroyo et al., 2007a), o Avatar (Fernandez et 
al., 2006) e o Tribler (Pouwelse et al., 2008) fazem uso de informações de contexto para adaptar a programação de TV a seus usuários.

No cenário de TVDI há pesquisadores que exploram o tema Social TV, que estuda a colaboração entre grupos de usuários de TV interativa. Diversos trabalhos exploram comunicação entre os telespectadores, como AmigoTV (Coppens et al., 2004), CollaboraTV (Nathan et al., 2008) e Telebuddies (Luyten et al., 2006). Através do uso de comunicação e de colaboração, o modelo proposto nesta monografia pretende abordar o tema de Social TV para compartilhar informações de contexto dos usuários e de grupos de usuários, além de abordar também o tema de redes sociais.

A comunicação entre grupos de usuários pode utilizar uma rede $\mathrm{P} 2 \mathrm{P}$. O trabalho de Pouwelse et al. (2008) reporta o uso de P2P para compartilhar programas de TV, com o objetivo de auxiliar a personalização que o sistema Tibler oferece. O uso de rede P2P pode auxiliar na comunicação entre vizinhos geográficos (a fim de obter informação de localização dos usuários, por exemplo) e entre grupos de usuários semelhantes.

É importante observar que o paradigma WaC faz uso de resultados do Projeto Tecnologia da Informação no Desenvolvimento da Internet Avançada Aprendizado Eletrônico (Tidia-Ae) ${ }^{1}$, tais como os trabalhos que suportam a interação do usuário com dispositivos baseados em caneta eletrônica, conforme detalhado por Cattelan et al. (2008b). O modelo CAPPA pode também ser utilizado no ambiente Tidia-Ae para auxílio em comentários de vídeos que possam ser utilizados no ambiente, como vídeos de vídeo-conferência para $e$-Learning.

\subsection{Objetivos}

Há pessoas que gostam de compartilhar opiniões e conversar enquanto realizam uma atividade, como assistir a um programa de TV (Nathan et al., 2008). A captura de opiniões das pessoas é estudada no paradigma WaC, em que as pessoas podem fazer comentários enquanto assistem a vídeos. Pode ser interessante que as opiniões possam ser compartilhadas e anotadas de modos alternativos, com sistemas que se adaptem aos usuários e às situações de anotação, sendo esse o foco no qual o modelo CAPPA foi projetado. Para prover a adaptação e compartilhamento, o modelo tem três principais objetivos:

\section{- Definir a coleta de informações de contexto de modo transparente} para o usuário, evitando que o mesmo desvie sua atenção da atividade

\footnotetext{
${ }^{1}$ Auxílio Pesquisa Fapesp Processo 2005/60951-1.
} 
de assistir a um vídeo. Tal coleta é realizada pela captura de informações de contexto do usuário, das anotações, do vídeo e de outros usuários com preferências em comum ao usuário em questão. Por exemplo, considerando dois usuários assistindo a um mesmo programa na televisão em locais diferentes, um deles anota que o programa é interessante, ou é violento. O outro usuário pode ter acesso a essa informação e essas anotações podem ser repassadas para outra aplicação ou mesmo para uma aplicação utilizando o paradigma WaC.

- Processar as informações de contexto para tomar ações, como adaptação de anotações possíveis ou classificação de usuários em grupos pelas preferências do mesmo. Por exemplo, quando um usuário está assistindo a um vídeo na Internet e deseja comentar um determinado trecho com seus amigos, é interessante que o usuário possa realizar uma anotação com alguma adaptação na interface gráfica. A aplicação pode sugerir palavras já utilizadas pelo usuário no caso de uma anotação de texto, ou uma cor mais contrastante no caso de anotação de tinta.

- Por consequência do uso de informações de grupos de usuários, Facilitar a colaboração de grupos de usuários no processo de anotação, permitindo anotações síncronas e fornecendo sugestões baseadas em anotações de outros usuários. Por exemplo, é possivel que um determinado usuário seja indicado a um grupo por ter assistido a vídeos de categorias em comum com outros usuários daquele grupo, ou que uma anotação de texto seja sugerida de acordo com as palavras utilizadas pelos outros usuários no mesmo trecho do vídeo.

Além dos objetivos do modelo, que são análogos ao desta dissertação, o protótipo CWaCTool possibilita a validação do modelo com a análise de usabilidade. A CWaCTool provê anotação síncrona e explora o uso de informações de contexto de vídeos, das anotações e de redes sociais na aplicação. O modelo atua em um tema de interesse para a comunidade científica, pois trata-se de um projeto multidisciplinar e está associado a vários editais recentes de agências de fomento a pesquisa.

\subsection{Metodologia de Construção do Modelo}

Primeiramente foi realizada uma pesquisa por conceitos que tinham relação com o trabalho proposto. No caso, estudou-se as definições de Computação Ubíqua, Sistemas de Recomendação, Ontologias, Social TV, TV Digital e de Redes Peer-to-Peer. As definições estão detalhadas no Capítulo 2, e foram a 
base para se explorar trabalhos relacionados, considerando o problema de adaptação do modo de realizar-se anotações em vídeos.

Em seguida foi realizado um levantamento de trabalhos relacionados aos conceitos definidos como interessantes a serem explorados, sendo os principais trabalhos detalhados no Capítulo 3. Dentre os trabalhos estudados, dois se destacam: trabalho do paradigma WaC (Pimentel et al., 2007; Cattelan et al., 2008a) e o que apresenta o modelo de ciência de informações de contexto SoCaM (Bulcão Neto, 2006).

Com os principais conceitos e trabalhos relacionados, foram identificados desafios nos temas pesquisados e definida uma versão parcial da arquitetura, que se caracterizava como um modelo simplificado de colaboração síncrona em anotações de tinta eletrônica em um cenário de TV digital simulado em PC. Essa arquitetura foi prototipada (CWaCTool) e avaliada com potenciais usuários.

A partir de resultados da avaliação realizada, uma nova etapa teve por objetivo incorporar informações de contexto e o ciclo de definição-prototipaçãoavaliação foi repetido por mais duas vezes, até se atingir o protótipo atual da CWaCTool e o modelo CAPPA.

Em paralelo à definição do modelo CAPPA, foram realizados trabalhos acadêmicos em conjunto com outros pesquisadores. Tal atividade proporcionou a inclusão de aspectos de outros trabalhos dos colaboradores (Maximino, 2009; Furtado, 2010; Gomes, 2010).

\subsection{Definição do Modelo}

Esta dissertação apresenta um modelo arquitetural, Context Aware Peer-toPeer Architecture (CAPPA), para incluir aspectos de ciência de informações de contexto ao paradigma WaC. O modelo CAPPA define como informações de contexto podem ser obtidas, compartilhadas com outros usuários e processadas em ações que influenciem o usuário. O conceito de modelo arquitetural é portanto, nesta dissertação, uma definição de como um sistema computacional para anotações em vídeo pode utilizar-se de informações de contexto e de aspecto de colaboração para prover facilidades ao processo de anotação do usuário.

O modelo CAPPA possui dois principais componentes: (i) a ferramenta CWaCTool, uma extensão da ferramenta WaCTool (Cattelan et al., 2008a) focando em colaboração, e (ii) o módulo Context Aware Peer-to-Peer Architecture Service (CAPPAS), que atua como um módulo de serviço da CWaCTool para 
prover ciência de informações de contexto e que foi integrado posteriormente a CWaCTool como um único protótipo.

O modelo arquitetural CAPPA é apresentado no Capítulo 5, enquanto que os protótipos construídos, CWaCTool e CAPPAS, são apresentados no Capítulo 6 .

\subsection{Organização da Dissertação}

Esta dissertação está dividida em sete capítulos. A seguir, no Capítulo 2, são apresentados conceitos fundamentais, considerando o modelo proposto. No Capítulo 3 são apresentados trabalhos relacionados ao modelo CAPPA. No Capítulo 4 é detalhado o paradigma Watch-and-Comment (WaC), base do modelo CAPPA, e são apresentados os detalhes da ferramenta WaCTool. Iniciando a apresentação do modelo, o Capítulo 5 apresenta a definição do modelo CAPPA, seguido do Capítulo 6, que detalha os protótipos construídos para o modelo e as avaliações realizadas. No Capítulo 7 são apresentadas as conclusões do trabalho, e discutido trabalhos futuros. 
CAPÍTULO

\section{Fundamentação Teórica}

O modelo de informações de contexto Context Aware Peer-to-Peer Architecture (CAPPA) envolve vários conceitos, os quais são introduzidos neste capítulo.

Este capítulo se inicia com a apresentação de Computação Ubíqua (Seção 2.1), e dois temas relacionados a esse conceito: captura automática e acesso de dados e computação ciente de informações de contexto.

Na Seção 2.2 é discutido o conceito de Sistemas de Recomendação, que tem por objetivo oferecer a recomendação de algum conteúdo ou alguma ação para o usuário. São discutidos também como o uso de ontologias e a mineração de dados trazem possibilidades de recomendar ações como exigidas pelo modelo CAPPA.

O aspecto colaborativo de sistemas computacionais em geral é discutido na Seção 2.3, em que é apresentado o cenário de colaboração com uso de redes sociais, mídias sociais, Social TV e redes P2P.

Por fim, na Seção 2.4 é discutido o conceito de Televisão Digital Interativa.

\subsection{Computação Ubíqua}

Computação Ubíqua, um termo criado por Mark Weiser (Weiser, 1991), se refere à computação presente de modo transparente no dia-a-dia do usuário, que utiliza sistemas computacionais inseridos de modo natural em seu cotidi- 
ano, por exemplo ao utilizar uma caneta digital para anotações em um Tablet $P C$.

O paradigma de Computação Ubíqua impõe vários desafios, como por exemplo os destacados por Meyer e Rakotonirainy (2003): usabilidade, utilidade, aceitabilidade social, proteção de privacidade, custo e carga administrativa. O tema de proteção de privacidade é importante pois as aplicações ubíquas funcionam normalmente de modo transparente, sem que o usuário saiba que está tendo informações capturadas, por exemplo. Outros dois desafios constantemente abordados são conectividade, pois normalmente há o uso de muitos dispositivos por uma mesma aplicação, e energia, já que muitas aplicações ubíquas utilizam dispositivos móveis. Parte desses desafios também se aplicam ao modelo a ser proposto, principalmente conectividade (não só entre dispositivos mas também entre usuários), privacidade e aceitabilidade social.

Abowd et al. (2002) identificaram temas subjacentes a aplicações de Computação Ubíqua, dentre os quais dois são de particular importância para o trabalho reportado desta dissertação: Captura Automática e Acesso e Ciência de Informações de Contexto.

\subsubsection{Captura Automática e Acesso}

Pesquisas têm sido realizadas para que aplicações capturem automaticamente informações sobre atividades que são realizadas no ambiente cotidiano do usuário, como por exemplo os comentários e anotações que um professor realiza enquanto ministra uma aula. É interessante que as informações capturadas também possam ser acessadas posteriormente, de modo que os registros das atividades possam não somente ser armazenados, mas também acessados e utilizados de algum modo.

Abowd et al. (2002) definem aplicações de Captura Automática e Acesso (ou Captura e Acesso) como aquelas que tem por objetivo preservar o registro de alguma experiência realizada pelo usuário para que, depois, a informação possa ser acessada. A importância de tal conceito no paradigma WaC é explorar o registro de anotações de vídeos dos usuários, para que depois tais anotações possam ser visualizadas por outros usuários.

Diversos sistemas de captura e acesso têm sido desenvolvidos para documentar experiências humanas em ambientes de reuniões, como o sistema Coral apresentado por Minneman et al. (1995) e o sistema LiteMinutes de Chiu et al. (2001); em ambientes de hospitais como o ActiveTheatre de Hansen e Bardram (2005), Hansen et al. (2006) e o estudo de Sarcevic (2010); e em 
ambientes educacionais como os sistemas eClass reportado por Brotherton e Abowd (2004), CareLog por Hayes et al. (2008), SmartClassroom de Shi et al. (2003) e iClass de Pimentel et al. (2000). Outros trabalhos e técnicas de captura e acesso são relatados por Truong e Hayes (2009).

Alguns trabalhos exploram o tema de Captura e Acesso na área multimídia, como a captura de áudio proposta por Hindus e Schmandt (1992), de comentários em vídeos reportado por Bargeron et al. (1999) e Goldman et al. (2008), de vídeo com anotações multimodais de Pimentel et al. (2008) e a captura de conteúdo multimídia em geral com anotações multimodais de Manzato et al. (2009). Na área da televisão, um dos principais dispositivos de comunicação entre um usuário (ou telespectador) e um televisor é o controle remoto. Este é um dos métodos mais simples e inerente para captura de informações do usuário, mas o mesmo possui algumas limitações como apontado por Omojokun et al. (2006). Os autores citam que existe uma limitação da interoperabilidade para controlar diversos dispositivos, teclas do controle remoto não utilizadas e a falta de personalização que um usuário possa precisar.

Devido às limitações existentes no modelo tradicional de controle remoto, diversos trabalhos vêm sendo realizados para estender esse modelo. Aroyo et al. (2007b) apresentam o trabalho de objetos no uso diário para operarem como controle remoto, como almofadas por exemplo. Kim et al. (2004), Kela et al. (2006) propõem um controle remoto baseado em gestos, enquanto que Berglund et al. (2004), Elting (2005) propõem o uso de voz para controlar conteúdo multimídia.

\subsubsection{Computação Ciente de Informações de Contexto}

Um dos conceitos principais em que o trabalho se baseia é de ciência de informações de contexto. Segundo Dey e Abowd (2000), Dey (2001), informação de contexto é a que pode caracterizar uma situação de uma entidade, sendo que essa entidade pode ser uma pessoa, um lugar ou um objeto que sejam considerados relevantes para a interação usuário-aplicação. As informações de contexto podem ser obtidas explicitamente, quando o usuário reporta tal informação, ou implicitamente, quando a informação é capturada do usuário sem a intenção do mesmo, normalmente com o foco do usuário em outra atividade (Bulcão Neto, 2006).

O uso de informações de contexto tem por objetivo auxiliar sistemas computacionais a melhor atenderem seus usuários, utilizando informações dos mesmos para causar algum melhoramento no sistema, como melhor intera- 
ção usuário-aplicação através de interfaces alternativas, como propõe o modelo apresentado nesta dissertação.

Um sistema é considerado ciente de informações de contexto, ou sensível a informações de contexto, quando utiliza essas informações para prover outras informações ou serviços relevantes ao usuário (Dey; Abowd, 2000). Um aspecto importante é que a relevância ou não de uma determinada informação de contexto é uma prerrogativa do desenvolvedor, dependendo da tarefa que o usuário deseja realizar.

Aplicações cientes de informações de contexto precisam extrair informações de contexto do usuário para melhorar a interação entre usuários e aplicações. A extração pode ser feita por um conjunto de regras (diretrizes), segundo Abowd e Mynatt (2000), através de cinco questões sobre a atividade que um usuário realiza:

- who (quem): Seres humanos realizam as atividades e recordam-se delas baseando-se na presença de outras pessoas e objetos. As aplicações cientes de informações de contexto devem incorporar informações de identificação do maior número de participantes.

- what (o que): É necessário identificar as atividades do usuário, se está realizando apenas uma atividade ou mais. Interpretar corretamente as atividades do usuário é um dos desafios na área de Ciência de Informações de Contexto.

- where (onde): A informação de localização é uma das mais exploradas em aplicações que utilizam informações de contexto, pois muitas aplicações adaptam-se de acordo com a localidade do usuário. Combinando a informação da localidade com a informação do momento, é possível prever as atividades que o usuário poderá realizar (Bulcão Neto, 2006).

- when (quando): As informações do momento ou intervalo de tempo em que ocorreu uma determinada atividade podem ser utilizadas na recuperação de eventos ou para prever eventos futuros ou, ainda, auxiliar na interpretação de atividades humanas e padrões de comportamento.

- how (como): Informações relativas ao modo com o qual o usuário realiza uma ação. Seu uso é mais comum em dispositivos móveis, já que eles expressam com que dispositivo o usuário está realizando uma atividade (Goularte et al., 2003).

Sistemas cientes de informações de contexto são cada vez mais comuns em diversas áreas, como um dos pioneiros em Ciência de Informações de contexto, o Context Toolkit (Salber et al., 1999; Dey, 2001), o framework SCK 
baseado no modelo de informações de contexto SeCoM (Bulcão Neto, 2006), a arquitetura CoBrA (Chen et al., 2003; Chen, 2004), o middleware para aplicações móveis CASS, o sistema IM4Sports (Wijnalda et al., 2005), o framework WildCAT (David; Ledoux, 2005) e o middleware SOCAM (Gu et al., 2004). Todos esses trabalhos são detalhados na Seção 3.1.

Diversos trabalhos voltados para a área de TVDI e de vídeos exploram o conceito de Ciência de Informações de Contexto principalmente quanto a recomendação, buscando informações dos usuários para sugerir à aplicação alguma ação ao usuário, como por exemplo a seleção de programas. Os trabalhos SenSee (Aroyo et al., 2007a), M4Note (Goularte et al., 2006), PersonalTV (Pessemier et al., 2009) e Tribler (Pouwelse et al., 2008) trabalham com esses conceitos, e são detalhados na Seção 3.2.

\subsection{Sistemas de Recomendação}

Os Sistemas de Recomendação (Recommender Systems) aplicam técnicas de análise de dados para ajudar usuários na tarefa de encontrar itens de seu interesse. No contexto da Web, a recomendação é normalmente aplicada a sites de compras para oferecer possíveis itens mais interessantes ao usuário (Sarwar et al., 2001).

Reischach et al. (2009) apresentam um estudo de características de Sistemas de Recomendação aplicados à Computação Ubíqua, com os parâmetros de Captura de dados, Recomendação de conteúdo e Acesso das recomendações, podendo cada parâmetro ser implícito ou explícito. Ainda apresentam outro parâmetro, Agregação, o qual determina se a recomendação é realizada de um para um usuário, de um para muitos, muitos para um ou muitos para muitos.

O modelo CAPPA utiliza alguns conceitos de Sistemas de Recomendação, com o objetivo de prover recomendações de interações alternativas a seus usuários. Considerando as características de Reischach et al. (2009), o modelo utiliza:

- Captura implícita de dados das interações que o usuário realiza, das anotações e das informações pessoais nas redes sociais do usuário, além de também capturar dados explicitamente no caso do usuário não utilizar o módulo de redes sociais;

- Recomendação implícita de conteúdo, em que as recomendações não utilizam informações diretas dos usuários, mas sim regras inferidas como 
quantidade de anotações em um mesmo momento de um vídeo para sugerir alguma ação ou informação;

- Agregação de recomendações de muitos usuários para muitos, uma vez que as recomendações geradas pelos usuários, implicitamente, são distribuídas para outros usuários do mesmo grupo;

- Acesso implícito a recomendações, já que as recomendações são oferecidas aos usuários através de mudanças na interação do mesmo com o vídeo ou com o processo de anotar no vídeo.

Dentre os conceitos relacionados a Sistemas de Recomendação, são mais importantes para o trabalho aqui reportado os conceitos de Ontologias e de Extração de Conhecimento.

\subsection{Ontologias}

O conceito de ontologias tem sido utilizado com frequência em aplicações cientes de informações de contexto (Chen et al., 2003; Gu et al., 2004). Uma definição bem aceita para o termo ontologia, na área de computação, é o de Gruber (1993), que define a ontologia como uma especificação formal de uma conceitualização. Fensel (2003) amplia a definição de ontologia para uma especificação explícita e formal de uma conceitualização compartilhada. Em outras palavras, a ontologia modela de uma maneira formal e abstrata um domínio de conhecimento (Bulcão Neto, 2006).

O uso de ontologias permite a prevenção de diferentes interpretações sobre alguma semântica de termos em um mesmo domínio, a interoperabilidade entre sistemas de software, a capacidade de reusar e estender definições de termos de outras ontologias e a possibilidade de deduzir novos fatos a partir de outros já declarados sobre um domínio (Bulcão Neto, 2006).

Um possível uso de ontologia em aplicações cientes de informações de contexto é utilizar um vocabulário que represente conhecimento sobre um domínio e que descreva situações em um domínio ( $\mathrm{Gu}$ et al., 2004). O padrão Resource Description Framework (RDF) descreve e representa metadados associados a recursos. A partir do RDF, o World Wide Web Consortium (W3C) criou a linguagem Web Ontology Language (OWL), uma linguagem de ontologias para Web, a qual estende o padrão RDF trazendo maior expressividade e semântica ao vocabulário. Utilizando alguma forma de representar ontologias, é possível definir como o modelo de ciência de informações de contexto manipula informações dos usuários. 


\subsubsection{Extração de Conhecimento}

O uso de Extração de Conhecimento (ou Knowledge Discovery) no modelo CAPPA utiliza resultado de outros trabalhos (Gomes, 2010; Furtado, 2010). Para realizar extração de conhecimento, o modelo CAPPA utiliza parcialmente conceitos de Mineração de Dados e Aprendizado de Máquina.

O conceito de Mineração de Dados (Data Mining) pode ser definido como um processo de descoberta de padrões em um conjunto de dados (Witten; Frank, 2005), resolvendo problemas pela análise de dados já presentes em bancos de dados.

Pesquisas em Aprendizado de Máquina (Machine Learning) investigam técnicas e algoritmos para aprendizado de conteúdo, podendo extrair conhecimento dos dados extraídos pela mineração dos dados (Witten; Frank, 2005).

\subsection{Colaboração e Aspectos Sociais}

Um dos pontos de contribuição do modelo CAPPA é o uso de colaboração para o processo de anotações em vídeos. O processo de colaboração é utilizado com conceitos de redes sociais e Social TV.

Computer Supported Cooperative Work (CSCW) é definido por Hoffman (1989) como o uso de computadores em grupos de trabalho. Também é definido por Schmidt e Bannon (1992) como um campo que estuda entender a natureza e as características do trabalho cooperativo, para criar tecnologias computacionais adequadas. Exemplos de ferramentas nessa área são repositórios de arquivos colaborativos (como Subversion ${ }^{1}$ ), editores de texto online (como Wikis $^{2}$ ), dentre outros.

Redes sociais são sistemas em que usuários se conectam e compartilham informações, sejam elas pessoais ou de interesse comum. A integração com redes sociais traz a uma aplicação informações de contexto do usuário, como interesses e quem são seus amigos.

O uso social de vídeos na Internet já é comum, pois podem ser compartilhados e discutidos com amigos distantes. Para tal, o usuário pode utilizar um sistema mensageiro online ou bases de dados em Websites especializados

\footnotetext{
${ }^{1}$ Subversion é uma ferramenta que permite controle de versões de arquivos, de modo colaborativo.

${ }^{2}$ Wiki é uma ferramenta na Web que permite a usuários criarem e editarem páginas colaborativamente.
} 
em vídeos, como o Youtube ${ }^{3}$, em que os usuários podem deixar comentários e dar notas aos vídeos (Oumard et al., 2008).

\subsubsection{Social TV}

A televisão é tradicionalmente usada em ambiente domiciliar e frequentemente é uma atividade social (Mantzari et al., 2008). Entretanto, conforme Nathan et al. (2008) observam, aproximadamente metade dos americanos assistem a TV sozinhos, mas que o maior problema é a falta de um meio de comunicação e não a falta de vontade dos telespectadores.

Mantzari et al. (2008) definem o termo "Social TV" como um meio de representar a comunicação e as interações sociais (remotas ou locais) em conteúdo de TV, ou relacionado a alguma atividade com TV, e a tecnologia que possibilita essas comunicações e interações.

A comunicação em Social TV, segundo Harboe et al. (2008), incluem presença (qual canal e programa alguém está assistindo), texto, vídeo, voz ou alguma combinação desses. Os sistemas de Social TV tipicamente integram esses elementos para mostrar o estado e informações de contexto de outros usuários do sistema (Harboe et al., 2008).

O uso de Social TV e de aspectos sociais em vídeos na Internet permitem a colaboração entre usuários para o modelo CAPPA.

\subsubsection{Redes P2P}

Segundo Shirky (2000), Peer-to-Peer (P2P) corresponde a uma classe de aplicações que utilizam-se de algumas das vantagens existentes pela Internet: armazenamento, ciclos de processamento, conteúdo e presença humana.

Androutsellis-Theotokis e Spinellis (2004) definem sistemas P2P como sistemas distribuídos dotados de nós (nodes) interconectados, capazes de se auto organizarem em topologias de redes. O propósito é de compartilharem recursos, como conteúdo, ciclos de Central Processing Unit (CPU), armazenamento e largura de banda. Os sistemas devem ser capazes de se adaptarem a falhas e aceitarem transições de nós enquanto mantêm conectividade e performance aceitáveis, sem requerer intermediação ou suporte de um servidor ou autoridade centralizadora.

$\mathrm{O}$ uso de P2P possibilita a remoção de gargalos de servidores pelo seu aspecto distribuído, apesar da performance do sistema depender do nível de

\footnotetext{
${ }^{3}$ http://www. youtube.com, Acesso em 20 Mai 2010.
} 
cooperação entre os pontos da rede (Fokker et al., 2007). Outros aspectos importantes a serem tratados em uma rede P2P são segurança e privacidade. Oram (2001) observa que um problema existente em redes P2P, pela sua natureza descentralizada se considerarmos a rede P2P pura, é o controle de Spam e outras ações abusivas, que devem ser levados em consideração quando uma rede $\mathrm{P} 2 \mathrm{P}$ for projetada.

Androutsellis-Theotokis e Spinellis (2004) classificam as aplicações P2P em cinco categorias: (i) Comunicação e Colaboração, que inclui sistemas que facilitem a comunicação e colaboração entre computadores, como sistemas de troca de mensagens síncronas; (ii) Computação Distribuída, com sistemas que têm por objetivo utilizar poder de processamento de computadores disponíveis em uma rede P2P; (iii) Serviços de Suporte a Internet, com sistemas que ofereçam serviços de Internet, como aplicações de segurança e sistemas multicast; (iv) Sistemas de Banco de Dados, com sistemas que tornam o banco de dados distribuído; e (v) Conteúdo Distribuído, com sistemas que compartilham dados em uma rede $\mathrm{P} 2 \mathrm{P}$, como aplicações que compartilham arquivos entre usuários.

Fokker et al. (2007) identificam vantagens como o baixo custo geral (na distribuição do conteúdo e na manutenção com servidores centrais) e a velocidade para transação de conteúdo entre os usuários de um sistema. Entretanto, eles observam que o fato de não possuir um servidor central no controle gera alguns problemas, como a falta de uma entidade para monitorar a rede no quesito segurança, e o comprometimento com a qualidade que depende muitas vezes da disponibilidade da rede, algo não garantido.

A tecnologia P2P oferece uma série de novas possibilidades para transformar a televisão, trazendo novas opções como custos reduzidos e conteúdo gerado pelos usuários (Fokker et al., 2008), além de permitir cooperação entre os usuários. O uso de redes P2P no modelo CAPPA é conceituado como uma alternativa, não sendo o único meio de comunicação existente.

\subsection{TV Digital Interativa}

No Brasil, a televisão representa um meio de comunicação de massas que possibilita a distribuição de informação para a maior parte da população se comparada a outros meios de comunicação. Segundo dados do IBGE $(2008)^{4}$, $94,5 \%$ dos lares brasileiros possuem um televisor, sendo que o pior índice é na região Norte de $88,5 \%$ da população (Tabela 2.1). 26,6\% das residências

\footnotetext{
${ }^{4}$ Instituto Brasileiro de Geografia e Estatística: http://www.ibge.gov.br, Acesso em 20 Mai 2010.
} 
possuem computador em casa, e apenas 20,2\% dessas residências possuem acesso a Internet, sendo que somente $8,2 \%$ da população da região Norte tem acesso. A porcentagem de domicílios com TV em casa no Brasil é também maior que a porcentagem de domicílios com rádio, outro meio de comunicação bastante comum, com $88,1 \%$.

\begin{tabular}{|c||c|c|c|c|}
\hline Grande Região & Rádio & Televisão & PC total & PC com Internet \\
\hline \hline Brasil & $88,1 \%$ & $94,5 \%$ & $26,6 \%$ & $20,2 \%$ \\
\hline Norte & $72,8 \%$ & $88,5 \%$ & $13,5 \%$ & $8,2 \%$ \\
\hline Nordeste & $82,0 \%$ & $89,7 \%$ & $12,2 \%$ & $8,8 \%$ \\
\hline Sudeste & $92,4 \%$ & $97,5 \%$ & $34,9 \%$ & $27,4 \%$ \\
\hline Sul & $94,0 \%$ & $96,3 \%$ & $33,0 \%$ & $24,0 \%$ \\
\hline Centro-Oeste & $85,1 \%$ & $93,9 \%$ & $25,2 \%$ & $18,4 \%$ \\
\hline
\end{tabular}

Tabela 2.1: Dados de domicílios particulares permanentes, por existência de alguns bens duráveis da população brasileira referente ao censo do IBGE (2008).

Sendo o televisor o equipamento fornecedor de informações mais comum nos domicílios brasileiros, é interessante explorar diferentes paradigmas de comunicação através desse meio. Um paradigma que vem sendo explorado é o de Televisão Digital Interativa (TVDI), que possibilita aos usuários não apenas assistirem a um programa de TV, mas também interagirem com o programa, através de seleção de cenas favoritas e atores, consultando informações adicionais de objetos na cena (como informações de uma roupa de um personagem), participando de programas de pesquisa de opinião (como um questionário, ou quiz) e até mesmo manipulando o curso natural do programa, adaptando-o de acordo com suas preferências.

Diversos autores definem TVDI sob diferentes pontos de vista. Para um engenheiro TVDI é um sistema de transmissão digital com canal de retorno. Para um profissional da mídia, por outro lado, TVDI é definido por novos formatos de conteúdo, como histórias interativas e jogos de quiz (Chorianopoulos; Lekakos, 2007). Para Chorianopoulos e Lekakos (2007), Cesar et al. (2008), TVDI é uma experiência audiovisual do usuário que envolve pelo menos um usuário e um ou mais dispositivos audiovisuais e de rede. Nesse contexto de visão do usuário, este atua criando, compartilhando e controlando conteúdo ao invés de ser apenas um telespectador que assiste à programação da TV. Na TVDI o usuário tem normalmente um dispositivo para interação, como um controle remoto, mas pode utilizar outros, como um celular ou um controle de Wii.

A TVDI também é chamada de TV Interativa (iTV), pois as pesquisas de sistemas interativos atuais na televisão fazem uso, em sua maioria, do padrão TV Digital (DTV) (Yang et al., 2008). A DTV tem sido confundida constantemente com High Definition TV, ou TV de Alta Definição (HDTV), a qual pode oferecer 
apenas melhor qualidade de vídeo e áudio (Fernandez et al., 2006). A TVDI incorpora não somente qualidade superior, mas também a tecnologia que permite conteúdo de TV interativo com mais componentes audiovisuais (Mantzari et al., 2008). A TVDI também incentiva os telespectadores a se comunicarem entre eles com o uso dos serviços presente nos televisores.

Farias et al. (2008) observam que três sistemas de TVDI pelo mundo que têm grande importância na indústria de DTV:

- Advanced Television System Committee (ATSC), desenvolvido nos Estados Unidos, o qual possui o ACAP (middleware Advanced Common Application Platform) como um padrão de Middleware.

- Digital Video Broadcasting-Terrestrial (DVB-T),desenvolvido pela União Europeia, que possui como padrão o Middleware Multimedia Home Platform (MHP).

- Integrated Services Digital Broadcasting Terrestrial (ISDB-T), desenvolvido no Japão.

O projeto para o desenvolvimento de um sistema de TVDI no Brasil iniciouse em 2003, com o International System for Digital Television (ISDTV), e em 2006 foi assinado pelo presidente brasileiro o decreto que define a transição do modelo analógico para o digital (Farias et al., 2008). O middleware Ginga foi proposto para auxiliar a construção de aplicações interativas na TVDI brasileira, e o modelo CAPPA utiliza o formato Ginga Nested Context Language (NCL) para representar as anotações dos usuários.

\subsection{Considerações Finais}

Os conceitos sumarizados neste capítulo são necessários para conceitualizar os principais aspectos que o modelo arquitetural proposto aborda. O uso de Computação Ubíqua, explorando as áreas de Captura Automática e Acesso e Ciência de Informações de Contexto, tem por importância prover melhor usabilidade ao sistema, explorando a captura e o processamento de informações de contexto de modo transparente ao usuário.

O modelo arquitetural CAPPA tem por tarefa principal a construção de recomendações, a qual é realizada com a instanciação de ontologias a partir dos dados capturados do usuário, da mineração de dados e do uso de algoritmos de aprendizado de máquina. Uma necessidade do modelo é da obtenção de 
informações contextuais de redes sociais, o que contribui para permitir anotações colaborativas entre pessoas que assistem a um vídeo ou a um programa de TV.

O estudo de redes P2P visa possibilitar a comunicação e o agrupamento de usuários. TVDI é um cenário de grande interesse para o modelo CAPPA.

No próximo capítulo serão apresentados trabalhos relacionados que envolvem os conceitos apresentados neste capítulo e que possuem pontos em comum com o modelo arquitetural proposto nesta dissertação. 


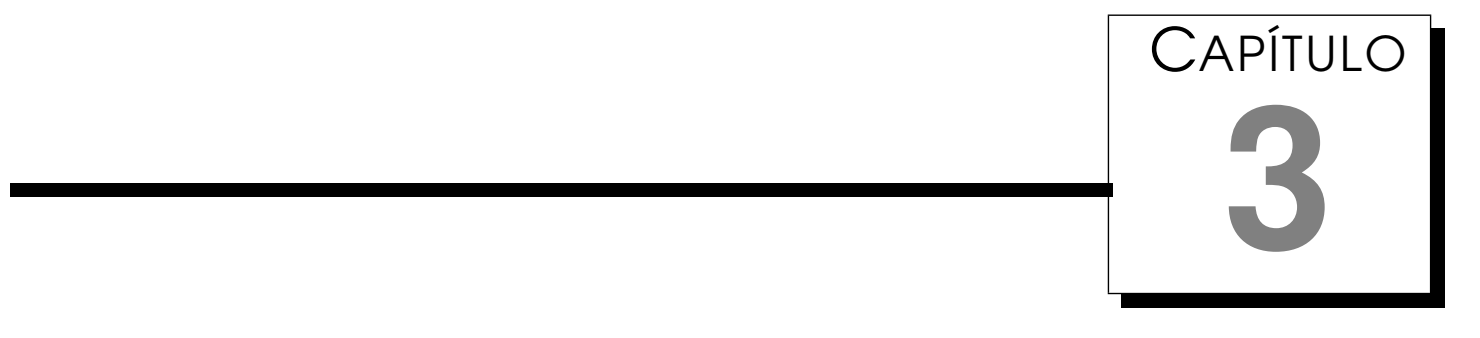

\section{Trabalhos Relacionados}

Neste capítulo serão abordados alguns trabalhos que contribuam para diversos aspectos do modelo CAPPA. A Seção 3.1 descreve sistemas e modelos que se utilizam do conceito de "Ciência de Informações de Contexto". A Seção 3.2 descreve sistemas de recomendação multimídia, que têm relação com o aspecto de recomendação de anotações do modelo CAPPA. A Seção 3.3 apresenta trabalhos que exploram a colaboração de usuários em sistemas de vídeo e TV digital. A Seção 3.4 descreve trabalhos que exploram a arquitetura P2P com informações de contexto. As considerações finais são apresentadas na Seção 3.5 .

\section{1 Sistemas e Modelos Cientes de Contexto}

Diversos modelos que fazem uso de informações de contexto são citados na literatura, sendo relacionados a aplicações cientes de informações de contexto, a frameworks, a middleware e ferramentas. Strang e Popien (2004) e Baldauf et al. (2007) categorizam os modelos em seis grupos, detalhados na Tabela 3.1, em que os modelos são estruturas que definem e armazenam informações de contexto em uma forma processável por uma máquina. Seguindo tais categorias, pode-se dizer que o modelo CAPPA baseia-se em Ontologias.

A seguir serão detalhados alguns trabalhos relacionados e que contribuam com conceitos para o modelo CAPPA. Parte dos trabalhos são citados em 


\begin{tabular}{|c|c|c|}
\hline Modelo & Definição & Exemplos \\
\hline Chave-Valor & $\begin{array}{l}\text { Utiliza a estrutura de dados mais sim- } \\
\text { ples, em que os pares chave-valor } \\
\text { são usados para descrever capaci- } \\
\text { dades de um serviço. }\end{array}$ & $\begin{array}{l}\text { CAPEUS - Samulowitz et al. } \\
\text { (2001) } \\
\text { Schilit et al. (1994) }\end{array}$ \\
\hline $\begin{array}{l}\text { Marcação } \\
\text { (Markup) }\end{array}$ & $\begin{array}{l}\text { Utilizam uma estrutura hierárquica ba- } \\
\text { seada em elementos com atributos e } \\
\text { conteúdo. }\end{array}$ & $\begin{array}{l}\text { Henricksen et al. (2002) } \\
\text { CC/PP - Klyne et al. (2004) } \\
\text { ConteXtML - Ryan (1999) }\end{array}$ \\
\hline Gráficos & $\begin{array}{l}\text { Um modelo amplamente utilizado é } \\
\text { a UML (Unified Modeling Language) } \\
\text { adaptada para modelagem de con- } \\
\text { texto, mas outros também podem ser } \\
\text { adaptados, como ORM (Object-Role } \\
\text { Modeling). }\end{array}$ & $\begin{array}{l}\text { ContextUML - Sheng e Be- } \\
\text { natallah ( } 2005) \\
\text { Extended ORM - Henrick- } \\
\text { sen et al. (2003) }\end{array}$ \\
\hline $\begin{array}{l}\text { Orientados } \quad \text { a } \\
\text { Objetos }\end{array}$ & $\begin{array}{l}\text { Modela informações de contexto uti- } \\
\text { lizando técnicas de orientação a ob- } \\
\text { jetos, empregando encasulamento, } \\
\text { reusabilidade, entre outros. }\end{array}$ & $\begin{array}{l}\text { Hydrogen - Hofer ef al. } \\
\text { (2003) } \\
\text { Fortier et al. (2007) }\end{array}$ \\
\hline $\begin{array}{l}\text { Baseados em } \\
\text { Lógica }\end{array}$ & $\begin{array}{l}\text { Tipicamente, fatos, expressões e re- } \\
\text { gras são o que definem um modelo } \\
\text { de informações de contexto. Infere- } \\
\text { se expressões e fatos derivando-os } \\
\text { de um conjunto de diversos outros } \\
\text { fatos e expressões. Gonzalez et al. } \\
\text { (2008) ainda definem o paradigma } \\
\text { Context-Based Reasoning, que uti- } \\
\text { liza algumas características do com- } \\
\text { portamento humano para controlar } \\
\text { agentes autônomos. }\end{array}$ & $\begin{array}{l}\text { McCarthy e Buvac (1997) } \\
\text { Gray e Salber (2001) } \\
\text { CxBR framework - Gonza- } \\
\text { lez et al. (2008) }\end{array}$ \\
\hline $\begin{array}{l}\text { Baseados em } \\
\text { Ontologia }\end{array}$ & $\begin{array}{l}\text { Por ontologias serem instrumentos } \\
\text { que representam a descrição de } \\
\text { conceitos e relações, seu uso para } \\
\text { modelar informações de contexto é } \\
\text { muito utilizado já que é possível apli- } \\
\text { car técnicas de inferência de con- } \\
\text { teúdo. }\end{array}$ & $\begin{array}{l}\text { CoBrA - Chen (2004) } \\
\text { SOCAM - Gu et al. (2004) }\end{array}$ \\
\hline
\end{tabular}

Tabela 3.1: Categorias de modelos de contexto seguindo classificação de Strang e Popien (2004).

outros trabalhos mais recentes por apresentarem diversos aspectos favoráveis a sistemas e arquiteturas cientes de informações de contexto.

\section{1.1 Context Toolkit}

Em um dos trabalhos pioneiros em estruturar aplicações com informações de contexto, Dey (2001) define uma visão de sistemas cientes de informações de contexto (apresentada no capítulo anterior) como consequência do trabalho relativo a construção do Context Toolkit (Salber et al., 1999). Para o autor, existem três categorias de características que uma aplicação ciente de informações de contexto pode ter:

1. Apresentação de informações e serviços a um usuário. 
2. Execução automática de um serviço por um usuário.

3. Registro de informações de contexto, permitindo recuperá-las posteriormente.

A arquitetura do Context Toolkit permite que aplicações obtenham informações de contexto necessárias sem saber exatamente como essa informação é obtida, através do Context Widget, uma abstração responsável por obter informação de contexto e tornar essa informação disponível às aplicações de modo genérico.

O Context Toolkit oferece suporte a armazenamento de informações de contexto, tornando possível que toda informação armazenada possa ser usada para prever ações ou interações futuras dos usuários. Outra característica importante que a arquitetura apresenta é o aspecto distribuído, que torna possivel às aplicações cientes de informações de contexto comunicarem-se por meio de diversos componentes.

As definições de Dey (2001), bem como a arquitetura do Context Toolkit (Salber et al., 1999), auxiliaram na definição do modelo CAPPA com as diretrizes de "quem", “quando", “onde”, "por que” e "como" para as informações de contexto.

\subsubsection{CoBrA}

Chen apresenta a Context Broker Architecture (Chen, 2004), uma arquitetura (Figura 3.1) que utiliza um Context Broker, ou um negociador de contexto, que mantém e gerencia um modelo compartilhado de informações de contexto.

O Context Broker (i) provê um modelo centralizado de informações de contexto que pode ser compartilhado entre dispositivos, agentes e serviços, (ii) adquire informações de contexto de fontes não atingiveis por dispositivos de recursos limitados, (iii) reconhece informações de contexto que não podem ser adquiridas diretamente de sensores, (iv) detecta e processa conhecimentos inconsistentes que são armazenados no modelo compartilhado de informações de contexto e $(\mathrm{v})$ protege a privacidade do usuário através de políticas, definidas por usuários para controlar o que é compartilhado.

Chen et al. (2003) utilizam ontologias para prover meios do Context Broker compartilhar o conhecimento de informações de contexto com agentes, e para prover um modelo de ontologia que possa ajudar o Context Broker a entender os conceitos e detectar inconsistências de conhecimento. O conceito de utilização de diferentes fontes para adquirir informações e o armazenamento 

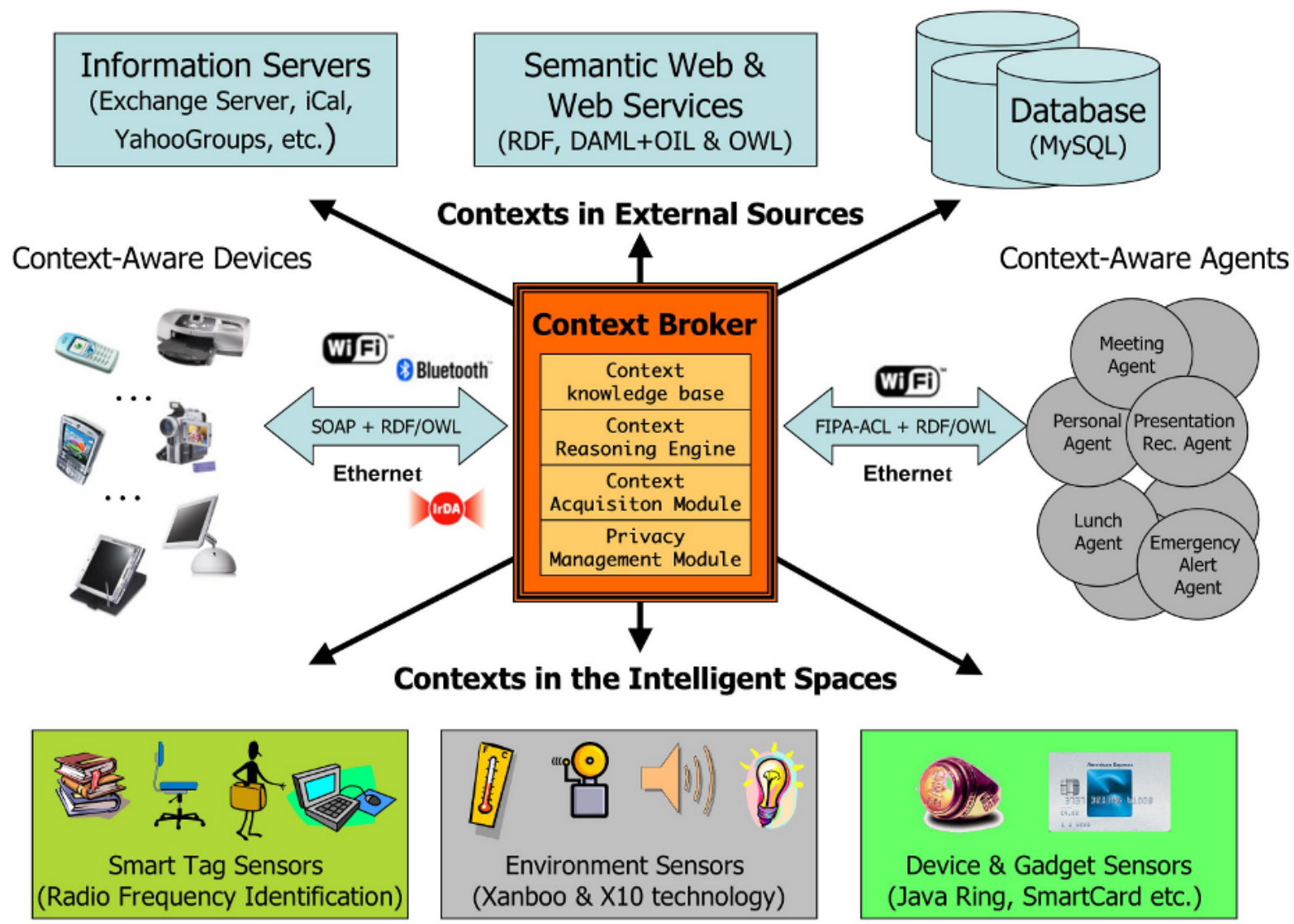

Figura 3.1: Interação de um Context Broker no modelo CoBrA, adquirindo informações de contexto de dispositivos, agentes e sensores no ambiente. As informações são unidas em um modelo compartilhado com os dispositivos e agentes (Chen, 2004).

compartilhado dessas informações são características em comum ao modelo CAPPA.

\subsubsection{CASS}

O CASS é um middleware para suportar aplicações cientes de informações de contexto em dispositivos móveis em geral, reportado por Fahy e Clarke (2004). Os autores citaram alguns requisitos que o sistema pode atender, dentre eles suportar um grande número de fontes de informações de contexto, suportar interpretação de informações de contexto e suportar o uso de fontes de informações de contexto distribuídas.

A arquitetura é cliente-servidor, em que as informações de contexto bem como dados de usuários, aplicações e regras de ciência de informações de contexto são armazenadas no servidor, já que dispositivos móveis normalmente possuem pouco espaço de armazenamento e poder de processamento. O uso de diversas fontes de informações de contexto é também utilizado no modelo 
CAPPA, entretanto o foco é o cenário de aplicações na Web e em TV, independentes de dispositivos móveis.

\subsubsection{IM4Sports}

Wijnalda et al. (2005) relatam um modelo que provê ciência de informações de contexto que captura informações físicas do usuário enquanto ele realiza treinamento físico, para então selecionar músicas de acordo com o estado atual do usuário e com o treino planejado.

O usuário transfere cada música com seus atributos (artista, gênero, etc.) e o programa de treinamento para seu player portátil. Os programas de treinamento são criados previamente e podem ser utilizados, adaptados ou novos podem ser criados pelos usuários. O usuário escolhe então uma música de uma coleção de músicas que se encaixa em seu programa de treinamento. Diferentes treinamentos físicos vão resultar em diferentes movimentos, intensidade, duração e passos. Diferentes músicas são escolhidas por gênero, artista e ritmo.

Através das características disponíveis, o sistema captura os resultados físicos que obtém do usuário com o uso de sensores (de batimentos cardíacos e de aceleração) para escolher a melhor música. Apesar do modelo CAPPA não utilizar diretamente informações de atividades físicas do usuário, o trabalho é relevante pelo uso de informações de contexto do usuário para adaptação de conteúdo multimídia (no caso música).

\section{1.5 SeCoM}

O trabalho reportado por Bulcão Neto (2006) relata a construção do modelo Semantic Context Model (SeCoM), desenvolvido com base em ontologias e em padrões da Web Semântica para a modelagem e a representação de informação contextual. Relata também a construção da infraestrutura de Software SCK (Semantic Context Kernel) a qual fornece a aplicações um conjunto de serviços que processam a semântica explícita de informações de contexto.

O modelo SeCoM representa conceitos básicos de atores, local, data, dispositivos, eventos e atividades, e as relações entre esses conceitos (Bulcão Neto; Pimentel, 2006), conforme visualizado na Figura 3.2. Os principais elementos do modelo são: 


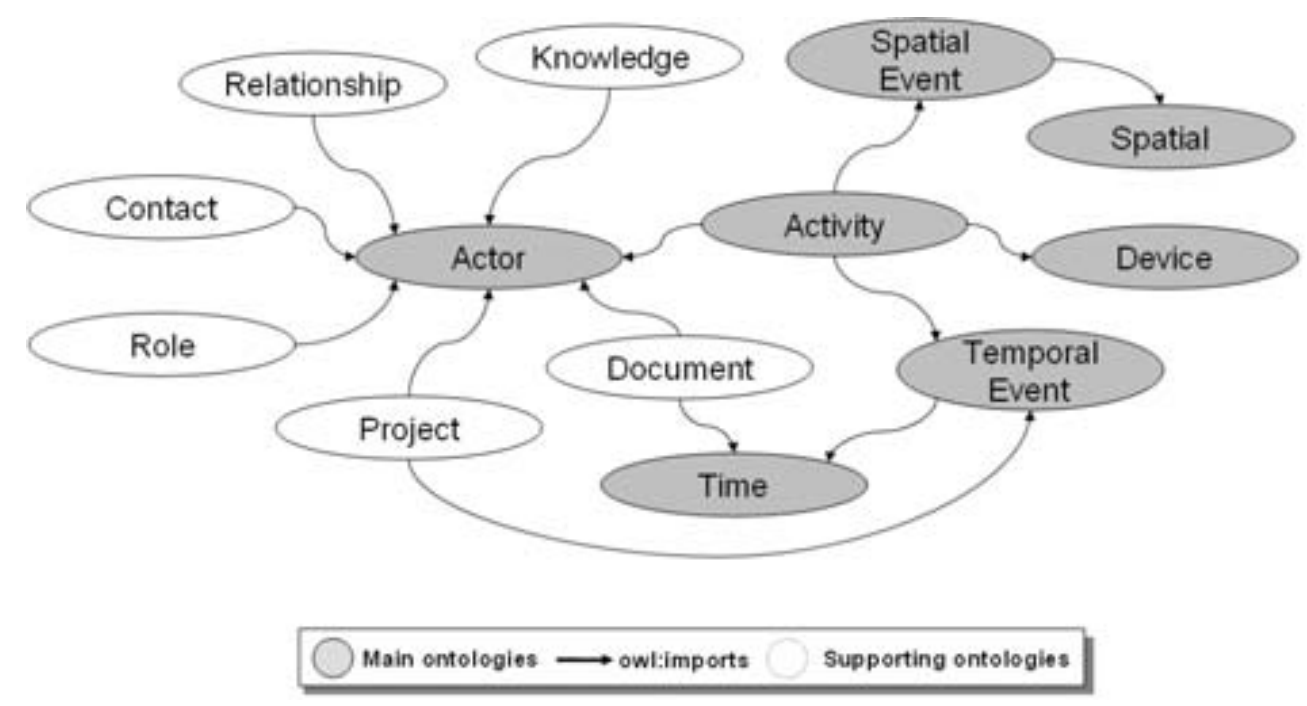

Figura 3.2: Visão geral do modelo de informações de contexto SeCoM (Bulcão Neto; Pimentel, 2006).

- Atores (Actor): modelam os perfis de entidades que podem realizar ações, como conhecimento, papel social, relações sociais e informações de contato.

- Espaço (Spatial): descreve o local dos atores, modelando locais, conteúdo e relações espaciais entre locais, coordenadas geográficas, dentre outras. Os eventos com extensões espaciais são chamados de Spatial Event.

- Data (Time): representa a informação temporal em instantes e intervalos de tempo. Modela relações entre instantes e intervalos, entre intervalos e calendários. Eventos estendidos são modelados em ontologias Temporal Event.

- Dispositivo (Device): descreve dispositivos pelas características das plataformas de hardware e software, incluindo informações como presença de bateria, suporte a conteúdo multimídia, conectividade de rede, dentre outras.

- Atividade (Activity): descreve ações que os autores podem realizar.

O modelo e seus principais elementos foram estendidos na ontologia do modelo CAPPA, como detalhado no Capítulo 5.

\subsection{Sistemas de Recomendação Multimídia}

Os trabalhos apresentados nesta seção são relacionados ao o uso de informações de contexto em vídeos, seja na forma de recomendação de vídeos ou na de extração de informações de contexto. 


\subsection{SenSee}

O trabalho reportado por Aroyo et al. (2007a) propõe o SenSee como um framework para personalização e interação em um ambiente multimídia. Existem implementações desse framework em aplicações, como o iFanzy, uma aplicação que oferece um guia de TV personalizado (Bellekens et al., 2009). Os autores listam alguns requisitos do sistema, que são relevantes ao modelo CAPPA. São eles:

1. Integração de busca e recuperação de conteúdo heterogêneo (como vídeo, texto e áudio) distribuído em meios de comunicação diversos.

2. Modelo de conteúdo semântico integrado, a fim de permitir mapeamentos a diversos vocabulários em diferentes domínios (como na forma de ontologias).

3. Experiência personalizada para usuários em grupos e individualmente. Os usuários podem interagir com diversos dispositivos ao mesmo tempo, na mesma sessão, sendo importante que o sistema permita entrada de informações diversas pelos usuários, como sensores, controle remoto, dentre outros.

4. Protocolo de comunicação aberto para interconectar os componentes do framework.

5. Manutenção, compartilhamento e recuperação de perfis pessoais de conteúdo com peers.

6. Administração de privilégios dos usuários para grupos de usuários e dispositivos.

A estrutura do framework, esquematizado na Figura 3.3, possui três componentes principais: UMS - User Model Service (Serviço de Modelo de Usuário), OS - Ontology Service (Serviço de Ontologia) e FS - Filter Service (Serviço de Filtro). O UMS armazena e gerencia os perfis dos usuários com informações diversas, como interesses, deficiências e preferências. O OS gerencia os vocabulários necessários para que o sistema entenda conceitos e os termos semânticos quanto procura e filtra conteúdos. O FS especifica diferentes filtros de conteúdo para serem usados quando algum conteúdo é procurado ou recomendado ao usuário.

Enquanto que o objetivo do SenSee é auxiliar na busca de conteúdo, o foco do modelo CAPPA é auxiliar na autoria de anotações por parte de um usuário 


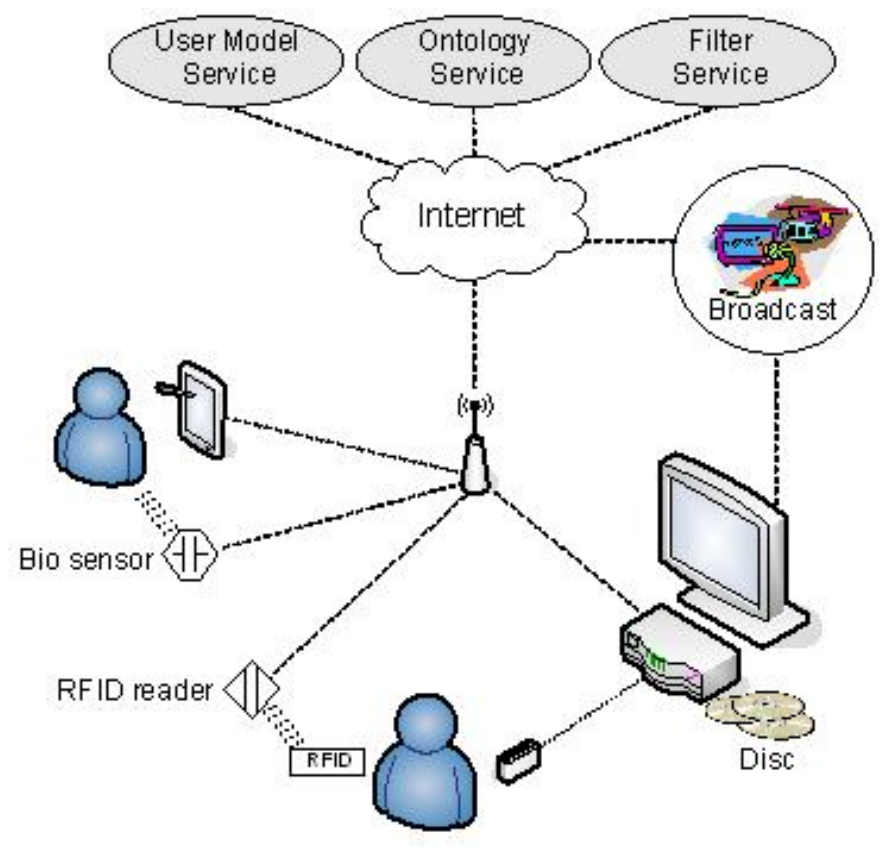

Figura 3.3: Estrutura do framework SenSee, exibindo como é realizada a interação entre os componentes principais e os usuários (Aroyo et al., 2007a).

ou por grupos de usuários. O SenSee apresenta algumas características interessantes que podem ser incorporadas, como um gerenciador de ontologias e o uso de informações diversas pelos usuários.

\subsubsection{Tribler}

O sistema Tribler, de Pouwelse et al. (2008), tem por objetivo aprender os interesses do usuário, a fim de recomendar, gravar ou mesmo transferir programas de outros usuários através de uma rede P2P. O sistema utiliza as informações aprendidas com cada usuário na rede $\mathrm{P} 2 \mathrm{P}$, o que cria redes sociais, ou comunidades online, que compartilhem interesses semelhantes, explorando a recomendação de programas implícita - inferidas pelo aprendizado automático, e explícitas, informadas por algum usuário da rede (Wang et al., 2008).

Tribler é considerado um sistema de recomendação distribuída, já que a recomendação dos programas é feita também pela rede. Para isso, o sistema captura e aprende os interesses de cada usuário implicitamente, conforme ilustrado na Figura 3.4. O sistema, então, filtra e compartilha os programas e interesses do usuário na rede $\mathrm{P} 2 \mathrm{P}$, a fim de encontrar usuários com perfis semelhantes. Além disso, o sistema armazena de modo distribuído os programas assistidos, permitindo que outros usuários da rede possam ter acesso remoto ao conteúdo recomendado pela rede $\mathrm{P} 2 \mathrm{P}$. 


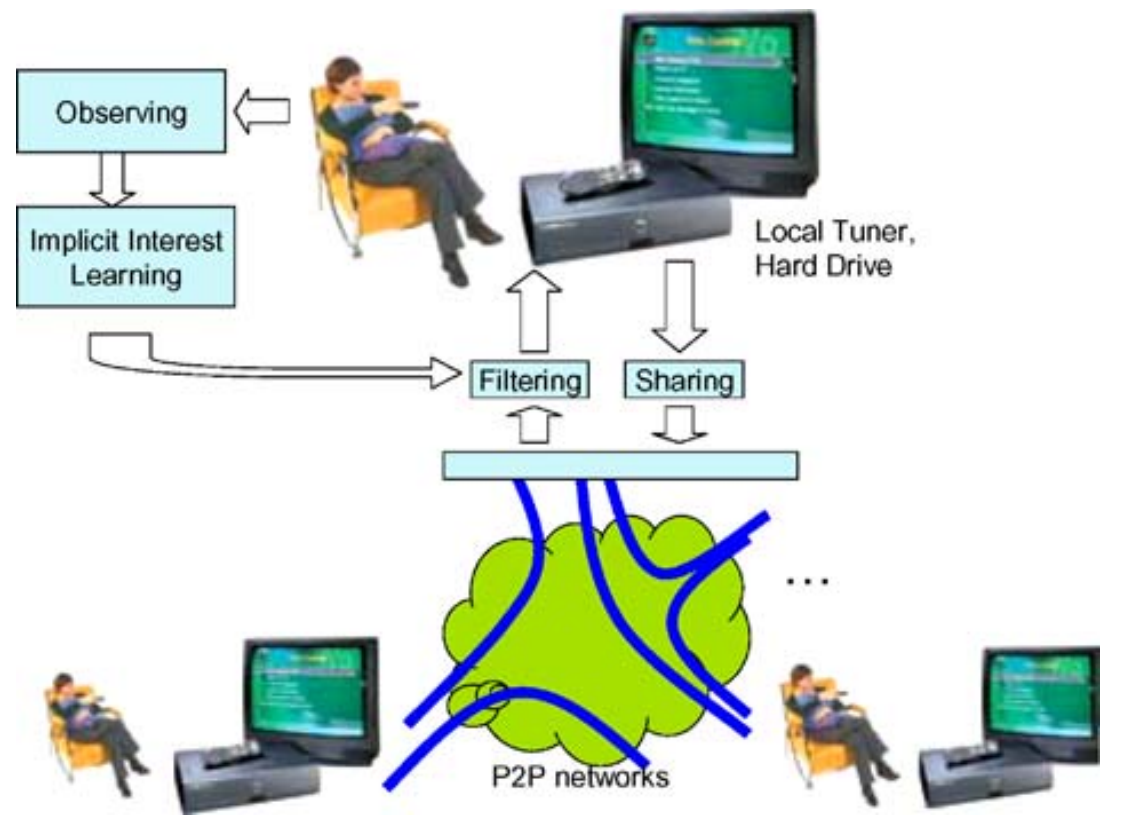

Figura 3.4: Estrutura do sistema Tribler, exibindo como é realizada a interação entre os usuários e a rede $P 2 P$.

O estudo de um sistema que utiliza a rede $\mathrm{P} 2 \mathrm{P}$ para recomendação de programas, no contexto de vídeo e TV, contribui para um dos modos de compartilhamento das informações no modelo CAPPA, que utiliza-se de uma rede P2P para compartilhar informações de contexto.

\subsubsection{M4Note}

A ferramenta MultiMedia MultiModal Annotation Tool (M4Note) é uma interface multimodal que permite captura e anotação de vídeos. Goularte et al. (2004) detalham a aplicação que controla uma WebCam acoplada a um TabletPC para permitir capturas de vídeo, áudio e tinta para o caso de anotações. A ferramenta WaCTool, na qual o protótipo CWaCTool é baseado, foi inspirada na ferramenta M4Note.

Goularte et al. (2004) discutem também a personalização da ferramenta, permitindo a criação de símbolos especiais ou personalizados. Quando um usuário realiza uma anotação em tinta com um símbolo diferente, a M4Note pergunta ao usuário um nome para o novo símbolo. É possível ainda criar relações entre os símbolos, como por exemplo um asterisco significar semanticamente que é algo importante.

Manzato et al. (2009) apresentam uma arquitetura que utiliza a ferramenta M4Note, realizando um estudo de extração de metadados para propor uma arquitetura que explore a capacidade de usuários interagirem com o conteúdo. A Figura 3.5 apresenta a arquitetura proposta, na qual existem duas principais 


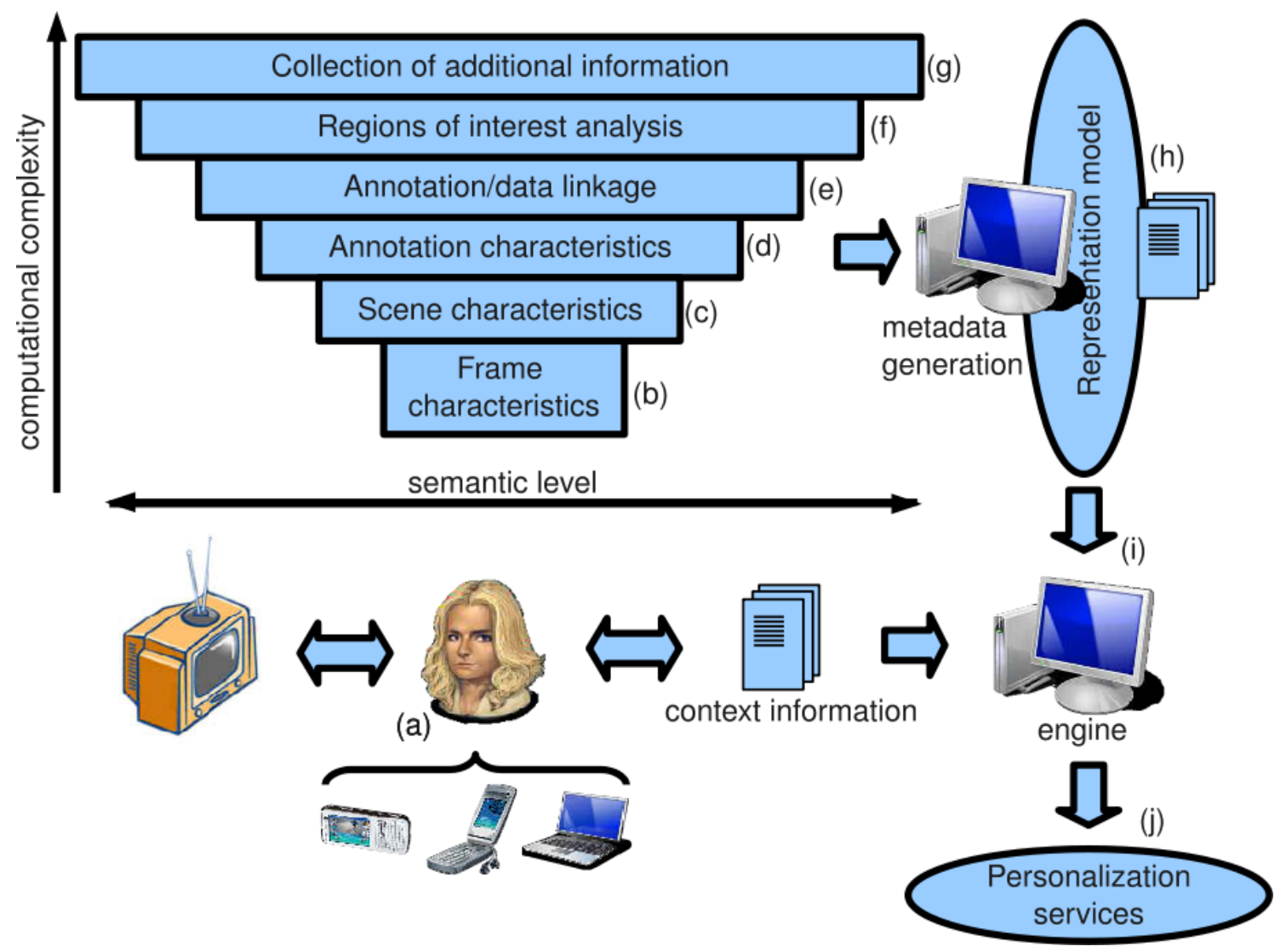

Figura 3.5: Arquitetura proposta por Manzato et al. (2009).

fontes de informação de contexto: (i) as informações provenientes do usuário e de seus dispositivos utilizados para captura das anotações (Figura 3.5.a), e (ii) o conhecimento proveniente de características do vídeo, como por exemplo informações dos quadros de vídeo (histogramas, níveis de cores) e da duração das cenas (Figura 3.5.b-g). As informações são, então, processadas (Figura 3.5.h) e disponibilizadas em serviços de personalização.

A arquitetura apresentada por Manzato et al. (2009) tem conceitos complementares ao modelo CAPPA, pois trabalha principalmente com informações do vídeo, extraídas por técnicas diversas.

\subsubsection{Social $C A B$}

Coppola et al. (2009) apresentam a ferramenta CAB (Context Aware Browser), que permite navegar em conteúdo digital usando dispositivos do mundo real. A CAB é baseada no framework MoBe, uma abordagem para prover infraestrutura básica para aplicações cientes de informações de contexto e pervasivas em dispositivos móveis. O framework utiliza-se de técnicas de Inteligência Artificial em uma combinação de sistemas de regras, redes Bayesianas e ontologias, aplicadas à inferência de informações de contexto. 
Mizzaro et al. (2009) apresentam uma extensão da ferramenta, a SCAB (Social $C A B$ ), que propõe o uso de colaboração na aplicação. Com o uso do aspecto social, a SCAB utiliza etiquetas (tags), que permitem a associação de um recurso a informações de contexto. As etiquetas são criadas nas buscas realizadas pelos usuários, que suprem uma comunidade virtual de etiquetas associadas a recursos.

A Social CAB é uma ferramenta que explora a anotação colaborativa, pois permite usuários adicionarem etiquetas aos recursos digitais. O uso de etiquetas é uma possível extensão para o modelo CAPPA, entretanto o modo assíncrono de anotação colaborativa já é explorado pela WaCTool.

\subsection{Sistemas Colaborativos de Vídeo}

Os sistemas detalhados a seguir apresentam aspectos semelhantes quanto a anotação colaborativa de vídeos, sem necessariamente utilizarem informações de contexto.

\subsubsection{AmigoTV}

O sistema AmigoTV é reportado por Coppens et al. (2004) como a implementação de um protótipo, que funciona sobre tecnologias da empresa Alcatel ${ }^{1}$, utilizando a plataforma de IPTV. Os autores consideram que uma experiência real de usuários na TV consiste de três componentes básicos:

- Conteúdo pessoal, os autores consideram que é interessante não só a disponibilidade de vídeos e fotos ao usuário, mas também o conteúdo que o usuário aprecia e recomenda.

- Comunicação melhorada, é interessante considerar como as pessoas se comunicam no dia-a-dia, utilizando voz, vídeo, textos, gestos, ou mostrando suas emoções atuais.

- Suporte a comunidades, é interessante que as características de uma rede social, como lista de contatos, função de convidar um amigo, calendário, dentre outras, possam ser incluídas no uso do sistema.

A partir desses três componentes, Coppens et al. (2004) apresentam um modelo de ferramenta que atende aos requisitos além de discutir a possibilidade de utilização da Multimedia Home Platform (MHP) (Yang et al., 2008).

\footnotetext{
${ }^{1}$ http://www.alcatel-lucent.com/, Acesso em 15 Jan 2010.
} 
Os aspectos de "comunicação melhorada" e, em especial, "suporte a comunidades" do sistema AmigoTV foram implementados para melhor experiência dos usuários no modelo CAPPA: a melhora na comunicação tomou com base anotações síncronas, e o suporte a comunidades é dado por grupos P2P.

\subsubsection{CollaboraTV}

Desenvolvido por Nathan et al. (2008), a ferramenta CollaboraTV permite que seus usuários criem comentários de texto enquanto assistem a um programa de TV. Além de comentários de texto, é possivel que os telespectadores compartilhem pontos de interesse e suas expressões em "avatares" enquanto assistem ao programa. Os comentários podem ser visualizados sincrona ou assincronamente, e as anotações dos usuários são compartilhadas em uma rede social.

Os comentários de texto criados pelos usuários são anexados ao fluxo de vídeo e áudio no momento correspondente ao comentário, permitindo que o comentário possa ser visualizado posteriormente por outros usuários. Apesar do mecanismo ser simples, Nathan et al. (2008) citam que o efeito gerado para quem assiste a um vídeo com comentários é positivo, e a pessoa que assiste o vídeo com comentários passados sente-se como se estivesse recebendo os comentários no mesmo momento em que assiste.

Pontos de interesses também são classificados como um tipo de anotação no sistema. Assim como nos comentários, os pontos de interesses podem ser anexados aos fluxos de mídia, mas ao invés de conter texto, eles são usados para expressar reações positivas ou negativas de um programa, como por exemplo se uma cena é engraçada ou não e se é emocionante ou previsível.

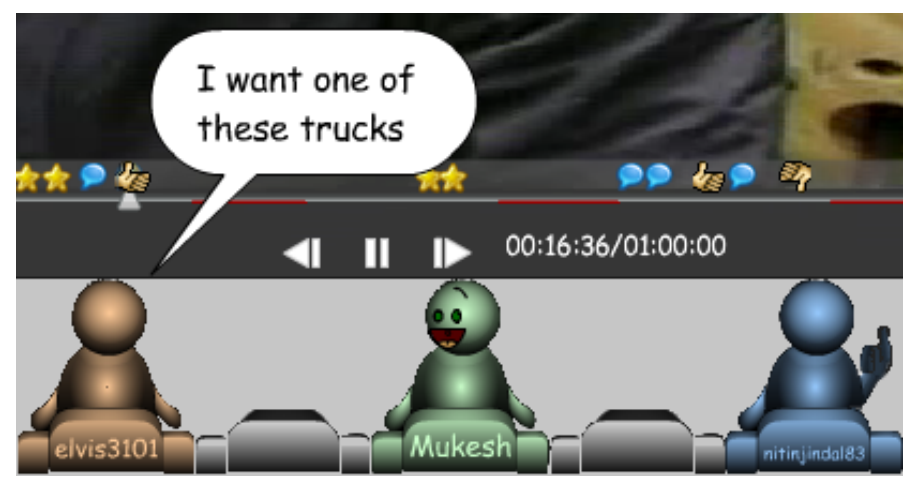

Figura 3.6: Parte da tela que o usuário visualiza enquanto assiste uma aplicação no CollaboraTV. Cada usuário é representado por um avatar contendo a expressão capturada do usuário correspondente. O usuário da esquerda apresenta o texto com uma mensagem de texto enviada. 
Outro tipo de anotação que é utilizado no sistema é a expressão atual do usuário, em que o mesmo seleciona a partir de uma lista de expressões disponíveis, tais como "feliz", "triste" e "nervoso". Quando um usuário escolhe "feliz", por exemplo, seu avatar expressa um sorriso, como pode ser visto na Figura 3.6, em que um usuário expressa um sorriso enquanto o da esquerda realiza um comentário de texto.

A ferramenta CollaboraTV implementa uma rede social simples para compartilhar essas anotações, e a comunicação é feita entre amigos e familiares. Utiliza para isso uma arquitetura cliente-servidor, não sendo possível conexões em redes $\mathrm{P} 2 \mathrm{P}$. O poder dos telespectadores compartilharem pontos de interesses e expressões na mídia temporal pode tornar a característica mais interessante do sistema, uma vez que a maior parte dos sistemas, como o Youtube, operam com pontuação de quanto o usuário gostou apenas relativo ao vídeo como um todo.

\subsubsection{Telebuddies}

O sistema Telebuddies permite que um usuário faça anotações em programas de TV, tornando-os interativos, além de fazer uso de similaridades e relações sociais entre telespectadores, conforme reportado por Luyten et al. (2006).

Como exemplo, os autores utilizam o cenário de um questionário, como mostrado na Figura 3.7, em que cada pergunta tem uma duração pré-definida. A interação é definida por uma ontologia associada ao formato do programa. Desse modo, quando uma pergunta é exibida, a entrada do usuário é adaptada ao tipo de resposta esperada, como campos de texto, datas, números, etc.

Para a comunicação entre os telespectadores, o sistema possui um servidor que gerencia a comunicação entre os set-top-boxes dos telespectadores. A comunicação é realizada através de perfis de usuários, sendo que cada perfil contém informações sobre relações sociais dos usuários e informações convencionais, como nome, endereço, hobbies e cor do cabelo (Luyten et al., 2006). Com os perfis, o sistema utiliza características comuns e mais usuais para criar grupos de telespectadores. Os autores citam que o sistema não conta com implementação de gerenciamento de segurança e privacidade, apesar de ressaltarem sua importância.

O modelo CAPPA também explora características em comum dos usuários para criar grupos, mas explora ainda informações de contexto para realizar as recomendações. 


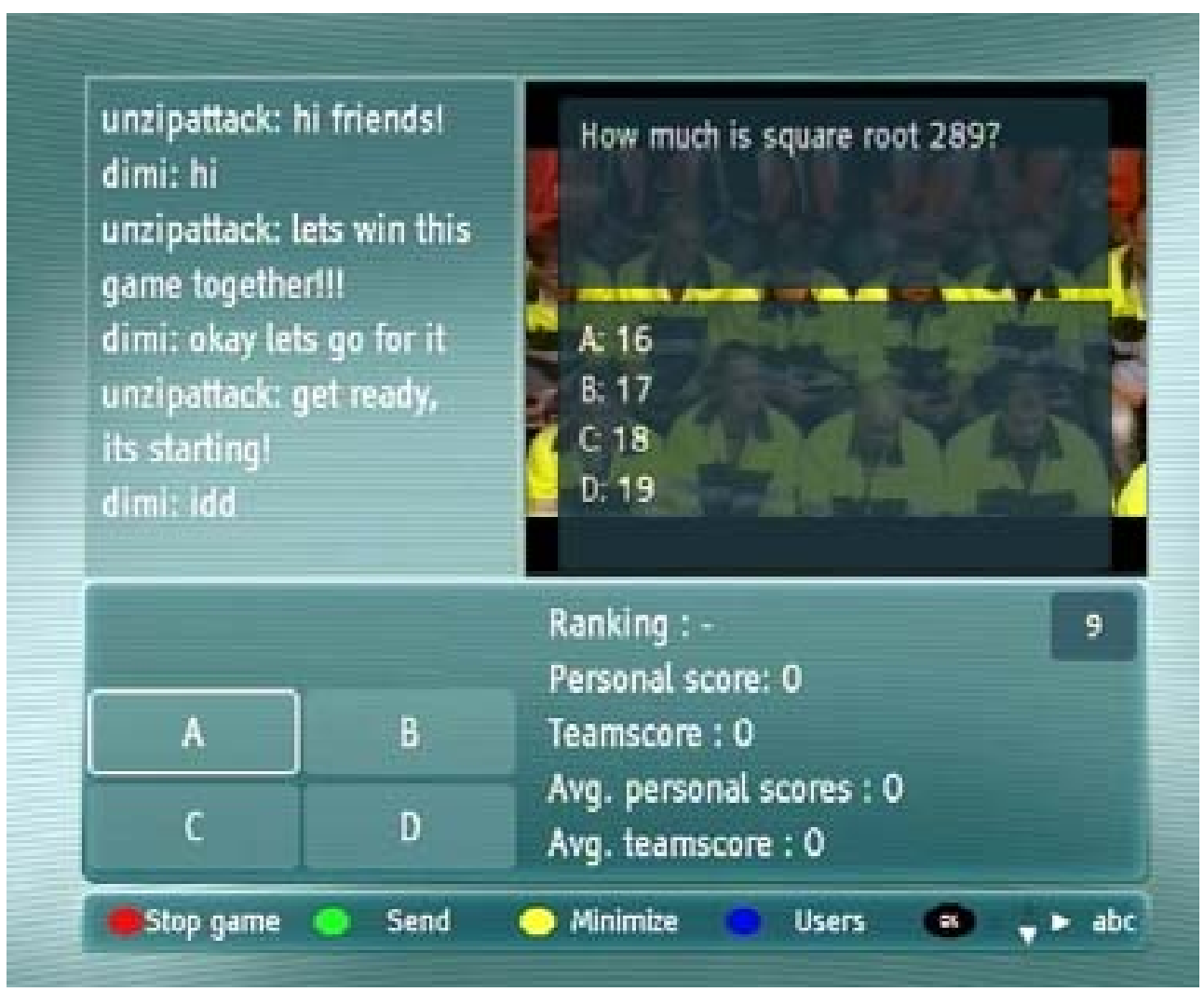

Figura 3.7: Exemplo de uso do sistema Telebuddies (Luyten et al., 2006). Uma questão é exibida em um televisor, em que a entrada do usuário é limitada a responder a questão entre as alternativas $A, B, C$ e $D$.

\subsubsection{STV3}

Com o objetivo de permitir que telespectadores conversem com texto e voz, Tullio et al. (2008) reportam a aplicação STV3. Considerando que o uso de comunicação em texto e áudio auxiliam na experiência de TV social, ou Social $T V$, os autores fazem um estudo do nível de comunicação que é necessário para atingir uma socialização razoável na TV (Huang et al., 2009)

O sistema STV3 é um protótipo em que os usuários possuem uma lista de amigos (ou contatos) e podem ver quem está online e ao que estão assistindo. Os usuários podem então iniciar uma conversa de voz, com microfones situados nas salas em que se encontram, ou então de texto, com uso de um teclado.

Huang et al. (2009) descrevem um estudo qualitativo realizado com cinco participantes que utilizaram a ferramenta STV3 por quatro dias. Os participantes reportam que, com o uso da ferramenta, acabam utilizando menos outros meios de comunicação (como o telefone) por já estarem se comunicando pela TV. Um resultado interessante é que os participantes preferiram o uso de conversa por texto do que por voz, por esta não exigir atenção da pessoa nem ser necessário esperar para responder, por exemplo. Os participantes também 
reportaram satisfação no uso do protótipo por estarem em maior contato com outras pessoas.

Apesar do protótipo CWaCTool construído do modelo CAPPA suportar somente conversa via texto digitado, esse estudo sugere que algumas pessoas preferem esse tipo de mídia. Entretanto, uma possível extensão que possibilite o uso de bate papo por voz pode ser interessante.

\subsubsection{PersonalTV}

Pessemier et al. (2009) apresentam um sistema de recomendação de vídeos para o sistema Youtube, o PersonalTV ${ }^{2}$. Trata-se de uma aplicação que integra os vídeos presentes no portal Youtube em uma rede social, no caso a rede Facebook. Os usuários podem utilizar o sistema diretamente na página da rede social para assistir a vídeos, avaliá-los e recomendá-los a seus amigos, realizando as Social Recommendations, ou recomendações sociais, como chamado pelos autores.

O principal objetivo da aplicação é prover recomendações de vídeos, enquanto que o modelo CAPPA tem por objetivo prover recomendação de anotações e um meio de realizá-las, considerando grupos de usuários. Um ponto interessante do PersonalTV é o modo como se integra completamente a uma rede social, sugerindo ideias para o modelo CAPPA, como a integração com o Youtube e com uma rede social para extrair informações de contexto do usuário e do vídeo.

\subsubsection{Outros Trabalhos Relevantes}

Alguns autores exploram ciência de informações de contexto para auxiliar anotações em vídeo, como Min et al. (2010). Esses autores apresentam um sistema que permite anotação de vídeo e é integrado a uma folksonomia ${ }^{3}$ de imagens, de modo que imagens podem ser sugeridas no momento de anotação do vídeo. A folksonomia possui algumas etiquetas (tags) associadas a cada imagem, que são utilizadas para melhorar a escolha de uma imagem para cada vídeo.

A anotação de vídeos de modo colaborativo é pesquisado por diversos autores, como ilustrado no trabalho de Geng et al. (2008), que apresentam um modelo de aprendizado colaborativo para anotações de vídeo e imagens. Zhai et al. (2005) por sua vez, apresentam um sistema de anotações de vídeo, o eS-

\footnotetext{
${ }^{2}$ http://apps.facebook. com/personaltv, Acesso em 20 Fev 2010.

${ }^{3}$ Uma folksonomia é uma maneira de usuários indexarem informações.
} 
ports, que utiliza uma arquitetura de cliente-servidor para compartilhar anotações.

O sistema Youtube fornece um recurso para usuários realizarem anotações colaborativas no próprio website do Youtube.com, que permite aos usuários adicionarem caixas de texto e notas no vídeo do autor ${ }^{4}$. No caso desse recurso, somente o autor pode convidar outros usuários a anotarem no mesmo vídeo, e o processo de anotação deve ser realizado em uma página de Web diferente da que é usada para visualizar vídeos.

\subsection{Sistemas Peer-to-Peer}

O compartilhamento de informações de contexto em uma rede Peer-to-Peer (P2P) é reportado por Yang (2006), em um ambiente de aprendizado. O ambiente utiliza a captura e a modelagem de informações de contexto em ontologias, a fim de criar sistemas adaptativos e prover serviços personalizados aos usuários do sistema de aprendizado, baseando-se em suas preferências.

A rede P2P no sistema de Yang (2006) é utilizada para compartilhar o material de cada peer, além de permitir a troca de mensagens entre peers - esta utilizada principalmente para procura por conteúdo e troca de informações de serviço. O sistema P2P de conteúdo provê acesso típico a serviços como descoberta de conteúdo, troca de conteúdo, replicação e sincronização de conteúdo, sincronização das ontologias, além de outras características. O serviço também é capaz de recomendar peers mais favoráveis a conter um determinado conteúdo que se busca.

Yang (2006) ainda cita a possibilidade de alguns peers serem mediadores em uma busca, criando uma hierarquia de peers normalmente categorizadas por algo previamente definido. O modelo CAPPA não utiliza uma hierarquia fixa, mas grupos P2P que representam uma hierarquia distribuída.

Apesar de propósitos distintos, a sincronização de ontologias foi o que permitiu o uso de redes P2P no modelo CAPPA, semelhante aos utilizados por Yang (2006) e também por Skoutas et al. (2008).

Considerando sistemas de Bancos de Dados distribuídos em redes P2P, Skoutas et al. (2008) reportam o uso ontologias para melhorar a questão de similaridade semântica de informações. Os autores consideram que as ontologias podem ser diferentes e distribuídas, realizando então um mapeamento

\footnotetext{
${ }^{4}$ http://www.google.com/support/youtube/bin/answer.py?hl=en\&answer=141107, Acesso em 9 Mai 2010.
} 
de elementos das diferentes ontologias (diferentes schemas), como ilustrado na Figura 3.8

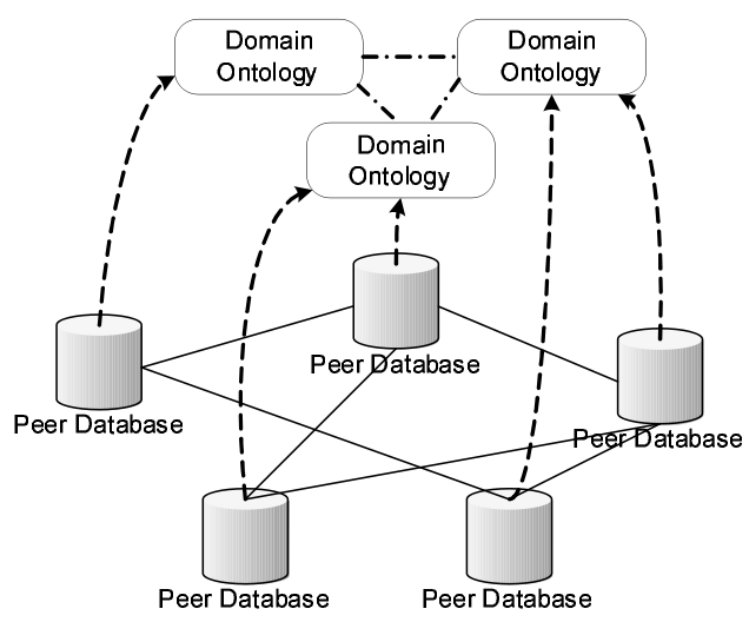

Figura 3.8: Ontologias diferentes em bases de dados P2P distribuidas (Skoutas et al., 2008).

Skoutas et al. (2008) ainda exemplificam redes sociais como um cenário em que a similaridade semântica é importante. Enquanto que as redes sociais têm como objetivos permitir a seus usuários criarem laços, se comunicarem e compartilhar interesses e características, a busca por informações em comum nem sempre é fácil para os usuários.

O uso de diferentes ontologias não é previsto pelo modelo CAPPA, o que poderia torná-lo mais interessante para aceitar diferentes fontes de informação. Entretanto, o foco de Skoutas et al. (2008) é encontrar similaridades, enquanto que o modelo CAPPA é o de criar sugestões com as informações já estruturadas.

\subsection{Considerações Finais}

Diversos dos trabalhos apresentados contribuíram para a construção do modelo CAPPA. Alguns trabalhos podem ser destacados, como o modelo SeCoM (Bulcão Neto, 2006), por ser a base da ontologia presente no modelo CAPPA, o sistema Tribler (Pouwelse et al., 2008), por utilizar uma rede P2P para recomendação de conteúdo multimídia, a ferramenta M4Note (Manzato et al., 2009; Goularte et al., 2004), por extrair informações de contexto de vídeos, e pela personalização oferecida, e o ambiente CollaboraTV (Nathan et al., 2008), por permitir captura de comentários e uso em uma rede social. 
No próximo capítulo será apresentado o principal trabalho do qual foi derivado o modelo CAPPA e a ferramenta CWaCTool: o paradigma Watch-AndComment. 


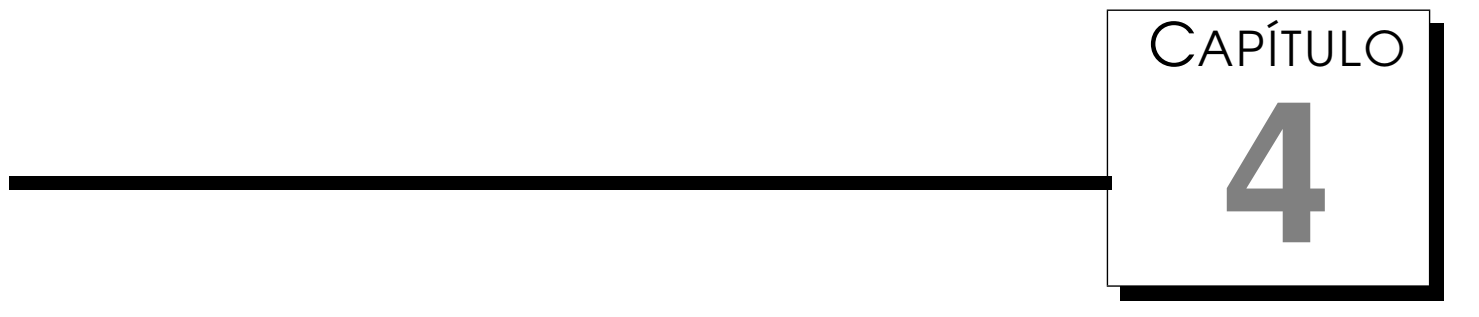

\section{Paradigma Watch-and-Comment}

Usuários comuns têm utilizado cada vez mais dispositivos que capturam e geram objetos digitais de mídias, como vídeos, anotações com voz, textos, fotografias, etc. Isso contribui para uma crescente disposição de artefatos digitais, criando desafios para manter-se a organização e a identificação dos mesmos.

Considerando a produção de vídeos digitais, as ferramentas tradicionais para autoria de vídeos são normalmente desenvolvidas para usuários avançados, assumindo que eles tenham experiência com tarefas avançadas, como aplicação de filtros de vídeo. Cattelan (2009) cita algumas dessas ferramentas avançadas, como o Movie Maker e o Premiere Pro CS4.

Em diversas oportunidades usuários comuns poderiam produzir vídeos interativos, como quando assistem a televisão em sua casa e desejam inserir comentários de texto ou voz em uma cena em especial (Cattelan et al., 2008a). Existem dispositivos capazes de capturar comentários e ações dos usuários, como microfone para captura de voz, controle remoto para captura de ações, dentre outras. Com o uso de métodos de captura automática das ações dos usuários, o paradigma Watch-and-Comment (WaC) foi criado e é estudado com o objetivo de prover meios transparentes ao usuário para captura de comentários e anotações em vídeos. O paradigma prevê ainda o acesso posterior das anotações com a produção de vídeos interativos pelos usuários. Deste modo, o WaC é um paradigma de autoria de documentos multimídia interativos. 
Este capítulo aborda o paradigma WaC com o detalhamento do paradigma na Seção 4.1, a apresentação da ferramenta de prova de conceito original WaCTool com seu histórico na Seção 4.2, e as considerações finais na Seção 4.3.

\subsection{Proposta Watch-and-Comment}

O paradigma Watch-and-Comment (WaC) faz uso de conceitos da área de Computação Ubíqua, considerando principalmente o aspecto de captura automática e do correspondente acesso às informações capturadas. Com o objetivo de prover meios transparentes de captura automática dos comentários e das anotações dos usuários para gerar vídeos interativos, a proposta original foi apresentada por Pimentel et al. (2007), e demonstrada em trabalho posterior (Pimentel et al., 2008).

A proposta traz contribuições em relação a produção, consumo e extensão de vídeos interativos, sendo eles (Cattelan et al., 2008a):

- Provimento de um paradigma para autoria de conteúdo, que permite ao usuário personalizar vídeos lineares (como programas de TV), produzindo vídeos interativos como resultado.

- Suporte a comunicação remota entre os usuários, permitindo que usuários assistam a vídeos e utilizem uma ferramenta de bate-papo ao mesmo tempo.

- Utilização de identificadores de vídeos para organizá-los e permitir colaboração dos participantes em grupos P2P. Utilização também de etiquetas (tags) para indexar partes dos vídeos, que permitam buscar partes dos vídeos e compartilhar anotações.

- Provimento de busca e acesso personalizados e orientados às anotações dos usuários, sendo sensível ao contexto dos vídeos.

A captura de informações do paradigma WaC pode ser realizada de diversos modos, contanto que seja transparente ao usuário, ou pelo menos facilite seu processo sem tirar o foco de sua atividade principal, nesse caso a tarefa de assistir a um vídeo. Existem diversos dispositivos capazes de capturar informações dos usuários de modo transparente, como microfones para áudio ou mesmo Personal Digital Assistants (PDAs) e Smart Phones. Também é considerado o uso de dispositivos baseados em caneta eletrônica, por exemplo para capturar traços dos usuários sobre a superfície que o mesmo utiliza para assistir ao vídeo (Cattelan et al., 2008a). 
Outro aspecto importante do paradigma WaC é o acesso posterior aos comentários, através da produção de vídeos interativos. Esses vídeos podem exibir os comentários feitos pelos usuários opcionalmente ou obrigatoriamente. A exibição opcional pode ser melhor por não prejudicar a experiência de assistir a um vídeo com muitos comentários, por exemplo.

Os seguintes princípios de projeto para a abordagem do paradigma WaC foram definidos (Cattelan, 2009; Pimentel et al., 2007):

- Não há restrição com relação a fonte do vídeo: o vídeo pode ser obtido de qualquer dispositivo ou meio, como uma câmera ao vivo, sinal de TV ou um arquivo de vídeo em um computador.

- Não há restrição com relação ao tipo de vídeo: o vídeo pode ser gerado a partir de um conjunto de imagens por exemplo.

- Não há restrição com relação à linguagem do documento resultante: pode ser utilizada qualquer linguagem declarativa para documento resultante, como $\mathrm{NCL}^{1}$ ou Synchronized Multimedia Integration Language (SMIL) ${ }^{2}$, ou qualquer outro formato que expresse os comentários.

- A sessão pode ser colaborativa, distribuída e síncrona: mais de um usuário pode colaborar na anotação de um mesmo vídeo ao mesmo tempo, remotamente ou no mesmo local.

- O documento contendo as anotações dos usuários mantém-se separado da midia original: dessa forma as anotações podem ser distribuídas independentes do vídeo, uma característica importante por não alterar o vídeo original.

- Não há restrição em relação às mídias usadas para a captura de comentários: desde que possam ser capturadas. A captura pode ser transparente para o usuário (utilizando por exemplo microfone para áudio, dispositivos de tinta eletrônica e sensores e acelerômetros para captura de gestos), como também explícita, através de palavras digitadas em um teclado por exemplo.

- Não há restrição com relação a como a captura da interação deve ser utilizada: as aplicações podem inovar em termos do que fazer com a interação capturada. Por exemplo, as aplicações podem oferecer ou não um comando de vídeo, e exibir ou não uma determinada anotação em tinta.

\footnotetext{
${ }^{1}$ http: //www.ncl.org.br/, Acesso em 20 Mai 2010.

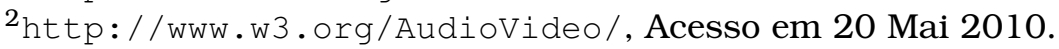


- Não há restrição com relação a como o documento dos comentários gerado é distribuído: o que significa que os vídeos interativos podem ser armazenados e visualizados apenas no local em que foi capturado ou pode haver uma integração com algum repositório Web, por exemplo.

- Uma sessão watching-and-comment pode ser iniciada a partir de uma sessão anterior.

Como prova dos conceitos,Pimentel et al. (2007) propõem a ferramenta WaCTool, a qual é descrita na seção a seguir.

\subsection{Protótipo WaCTool}

O paradigma WaC pode ser investigado em diversos aspectos, como no estudo de captura automática e acesso de informações e anotações, na colaboração de usuários e em ambiente de TVDI. O trabalho aqui reportado explora o aspecto de captura e uso de anotações e o de colaboração entre usuários.

Em trabalhos anteriores, Pimentel et al. (2005) apresentam o sistema iClass, que realiza a captura automática de uma sessão de aula e faz uso de uma lousa digital para captura de tinta eletrônica, câmera para captura de vídeo e microfone para o áudio. As anotações realizadas bem como os comentários capturados podem ser disponibilizados online através da Internet ou de algum outro meio digital, já que as anotações são armazenadas e/ou indexadas em Extensible Markup Language (XML). O principal domínio no qual a ferramenta foi utilizada é o educacional (Macedo et al., 2008), o que explica seu nome. O interessante desse trabalho para o paradigma WaC é o modo de captura das informações, transparente, além da ferramenta servir de modelo para implementação de uma nova ferramenta, a Whiteboard.

A ferramenta Whiteboard permite anotações baseadas em caneta digital em uma lousa digital ou com uso de dispositivo de tinta, e sua estrutura é aproveitada na WaCTool e usada no ambiente Tidia-Ae.

A partir da Whiteboard e da M4Note (Manzato et al., 2009), foi projetada a ferramenta Watch-and-Comment Tool (WaCTool) como prova de conceito do paradigma WaC (Cattelan et al., 2008a). A ferramenta permite que usuários conectem-se por uma rede $\mathrm{P} 2 \mathrm{P}$, criem anotações utilizando formas multimodais para captura, editem o video com comandos interativos e colaborem com outros usuários através de bate-papo e compartilhamento de conteúdo.

Os componentes de anotação da arquitetura da WaCTool são exibidos na região esquerda da Figura 4.1. O módulo Integração de mídias captura as 
interações multimodais, dos módulos abaixo dele, e utiliza tais informações para gerar um documento SMIL ou NCL. Os módulos Fonte de vídeo e Video Player são responsáveis pela decodificação e reprodução dos vídeos e o módulo Comandos interativos possibilita o usuário interagir com o fluxo de vídeo. Na região central dos componentes de anotação estão presentes os módulos Whiteboard, que permite anotações em tinta digital em quadros de vídeo, e Inkteractors, que determina visualizações personalizadas de anotações produzidas por tinta eletrônica (Cattelan, 2009). Por fim, os módulos de Text notes e Audio notes permitem a captura de voz e texto no vídeo.

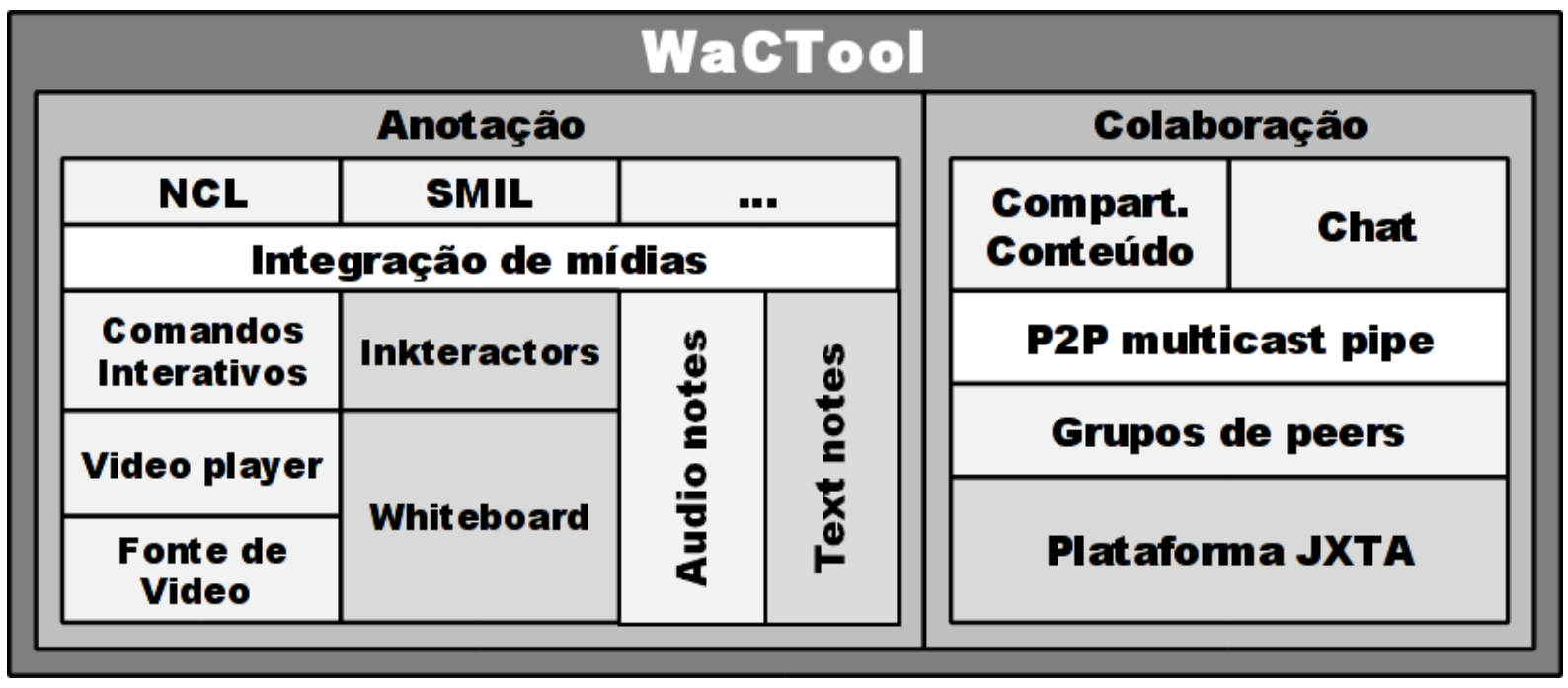

Figura 4.1: Arquitetura da ferramenta WaCTool com seus componentes - Adaptado de Cattelan (2009, p.36) e Cattelan et al. (2008a).

Os componentes de colaboração são mostrados na porção direita da Figura 4.1. O módulo Compartilhamento de Conteúdo permite que usuários possam visualizar e compartilhar as anotações realizadas. O módulo Chat permite o uso de bate-papo textual entre os usuários, que junto com o de compartilhamento utilizam um canal de comunicação P2P em multicast (cada usuário se conecta com todos os outros), fornecido pelo módulo P2P multicast pipe. Esse canal de comunicação é referente a um grupo P2P exclusivo para cada vídeo, com uso do módulo Grupos de peers, que por fim utiliza a Plataforma JXTA.

Quando o usuário escolhe um vídeo para assistir na ferramenta WaCTool, ela apresenta quatro painéis conforme ilustrado na Figura 4.2. O usuário pode utilizar algum dispositivo de captura de tinta digital, como um Personal Digital Assistant (PDA) ou Smartphone, algum modo de escrever texto, para bate-papo e anotações em texto, e algum modo de capturar voz, para anotação em áudio.

Enquanto o usuário assiste a um vídeo, pode a qualquer momento enviar uma mensagem na janela de bate-papo para outros usuários que assistem ao mesmo vídeo. O usuário também pode criar uma anotação de áudio ou de 


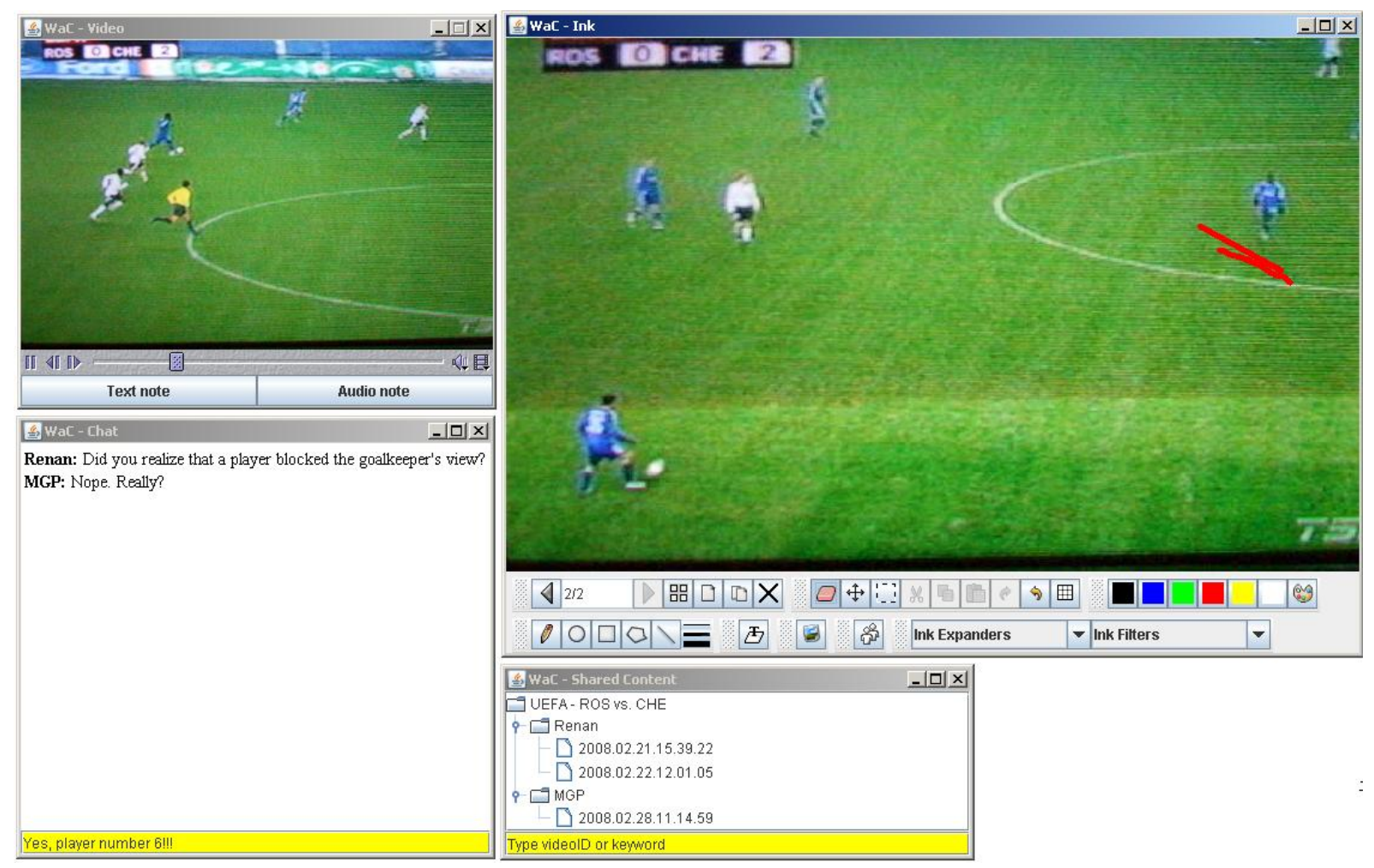

Figura 4.2: Ferramenta WaCTool. O canto superior esquerdo mostra o vídeo em reprodução, que permite anotações de texto e áudio além de permitir captura de tela com um clique do quadro. Quando há a captura de tela, o quadro de vídeo atual aparece na região superior direita. Nessa janela é possível realizar anotações de tinta eletrônica e inserção de textos. No canto inferior esquerdo há uma janela de bate papo entre usuários que estão visualizando o mesmo vídeo, e na parte inferior direita uma janela com as sessões anotadas do vídeo (Cattelan et al., 2008a).

texto em um determinado instante, ou clicar (com o mouse ou uma caneta eletrônica) no vídeo para que o quadro correspondente possa ser anotado com tinta eletrônica. É possível ainda que o usuário aponte para um dos cantos do vídeo a fim de criar comandos de edição de vídeo, como o uso de slow motion (para deixar um trecho do vídeo em câmera lenta) e o uso de skip (quando o usuário ache que o trecho demarcado pode ser pulado no vídeo), conforme exibido na Figura 4.3.

Outro recurso interessante da ferramenta WaCTool é de permitir conteúdo compartilhado, conforme Figura 4.4. A árvore apresentada é referente ao vídeo, e cada usuário tem uma lista de anotações, representadas por folhas nessa árvore. O usuário precisa apenas clicar em uma anotação e baixar para visualizá-la. O conteúdo é armazenado inicialmente por quem faz a anotação, mas quando um outro usuário baixa em seu dispositivo, ele também compartilha essa anotação, tornando a rede P2P com o propósito de replicar anotações entre os usuários do sistema. 


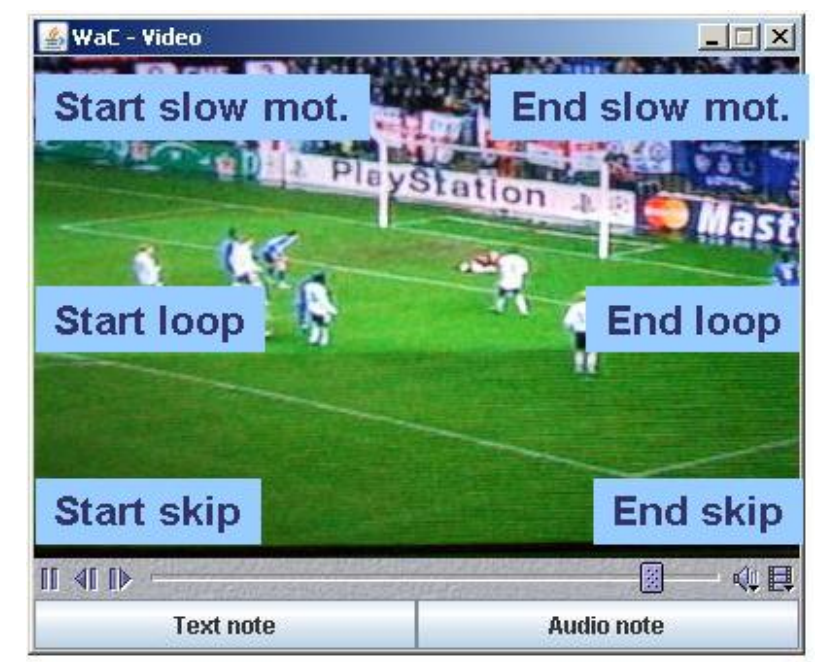

Figura 4.3: Janela da ferramenta WaCTool que mostra os comandos de edição de vídeo que o usuário pode inserir (Cattelan et al., 2008a).

\begin{tabular}{|c|c|}
\hline \multicolumn{2}{|l|}{ 毛WaC-5hared Content } \\
\hline \multicolumn{2}{|l|}{ qUEFA-ROS vs. CHE } \\
\hline \multicolumn{2}{|l|}{$9 \square$ Renan } \\
\hline \multicolumn{2}{|l|}{$-\square 2008.02 .21 .15 .39 .22$} \\
\hline \multicolumn{2}{|l|}{$\square 2008.02 .22 .12 .01 .05$} \\
\hline \multicolumn{2}{|l|}{$9 \square M G P$} \\
\hline$\square$ ( 2008.02 .28 .11 .14 .59 & \\
\hline Type videolD or keyword & \\
\hline
\end{tabular}

Figura 4.4: Janela de compartilhamento das anotações, em que a raiz é o arquivo de vídeo e os nós são as anotações, que ficam internas aos usuários, associando-os diretamente (Cattelan et al., 2008a).

Como resultado das interações, a ferramenta WaCTool produz vídeos interativos, nos formatos de documentos Ginga-NCL e SMIL (Cattelan, 2009). O formato NCL pode também ser produzido pela ferramenta Composer (Guimarães et al., 2008), voltada para usuários avançados devido a complexidade de uso. Os vídeos interativos gerados pela WaCTool acompanham as opções que permitem visualização dos comentários, sejam de áudio, texto, tinta ou comando de vídeo.

A ferramenta WaCTool é utilizada como base do protótipo para o modelo CAPPA, no entanto uma outra abordagem também vem sendo realizada, voltada ao ambiente de dispositivos móveis e TV Digital brasileira, denominada WaCTV (Pimentel et al., 2010). Tal abordagem pode ser entendida como complementar a apresentada nesta dissertação, uma vez que Pimentel et al. (2010) apresentam o estudo de utilização de dispositivos móveis que auxiliem na anotação em vídeos presentes na TV, enquanto que o modelo CAPPA explora informações de contexto no paradigma WaC. 


\subsection{Considerações Finais}

Este capítulo apresentou uma descrição do paradigma Watch-and-Comment e o histórico e funcionamento da ferramenta WaCTool, construída como prova de conceito de paradigma. Tal paradigma permite captura automática e transparente e acesso de comentários e anotações, enquanto um usuário assiste a um vídeo em um sistema computacional. A ferramenta permite, além da captura e do acesso às anotações, o compartilhamento das anotações e a comunicação através de um "bate-papo".

São apresentados no capítulo seguinte o modelo arquitetural CAPPA, que propõe o uso de informações de contexto de novas formas e colaboração no paradigma WaC. O protótipo correspondente a ferramenta CWaCTool é apresentado no Capítulo 6. 


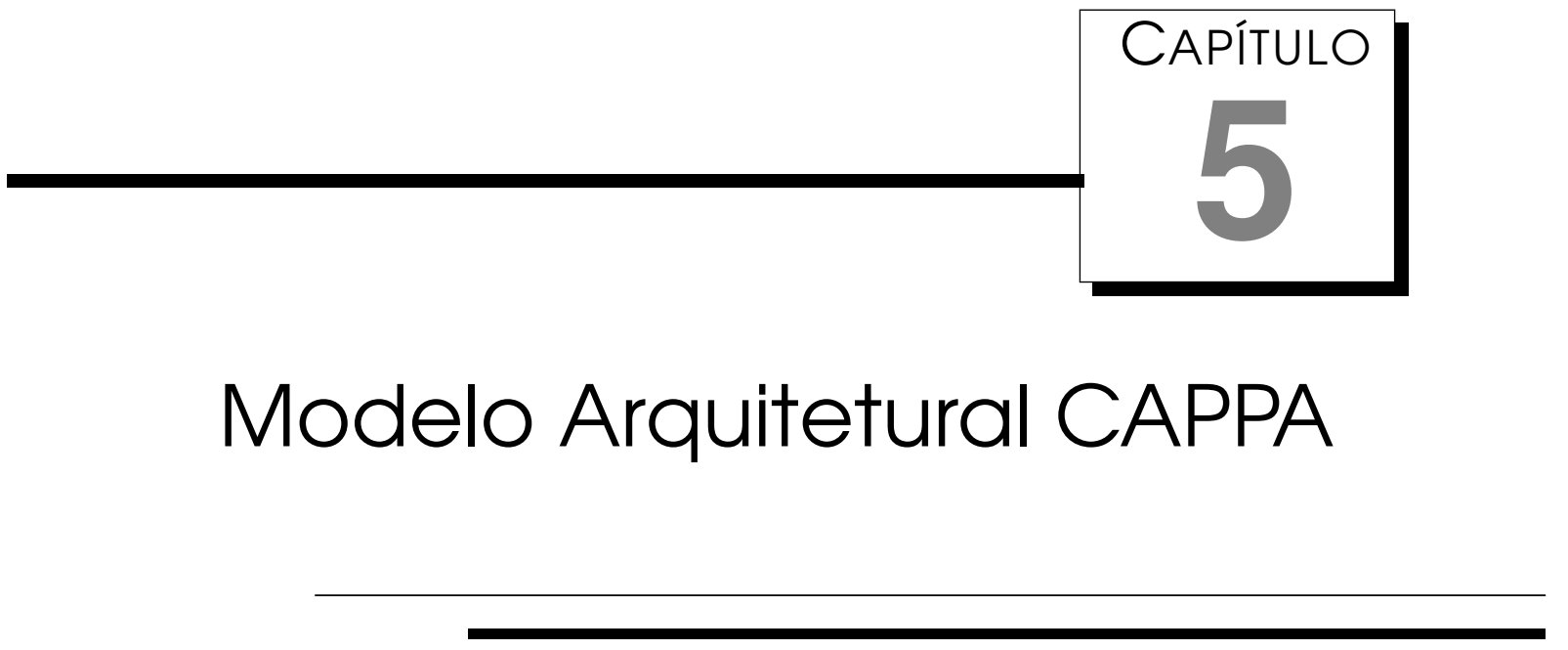

Estabelecido para prover de modo transparente a captura, o compartilhamento e o uso de informações de contexto em um sistema de anotações em vídeo, o modelo Context Aware Peer-to-Peer Architecture (CAPPA) faz uso de fontes de informações dos usuários e dos vídeos além de uma rede Peer-toPeer (P2P). O modelo CAPPA permite adicionar ciência de informações de contexto a aplicações de anotações em vídeo.

O propósito principal do modelo é o de prover ciência de informações de contexto ao paradigma WaC. Durante a pesquisa, três versões do modelo foram projetadas, e as principais contribuições de cada versão foram reutilizadas nas versão seguinte. A construção de três versões é parte do modo de construção utilizado, que envolve prototipação do modelo e avaliação dos protótipos que o validam.

Este capítulo apresenta a construção do modelo na Seção 5.1. Os requisitos para o modelo CAPPA são apresentados na Seção 5.2. A arquitetura resultante, com os diferentes elementos, é detalhada na Seção 5.3, que inclui uma discussão das versões intermediárias realizadas. A Seção 5.4 explora o uso das fontes de informação distintas do modelo, sendo detalhado na Seção 5.5 o formato XML definido para intercâmbio das informações de contexto e de anotações. O armazenamento das informações de contexto é detalhado na Seção 5.6, e o processamento das informações para recomendações é explorado no módulo de raciocínio do modelo, apresentado na Seção 5.7. O 
funcionamento da rede P2P no modelo é relatado na Seção 5.8. O capítulo inclui uma discussão final na Seção 5.9.

\section{1 Construção do Modelo CAPPA}

O modelo foi construído com auxílio de prototipação, avaliação, e refinamento do modelo. Foi possível utilizar os resultados das avaliações e pesquisas de outros conceitos e de trabalhos relacionados para evoluir o modelo.

A Figura 5.1 ilustra que o trabalho se iniciou com uma análise de conceitos fundamentais, trabalhos relacionados e do paradigma WaC (A). Com isso, foi obtido o modelo CAPPA (B), que foi evoluído com a pesquisa de novos trabalhos relacionados e com novos conceitos. A partir do primeiro modelo foi então construído o primeiro protótipo (C), que foi avaliado (D). Esse ciclo se repetiu $(B-C-D)$ até se obter o modelo CAPPA em sua versão atual (E).

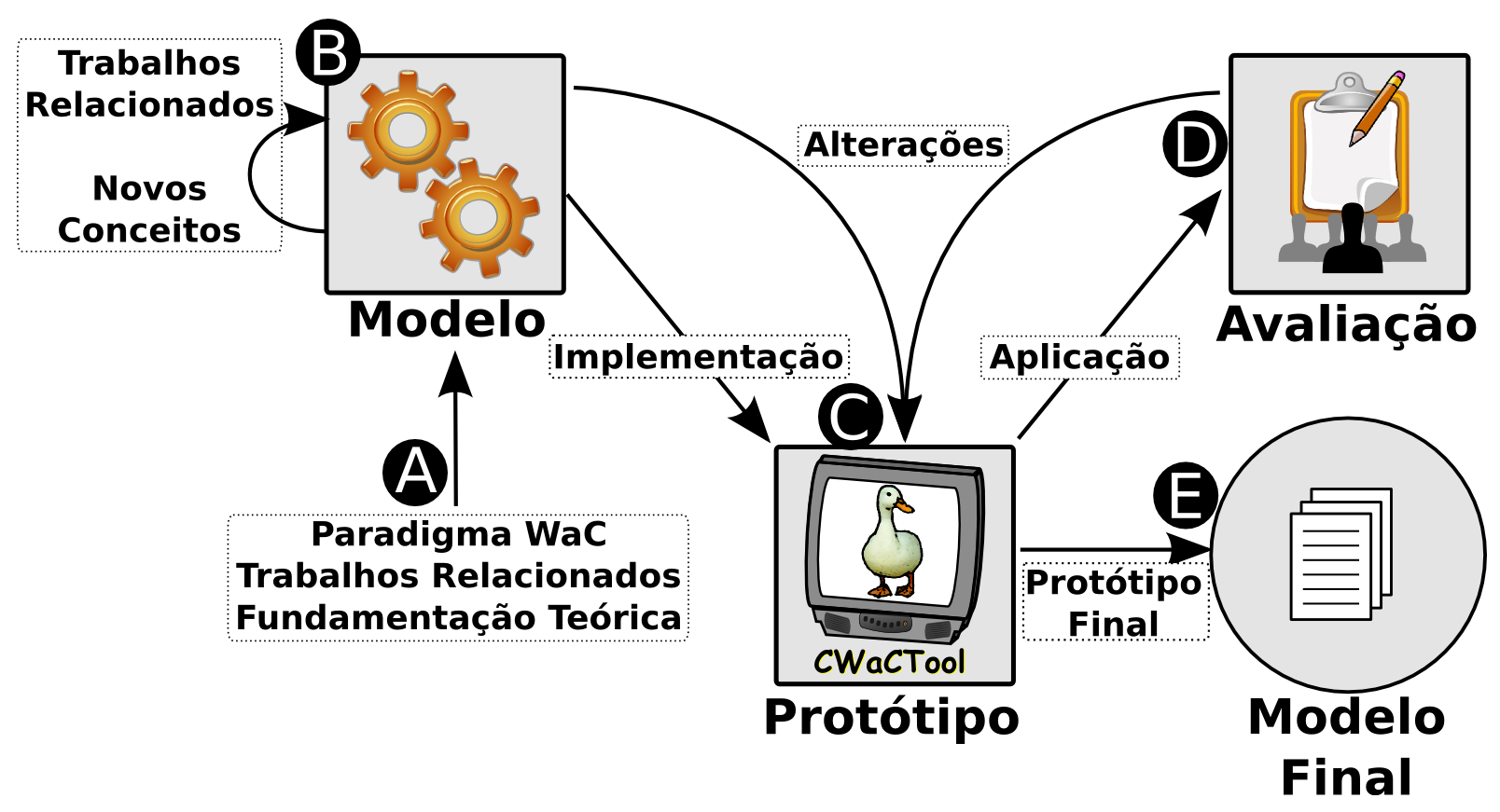

Figura 5.1: Construção em etapas do modelo.

O ciclo de desenvolvimento do modelo CAPPA consistiu em três etapas: (i) avaliação do modelo (Figura 5.1.D) com usuários ou especialistas, (ii) proposição de alterações no protótipo a partir das avaliações e, em paralelo às duas etapas anteriores, a (iii) evolução do modelo conforme novos trabalhos relacionados e conceitos para propor novas alterações. O término do ciclo (E) ocorreu quando o protótipo atinge um nível satisfatório, seja por resultados positivos nas avaliações ou por se atender ao objetivo primário do modelo, de prover ciência de informações de contexto ao paradigma WaC. O último modelo so- 
mado aos pontos explorados e avaliados no protótipo final definem então o modelo final.

Para se obter a formalização do modelo CAPPA foram necessárias três iterações do ciclo de desenvolvimento, que são detalhadas a seguir.

A primeira iteração, levando à primeira versão do modelo, considerou principalmente o conceito de Social TV e trabalhos relacionados para explorar no paradigma WaC a colaboração entre usuários. Apesar da já existente colaboração assíncrona de anotações na ferramenta WaCTool (Cattelan et al., 2008a), o novo conceito explorou colaboração síncrona, com o objetivo de se manter um canal de comunicação síncrono de dados além do já existente de bate-papo. Essas características do modelo foram incluídas no protótipo, que foi avaliado com usuários e especialistas em sistemas multimídia.

A segunda iteração passou a fazer uso de ontologias e modos alternativos para captura no cenário de TV digital. Com o estudo de outros modelos de ciência de informações de contexto, aplicações sensíveis ao contexto em TVDI e uso de redes $\mathrm{P} 2 \mathrm{P}$, a segunda versão do modelo já utilizava um modelo ontológico para as informações de contexto. As instâncias da ontologia geradas pelos usuários durante o uso em uma TV seriam idealmente compartilhadas em uma rede P2P, e tais instâncias seriam utilizadas diretamente para sugerir mudança de canal ou sugestões de auto-completar em anotações de texto.

A terceira iteração passou a a considerar o cenário de repositórios de vídeos na Web. Um dos motivos é o fato do protótipo não possuir ainda possibilidade de integração em tempo real com um middleware de TVDI. Outro motivo é a oportunidade de integração com portais de vídeos na Web. O modelo foi incrementado para não só capturar e armazenar em ontologias, mas também para processar as informações com regras de extração de conhecimento e mineração de dados. Outra nova característica foi a integração com redes sociais, que permite novas alternativas de informações de contexto do usuário e do vídeo ao qual o mesmo assiste e sobre o qual realiza anotações.

O modelo final, intitulado de modelo arquitetural CAPPA, é detalhado nas próximas seções. É importante ressaltar que, apesar de o foco do protótipo final (CWaCTool) ser de uso para vídeos na Web, o modelo ainda considera a possibilidade de uso em TVDI, e cada iteração desenvolveu basicamente um dos três módulos da arquitetura, apresentada na Seção 5.3. 


\subsection{Requisitos para o Modelo}

Para a construção do modelo de ciência de informações de contexto no paradigma $\mathrm{WaC}$, foi necessário ainda analisar o paradigma WaC original sob os seguintes aspectos:

- Ontologias: O estudo de como se pode aplicar ontologias no paradigma, em especial na ferramenta CWaCTool, a fim de tratar informações de contexto de modo a serem úteis a aplicações.

- Anotações em TV e outros dispositivos: As anotações realizadas em dispositivos que não com teclado e mouse são um ponto crucial do modelo. Ainda, um possível propósito do modelo é auxiliar na captura das informações, adaptando a aplicação às anotações que o usuário deseja realizar.

- Redes P2P: O uso de redes P2P influenciam em como as informações de contexto podem ser distribuídas, compartilhadas e obtidas. Por exemplo, é possivel extrair a localização aproximada de um usuário se um vizinho dele possuir as coordenadas Global Positioning System (GPS) e o sistema reconhecer de algum modo que o mesmo é vizinho fisicamente próximo.

- Formato de informações do usuário: É importante ter um formato padrão com as informações necessárias ao sistema. Dessa forma, no contexto de TVDI, é possível ainda que haja intercâmbio de informações de contexto com outras aplicações que não a CWaCTool.

- Social TV e Redes Sociais: É importante também analisar que, quando em um cenário de TVDI, pode haver mais de um usuário assistindo a um mesmo televisor, ou mais de um usuário comentando um vídeo em um mesmo dispositivo. Em um cenário Desktop, ou mesmo em TVDI, pode também haver a conexão com redes sociais na Internet, possibilitando outro meio de comunicação. Desse modo, a extração de informações de contexto é afetada, pois tratam-se de grupos de usuários, e não de indivíduos como em alguns outros modelos de informações de contexto.

- Colaboração: Devido ao fato de que grupos de usuários podem realizar comentários sobre um mesmo vídeo, o uso de colaboração nos comentários deve ser considerado na construção do modelo, já que o mesmo deve prever que as informações produzidas podem ser compartilhadas e construídas em conjunto. 


\subsection{Arquitetura do Modelo CAPPA}

O modelo CAPPA apresenta uma arquitetura de camadas baseada em três módulos principais: (i) módulo de Comunicação, (ii) módulo de Conhecimento e (iii) módulo de Raciocínio. Cada um dos módulos estabelece características do modelo e das interações existentes. A Figura 5.2 mostra os módulos e seus componentes.

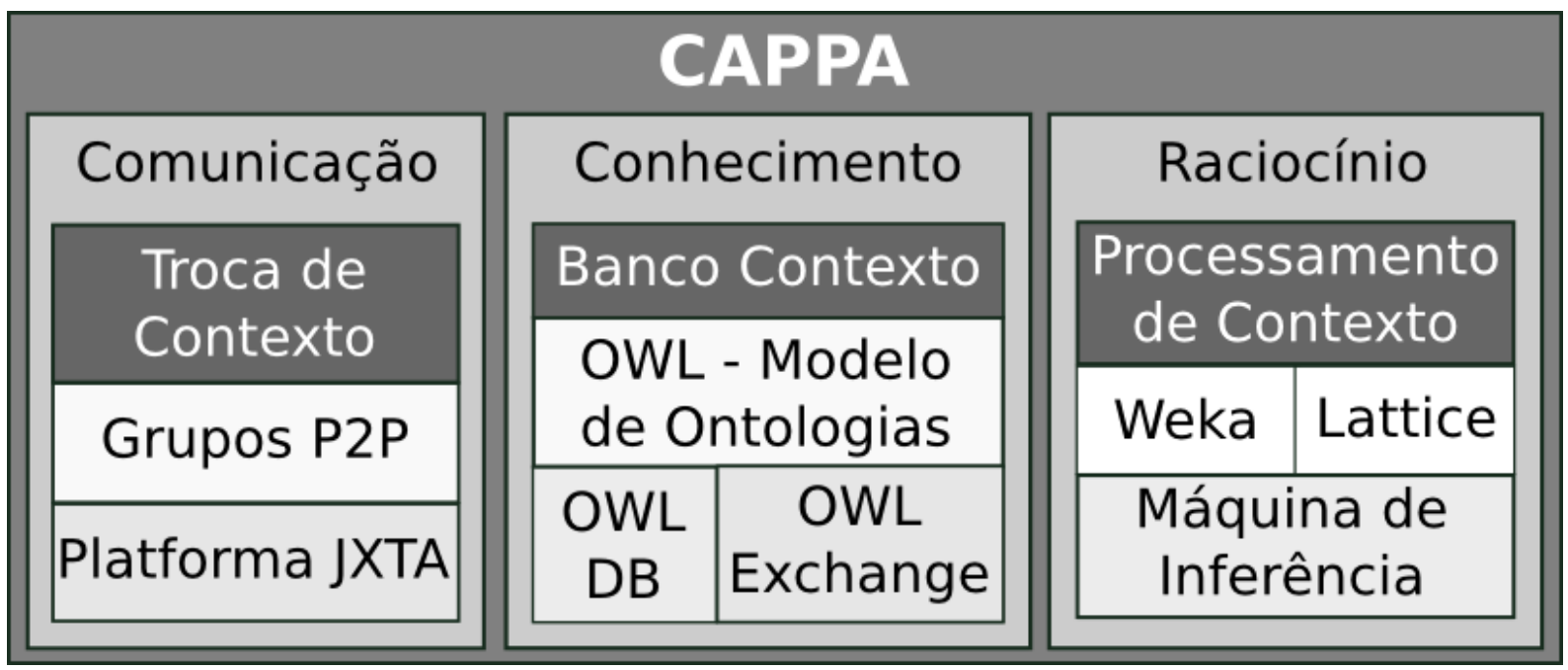

Figura 5.2: Arquitetura do modelo CAPPA.

O módulo de Comunicação é responsável pela troca de informações de contexto entre os usuários. A troca é realizada com uso de uma rede $\mathrm{P} 2 \mathrm{P}$, em que os usuários agrupam-se em Grupos P2P de acordo com interesses em comum, com o objetivo de compartilhar informações que possam ser relevantes aos usuários. Em termos de implementação do protótipo, os grupos são formados com uso da plataforma JXTA, uma tecnologia P2P que possibilita operações, tais como a formação de grupos e a criação de conexões entre os peers.

O módulo de Conhecimento é responsável pelo armazenamento das informações de contexto em Ontologias. As informações de contexto devem ser então armazenadas em instâncias de ontologias previamente estabelecidas, havendo a conversão com os principais objetivos de manter semântica nas informações e evitar redundância de dados capturados. O modelo CAPPA utiliza OWL, que define em XML as informações em forma de ontologias para serem armazenadas. Em termos de implementação, o módulo possui a base de dados local (OWL DB) e um componente para permitir a troca das informações de contexto pelo módulo de Comunicação, convertendo as informações em um formato XML diferenciado, que é detalhado na Seção 5.5. 
O módulo de Raciocínio é responsável pelo processamento de informações de contexto, para tomar alguma ação a partir dessas informações. Em termos de implementação, as informações de contexto, armazenadas em ontologias, são recuperadas e processadas pela ferramenta Weka (2010) ou convertidas em Lattices, o que permite realizar a inferência de alguma ação pela Máquina de Inferência. As ações são realizadas de acordo com um conjunto de regras previamente estabelecidas, e resultam em alguma adaptação ou decisão para o usuário do sistema.

A Figura 5.3 ilustra o fluxo de como os diferentes componentes da arquitetura processam as informações de contexto. Primeiramente ocorre a captura de uma informação (A), que pode ser de uma anotação do usuário ou alguma informação de contexto de uma rede social, por exemplo. A informação é registrada em XML e enviada para armazenamento na forma de ontologias (B), e para a uso dessas informações de contexto na rede P2P (C). Uma outra alternativa é o uso de concept lattices (D), que permitem a construção da ontologia de modo incremental, como explicado na Subseção ??. As informações para os concept lattices podem vir do usuário (A) ou da rede (C), e são sempre encaminhadas para a ontologia (B).

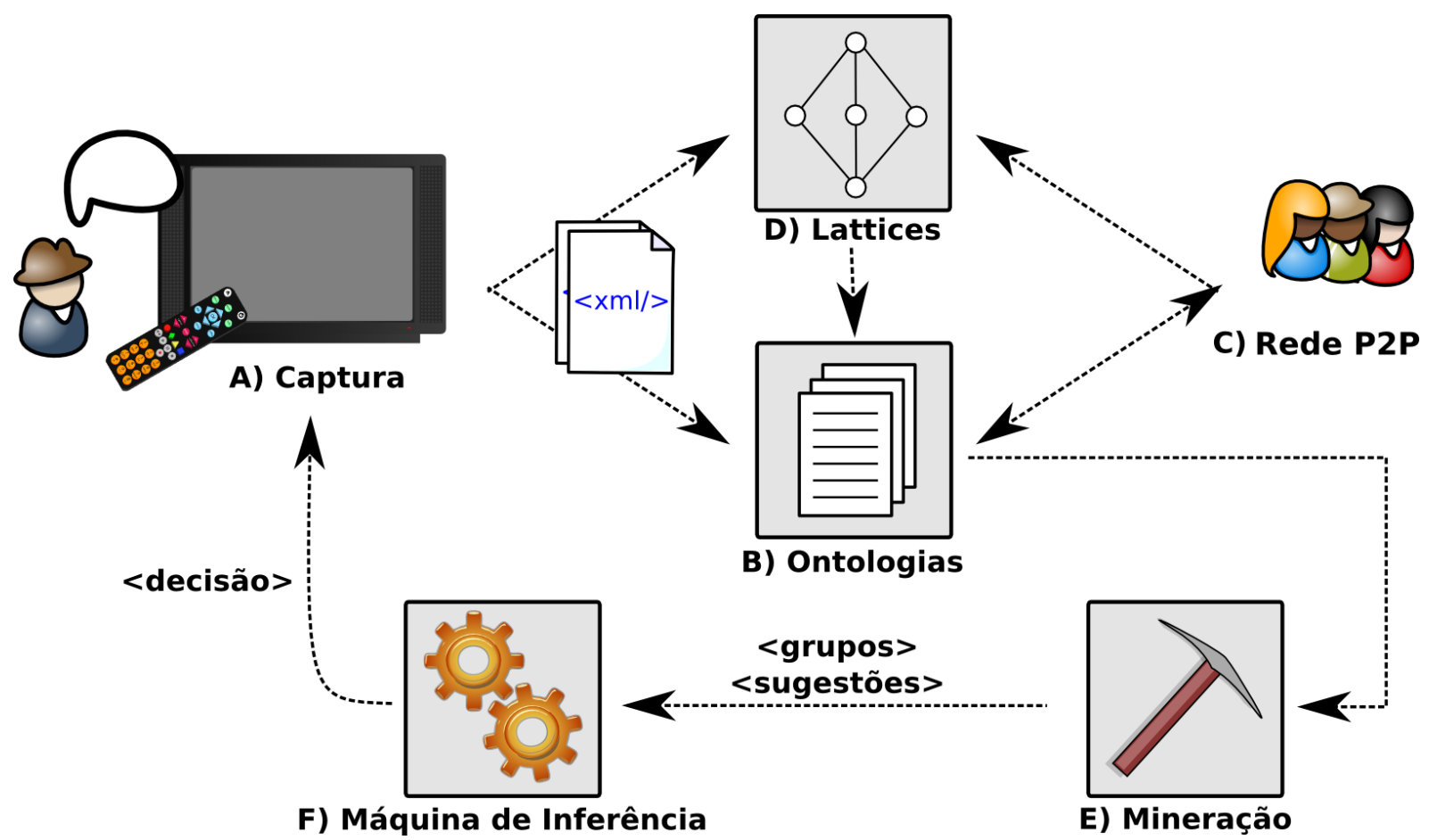

Figura 5.3: Fluxo de informações do modelo CAPPA.

A partir das ontologias, ocorre a mineração de informações (Figura 5.3.E) para então enviar à Máquina de Inferência sugestões de ações ou grupos que o usuário possa pertencer. A máquina $(\mathrm{F})$ toma uma decisão que influencia diretamente o usuário (A), encerrando o ciclo da obtenção da informação de 
contexto ao processamento da mesma. A seguir serão detalhados os diferentes componentes presentes na arquitetura.

\subsection{Fontes de Informações e Dados}

O modelo CAPPA representa a informação capturada dos usuários e dos vídeos em ontologias ou em um formato de documento XML para intercâmbio. O formato XML faz-se necessário para permitir que dispositivos dotados de menor poder de processamento possam integrar a arquitetura, uma vez que muitos dispositivos móveis não têm capacidade ou tecnologia para processar ontologias. O formato também possibilita a troca de informações na rede P2P, permitindo que as informações sejam utilizadas em outras arquiteturas e modelos.

\begin{tabular}{|c|c|c|}
\hline Fonte & Modo de Acesso & Descrição \\
\hline $\begin{array}{l}\text { Redes Soci- } \\
\text { ais }\end{array}$ & $\begin{array}{l}\text { APls das redes, ID } \\
\text { do usuário }\end{array}$ & $\begin{array}{l}\text { Com o uso de um login ou código do usuário for- } \\
\text { necido pelo mesmo, são extraídas informações do } \\
\text { perfil do usuário em redes sociais, além de listas de } \\
\text { amigos em comum, formando grupos por interesses } \\
\text { do usuário ou pelos próprios amigos. }\end{array}$ \\
\hline $\begin{array}{l}\text { Sistemas de } \\
\text { vídeo }\end{array}$ & $\begin{array}{l}\text { APls de websites } \\
\text { e de dispositivos } \\
\text { de vídeo }\end{array}$ & $\begin{array}{l}\text { A partir do vídeo que o usuário está assistindo, bus- } \\
\text { car informações sobre o conteúdo em websites da } \\
\text { Internet e mesmo de informações presentes no dis- } \\
\text { positivo do usuário, como preferências pessoais em } \\
\text { um sistema operacional ou em um set-top-box. }\end{array}$ \\
\hline Redes P2P & Plataforma JXTA & $\begin{array}{l}\text { As informações de contexto dos usuários são com- } \\
\text { partilhadas com os outros dos mesmos grupos, per- } \\
\text { mitindo que anotações, informações extraídas de } \\
\text { redes sociais e de vídeos de outros usuários possam } \\
\text { também integrar a base de dados do usuário. }\end{array}$ \\
\hline $\begin{array}{l}\text { Anotações } \\
\text { no vídeo }\end{array}$ & $\begin{array}{l}\text { tinta eletrônica, } \\
\text { texto }\end{array}$ & $\begin{array}{l}\text { Analisar as anotações realizadas em um determi- } \\
\text { nado vídeo para extrair informações como cores } \\
\text { de tinta mais usadas ou palavras em um trecho do } \\
\text { vídeo, ou algum outro padrão que o usuário utilize } \\
\text { com maior frequência para sugerir esse mesmo pa- } \\
\text { drão de anotação. }\end{array}$ \\
\hline $\begin{array}{l}\text { Operações } \\
\text { da interface }\end{array}$ & $\begin{array}{l}\text { Controle remoto, } \\
\text { dispositivos que } \\
\text { operem vídeo }\end{array}$ & $\begin{array}{l}\text { Capturar as ações do usuário que não apenas as } \\
\text { anotações, como mudança de canal em uma TVDI } \\
\text { ou de um vídeo na Web, alteração do volume em } \\
\text { um trecho, dentre outras. Essas ações podem levar } \\
\text { a decisões para adaptar o modo de anotação ou } \\
\text { mesmo sugerir mudança de canal para usuários de } \\
\text { um mesmo perfil. }\end{array}$ \\
\hline
\end{tabular}

Tabela 5.1: Diferentes fontes de informações para o modelo CAPPA.

A Tabela 5.1 apresenta a descrição e modo de acesso das principais fontes de informação utilizadas no modelo CAPPA. Apesar de serem cinco fontes, algumas são diretamente dependentes de outras, como as Redes P2P são dependentes das outras quatro apresentadas. 
O modelo não determina quais informações de cada fonte devem ser extraídas, apenas quais são as fontes e como deve ser realizada a extração. A captura das informações é de responsabilidade da aplicação, a qual deve considerar a relevância dos tipos de informações obtidas das fontes.

\subsection{Informações sobre o Usuário}

Para o intercâmbio de informações entre dispositivos de captura, set-top boxes de TVDI e computadores em geral, adotou-se um modelo próprio de documento. O formato representa usuários de computadores e telespectadores, com o uso de informações de contexto e das interações realizadas.

O modelo é descrito em um documento XML e tem por objetivo ser um formato intermediário processável por dispositivos de captura e por sistemas presentes no próprio dispositivo ou remotos. O uso de XML para representação de informações de contexto em vídeo é reportado por diversos autores, como Goularte et al. (2006).

Os elementos principais do documento modelam os cinco aspectos de Abowd e Mynatt (2000) para informações de contexto:

- Quem (who): Representado pelo elemento user, possui informações referentes ao usuário, como nome, idade, sexo, preferências pessoais dentre outras.

- Quando (when): A data é armazenada quando uma interação é realizada, com seu início no atributo start, e quando termina, atributo end, ambos presentes no elemento interaction

- Onde (where): Local onde a captura está sendo realizada, como cidade, país, coordenadas geográficas se possivel, no elemento location.

- Como (how): Como a captura foi feita, contendo informações de características de hardware e demais dispositivos utilizados para interação, elemento device.

- O que (what): Representado pelos elementos interaction e media, que registram qual a interação realizada e qual a mídia em questão.

A utilização de um formato que não represente uma ontologia é uma escolha de projeto, que considerou o cenário em que o dispositivo de captura pode não ter processamento computacional suficiente para processar ontologias. 
O documento possui cinco elementos que estão sempre presentes na raiz do XML. Os elementos podem aparecer em qualquer ordem e em qualquer quantidade, com exceção do elemento interaction que deve aparecer depois da ocorrência de pelo menos um de cada dos outros quatro tipos de elementos, pois estes são citados pelo interaction. Com isso, é possivel que a aplicação permaneça enviando os elementos do documento em modo síncrono, sem ainda finalizar o documento e permitindo processamento por Simple API for $X M L(\mathrm{SAX})^{1}$.

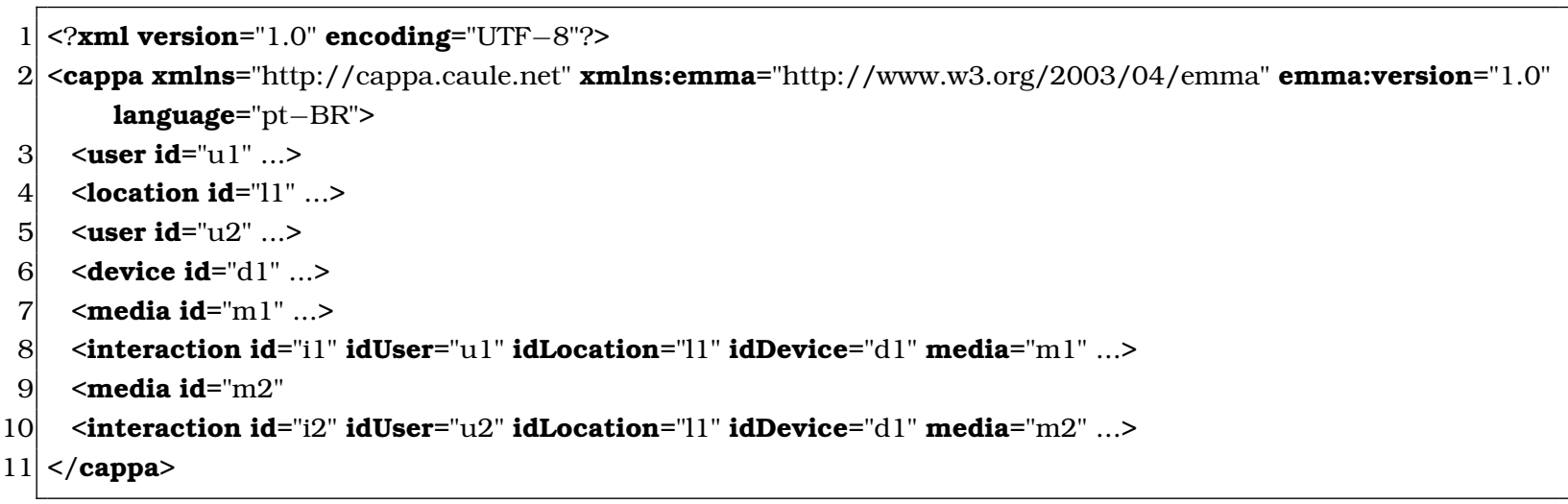

Quadro 5.1: Formato XML com os elementos principais da raiz do documento.

O Quadro 5.1 ilustra, de modo resumido, um documento típico. Cada um dos elementos deve sempre possuir um $i d$ único, que pode ser de qualquer formato (no exemplo está sendo utilizada uma letra inicial em relação a qual tipo de elemento pertence o ID e um número).

A possibilidade de vários elementos de um mesmo tipo permite, por exemplo, registrar um mesmo usuário utilizando diferentes dispositivos em um mesmo vídeo, um mesmo dispositivo em diferentes vídeos, assistir e anotar em um mesmo vídeo em diferentes localizações (no caso de dispositivos móveis por exemplo), ou de vários usuários colaborarem em um mesmo vídeo para realizarem anotações. A seguir cada uma desses cinco elementos serão detalhados.

\subsubsection{Elemento user}

Os elementos aninhados no elemento user contêm informações sobre o usuário. Como muitas das informações desse elemento só podem ser obtidas explicitamente, isso é, perguntando ao usuário, todas as propriedades e elementos internos são opcionais, com exceção do atributo $i d$.

\footnotetext{
$1<$ user id="u1" age="31" genre="male">

2 <name $>$ Claudio Silva $</$ name $>$
}

\footnotetext{
${ }^{1}$ O processamento por SAX possibilita que os elementos XML sejam processados a medida que são lidos. Maiores informações em http://www. saxproject. org, Acesso 20 Mai 2010.
} 


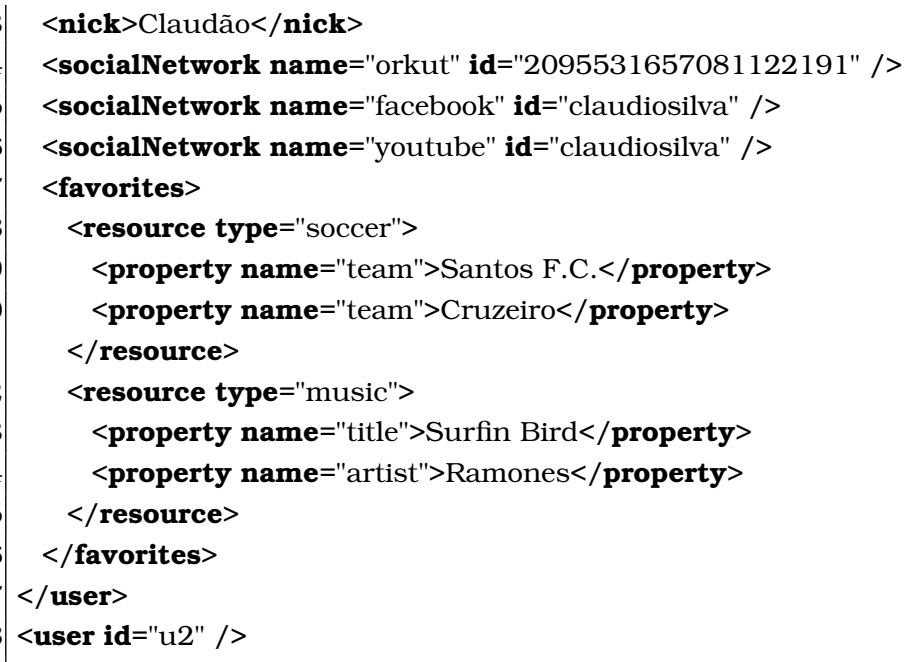

Guadro 5.2: Estrutura de dois elementos user, sendo o primeiro mais detalhado.

No Quadro 5.2, existem dois usuários: o primeiro nas linhas 1 a 17 e o segundo na linha 18. O primeiro usuário, que possui todos os elementos e atributos possíveis do elemento user, contém o nome no elemento name e um apelido no elemento nick, nas linhas 2 e 3 respectivamente, além das informações adicionais possíveis. O segundo usuário possui apenas o atributo $i d$, podendo ser o caso de um usuário visitante em colaboração com o primeiro usuário, por exemplo.

As linhas de 4 a 6 do Guadro 5.2 apresentam informações sobre as redes sociais do usuário. Com a identificação do usuário e o nome da rede uma aplicação, que trabalhe com esse formato XML, pode extrair as informações desejadas diretamente da rede social na Web.

As linhas 7 a 16 apresentam o elemento opcional favorites, que representa as preferências pessoais do usuário, ou seja, o que o mesmo considera como favorito. O elemento pode conter os elementos resource com informações sobre qualquer assunto, registradas em elementos aninhados (property) com seus atributos e valores. No exemplo do Guadro 5.2, as linhas 8 a 10 registram preferências em relação a futebol, no caso dois times favoritos do usuário. Já as linhas 12 a 14 registram a preferência musical do usuário (música e artista). O objetivo do elemento favorites é repassar informações do usuário, quando possivel, sobre o que o mesmo prefere, sendo que algumas dessas informações podem ter sido inferidas conforme o tipo de conteúdo ao qual o usuário assiste (por ex. se assiste a jogos de futebol dos times informados). 


\subsubsection{Elemento location}

Outro elemento de informações de contexto do usuário que só requer o atributo $i d$ é o location, e tem por objetivo armazenar informações de localização geográfica do usuário no instante que realizou uma determinada sessão WaC. As informações de localização podem ter utilidade para identificar não só preferências do usuário, mas também questões como fuso-horário, perfil de pessoas em uma mesma cidade ou região. O local pode ser integrado com outras informações do mesmo usuário, por exemplo consultar as condições climáticas no instante que um usuário está assistindo a um determinado programa.

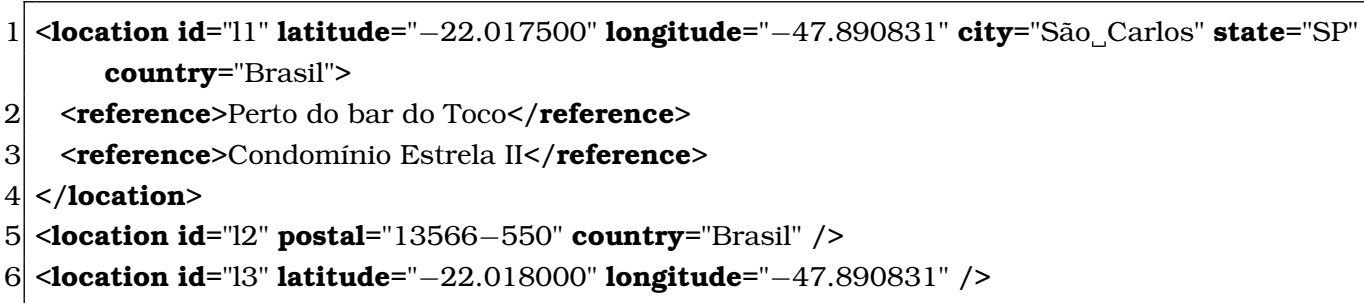

Quadro 5.3: Estrutura de três elementos location, exibindo diferentes configurações.

O Quadro 5.3 apresenta três elementos location, com diferentes niveis de detalhes. O primeiro, linhas 1 a 4 , informa um local com vários dos atributos possiveis (foram omitidos os atributos postal para código postal e region para região ou província). Nesse local, são informadas a latitude e longitude obtidas por um dispositivo com suporte a GPS, por exemplo. Outra informação presente é a cidade (city), estado (state) e o país (country). O primeiro local também contém informações de referências, que podem ser obtidas tanto explicitamente informadas pelo próprio usuário, como implicitamente, por vizinhos fisicamente próximos do mesmo, ou ainda consultando informações na Web a partir das coordenadas geográficas.

Os outros dois locais descritos no Quadro 5.3, nas linhas 5 e 6, registram um número menor de informações. O segundo local (l2), na linha 5, apresenta apenas as informações do código postal (CEP, no caso do Brasil) e do país. Com essa informação, é possível se obter a localização aproximada do usuário, como cidade, estado e em alguns casos o logradouro em que ocorreu a interação. O terceiro local, na linha 6, apresenta apenas informações obtidas a partir de um GPS.

Outro possível cenário seria um elemento location contendo apenas com o atributo $i d$, que representa uma localização totalmente desconhecida. Isso pode ocorrer quando o dispositivo gerador do documento XML não possuir informações de localização. 


\subsubsection{Elemento media}

Com o objetivo de permitir que o formato seja aplicável a qualquer fonte de vídeo, o elemento media possibilita que as anotações sejam realizadas em vídeos presentes na Internet, em dispositivo local ou em programas da TVDI. Esse elemento tem por objetivo descrever informações sobre a mídia, possibilitando que o sistema que realiza a leitura do documento XML recupere a mídia original ou outra semelhante. O elemento media possui o atributo source e é obrigatório.

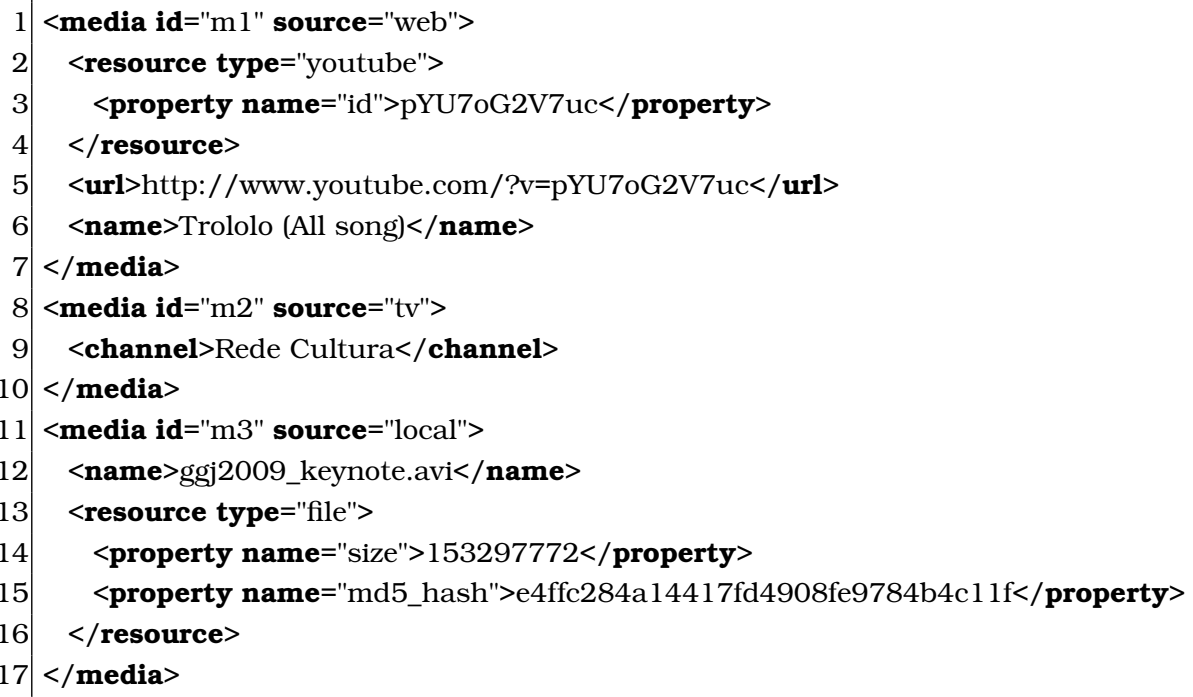

Quadro 5.4: Documento com três elementos media, de três diferentes fontes.

O Quadro 5.4 apresenta três elementos media, de três fontes de vídeos. A primeira, nas linhas 1 a 7 , descreve um vídeo disponibilizado em um repositório na Internet, cujo atributo source é de valor web. Cada elemento media pode conter zero ou mais elementos resource, que descrevem quaisquer outras informações sobre a mídia, como é o caso nas linhas 2 a 4 que descrevem o $i d$ segundo o sistema Youtube. O tipo do recurso também identifica que a mídia está presente no sistema Youtube, mas poderia haver outros recursos referentes a outros sistemas de vídeo na Web com o mesmo vídeo. A linha 5 contém a URL do vídeo e o nome do vídeo é apresentado na linha 6.

O segundo vídeo ( $m 2$ ) do Quadro 5.4 é especificado nas linhas de 8 a 10 , e descreve um programa na TVDI. Possui internamente o elemento channel, com o nome do canal, mas poderia também conter elementos como o name com o nome do programa e algum elemento de recurso (resource) contendo, por exemplo, qual câmera foi utilizada (no caso de várias câmeras simultâneas no programa), qual o número do canal e até o uso do vídeo em algum repositório Web. 
O terceiro vídeo $(\mathrm{m} 3)$, nas linhas 11 a 17 , descreve um vídeo presente no dispositivo local do usuário (fonte é determinada como local) e contém o nome do vídeo, na linha 12, e informações sobre o arquivo de vídeo, nas linhas 14 e 15, (no caso o tamanho em bytes do vídeo) e um hash ${ }^{2}$, respectivamente. $\mathrm{O}$ nome do vídeo coincide com o nome do arquivo, considerando que o arquivo em questão não fornece um título como informação de contexto.

Dado que para alguns vídeos os direitos autorais podem restringir que o vídeo seja compartilhado junto com as anotações, a não acoplação do vídeo às anotações permite não infringir esses direitos autorais. Outro propósito é permitir associação das anotações a quaisquer cópias do mesmo vídeo.

\subsubsection{Elemento device}

O quarto elemento necessário para representar cada interação é o de informações do dispositivo (device), no qual são processadas e capturadas as anotações. O elemento tem como atributos obrigatórios, além do $i d$, os elementos que identificam quais são as capacidades de interação do mesmo - ink, voice, text, se o dispositivo é do tipo móvel (mobile) e qual o tipo do dispositivo. Com as informações do dispositivo é possivel, por exemplo, adaptar a interface de captura para o que o dispositivo oferece ou para o que é capaz de processar.

Os atributos de capacidades de interação informam se o dispositivo permite que o usuário realize cada um dos tipos de interação: ink para anotações com tinta (possuindo um apontador ou tela sensivel ao toque, por exemplo), voice para captura da voz do usuário e text para entrada de texto (podendo ser um teclado físico ou virtual). O atributo type descreve o tipo de dispositivo, como por exemplo set-top-box, smartphone, notebook, pc, dentre outros.

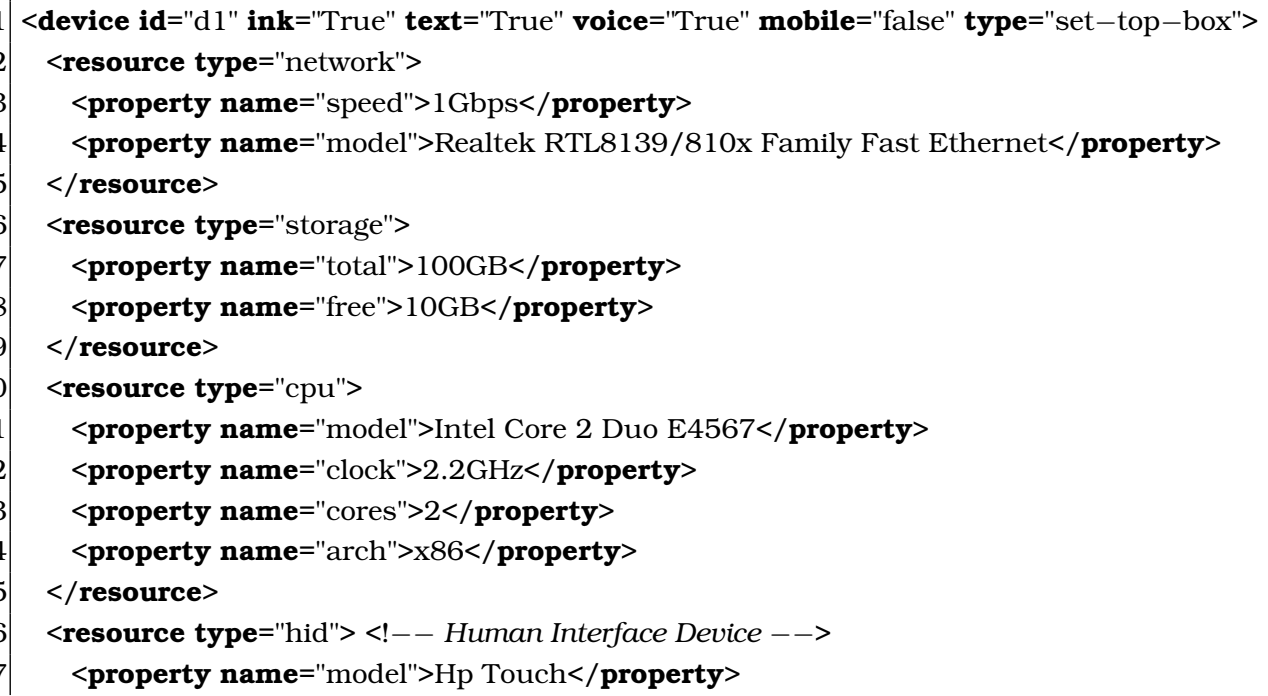

${ }^{2}$ no caso de vídeos, hash pode ser o valor de uma função para identificação do vídeo a partir de seu conteúdo binário. 
18 <property name="type">tablet</property >

$19</$ resource $>$

$20</$ device $>$

21 <device id="d2" ink="False" text="True" voice="True" mobile="True" type="smartphone" />

Guadro 5.5: Documento com dois elementos device.

O Guadro 5.5 ilustra a descrição de dois dispositivos. O primeiro, nas linhas 1 a 20, corresponde a um set-top-box. Na primeira linha, é possível observar que o dispositivo permite os três modos de interações, podendo então possuir um dispositivo sensivel ao toque com teclado virtual e microfone, por exemplo.

O elemento device possui zero ou mais elementos resource, que descrevem diversos recursos presentes no dispositivo. Cada resource possui um ou mais propriedades, sendo que cada uma possui o nome da propriedade (atributo name) e o valor. O dispositivo $d 1$ do Quadro 5.5 descreve na linha 2 as propriedades de conexão de rede do set-top-box, na linha 6 as de armazenamento, na linha 10 as de processador, e na linha 16 as de dispositivo de interface (Human Interface Device).

O segundo dispositivo do Quadro 5.5, na linha 21, corresponde a um smartphone. No caso, não foi possível para a aplicação geradora do XML descrever os recursos do dispositivo, por isso nenhum elemento resource está presente. O dispositivo $d 2$ não tem suporte a anotações de tinta, mas tem de texto e voz, no exemplo do quadro.

\subsubsection{Elemento interaction}

O elemento interaction pode ser considerado o principal elemento do documento, e é também o mais complexo por ser responsável de registrar a descrição de todas as interações do usuário com o vídeo. Internamente a esse elemento, é permitido a inserção de elementos Extensible MultiModal Annotation markup language (EMMA) ${ }^{3}$, como se cada elemento interaction fosse um elemento raiz emma : emma.

O formato EMMA define como são descritas as interações multimodais realizadas e o modo de interação (se por voz, por tinta, por teclas, etc). No entanto, o formato permite a definição própria de como os dados das interações devem ser representados, por exemplo como deve ser representado o conteúdo de uma anotação de áudio, ou os pontos e cores em uma anotação por tinta.

\footnotetext{
${ }^{3}$ http://www.w3.org/TR/emma/, Acesso 20 Mai 2010
} 
O elemento interaction possui seis atributos obrigatórios: $i d$, com a identificação única, userId com identificação de um usuário (user), deviceId com a identificação do dispositivo (device), locationId com a identificação do local (location), mediaId com a identificação da mídia (media) e start com o valor do início da interação no mesmo padrão de tempo do EMMA. As identificações dos outros elementos associam unicamente cada um dos outros elementos à interação. As marcações de tempo do EMMA são em milissegundos a partir de 01/01/1970, padrão esse utilizado por alguns sistemas operacionais.

Como atributos opcionais, o interaction pode apresentar o final da interação (end), também em milissegundos, e a posição na mídia, em nanossegundos. A posição acaba sendo mais precisa para delimitar o quadro exato em que se inicia a interação, possibilitando resgatar as interações em anotações.

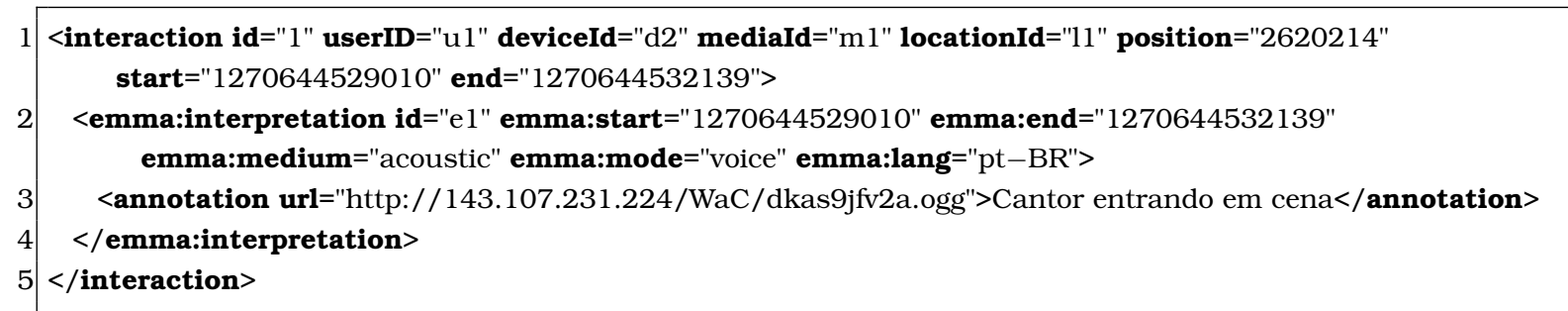

Quadro 5.6: Exemplo de uma captura por voz de interaction.

O Quadro 5.6 descreve um exemplo de interação realizada por voz. Na linha 1, é possivel notar que o interaction possui todos os atributos disponiveis para uma interação, com posição, início e fim da interação. A linha 2 descreve um elemento emma : interpretation, como referência do padrão para uma interação capturada, contendo o início e fim dessa interação, os atributos de meio da interação (acoustic) e o modo como foi capturada (emma: mode), além do idioma (emma : lang). O elemento da linha 2 especifica os mesmos início e fim da interação que os descritos na linha 1, desnecessariamente. Entretanto, isso acontece pois é possível existir mais do que um elemento emma : interpretation, pois pode ocorrer o uso de mais que um modo de captura simultaneamente, por exemplo.

A linha 3 do Quadro 5.6 descreve uma anotação (annotation) em áudio, resultado da captura da voz. O valor do elemento annotation é resultante da interpretação, sendo que o formato EMMA permite outros modos de se representar a interpretação de uma fala. O elemento annotation possui um atributo opcional, o url, que pode conter uma Uniform Resource Locator (URL) ${ }^{4}$ da gravação acessível pela Internet, ou de alguma mídia que o represente (como uma imagem em bitmap ou um vídeo do usuário comentando).

\footnotetext{
${ }^{4}$ URLs são cadeias de caracteres que permitem a localização de recursos na Web. Maiores informações em http://www.w3.org/Addressing/, Acesso em 20 Mai 2010.
} 


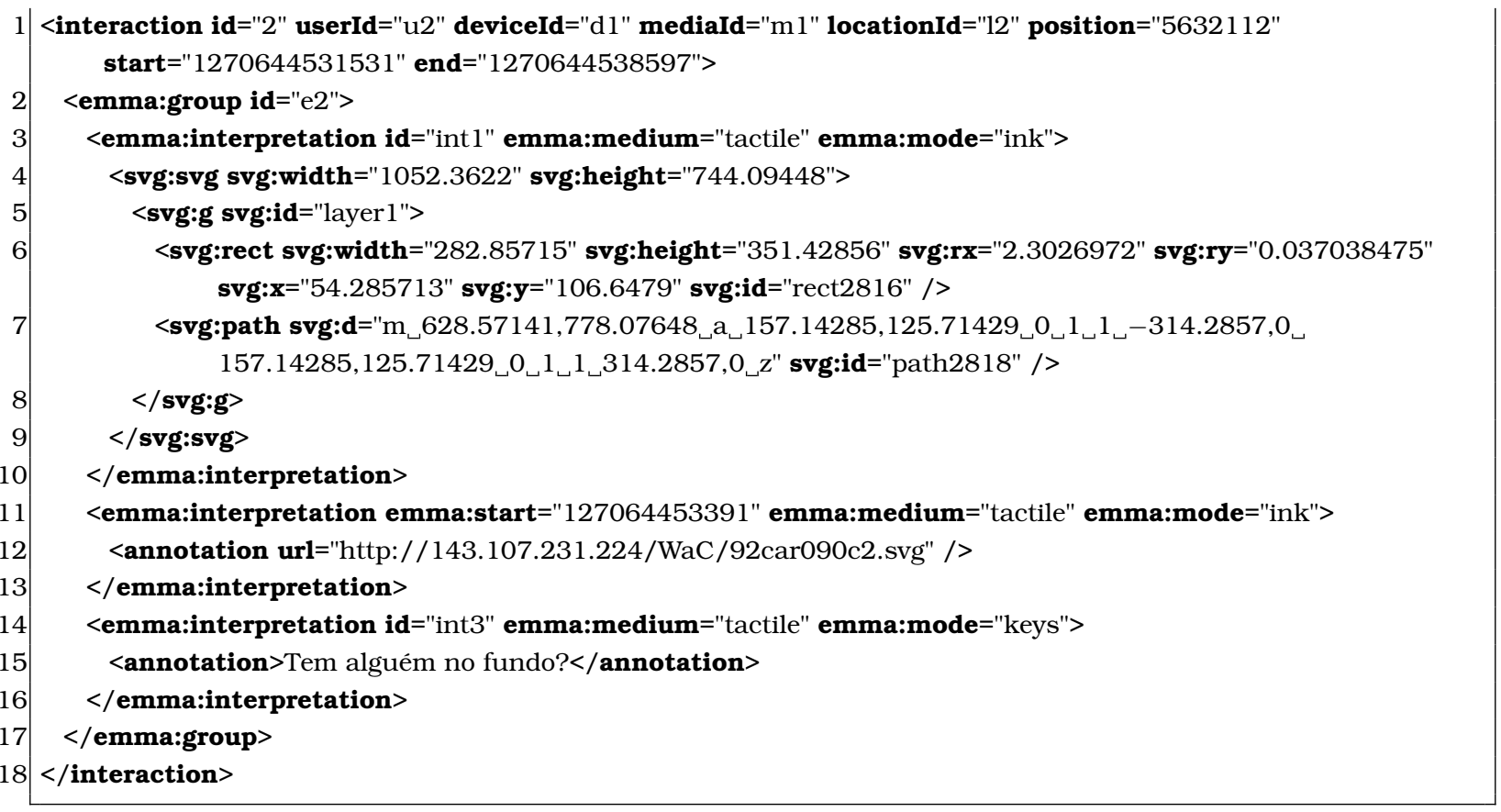

Quadro 5.7: Exemplo de uma captura por tinta e teclas de interaction.

Exemplificando um uso simultâneo de interação com tinta eletrônica e teclas, o Quadro 5.7 apresenta as duas interações aninhadas em um grupo de elementos EMMA, o emma : group, na linha 2. A linha 3 apresenta uma interpretação (emma : interpretation) que usa como meio o tato (tactile), em modo ink, de tinta eletrônica. Internamente a uma interpretação de tinta, nas linhas 3 a 10, o formato XML do modelo CAPPA requer a apresentação de um documento Scalable Vector Graphics (SVG), padrão da W3C para gráficos vetoriais.

O padrão SVG especifica diversos elementos que podem representar traços vetorialmente, como é o caso da linha 6 do Quadro 5.7, que apresenta um retângulo. A linha 6 apresenta um path, um conjunto de pontos que, no caso, trata-se de uma elipse. A escolha pela inclusão de um documento SVG internamente ao emma : interpretation para representação de tinta deu-se pela padronização do formato SVG em cenários de desenhos vetoriais e pela grande quantidade de ferramentas e Application Programming Interfaces (APIs) especializadas em SVG. É possível também a inclusão apenas de uma URL para um arquivo SVG (atributo url) em um elemento de anotação, como descrito na linha 12.

A linha 14 do Quadro 5.7 registra uma interpretação de uso de teclas, que pode ser em um controle remoto, em um teclado físico ou mesmo virtual. $\mathrm{O}$ conteúdo apresentado na linha 15, é o de uma anotação textual criada pelo usuário. Ainda no exemplo do Quadro 5.7, é possível notar que nem todos os elementos de interpretação possuem valores de início (emma: start) e fim (emma : end), o que pode indicar que ocorreram do início ao fim da interaction, ou que simplesmente não foi possivel registrar tais instantes. 


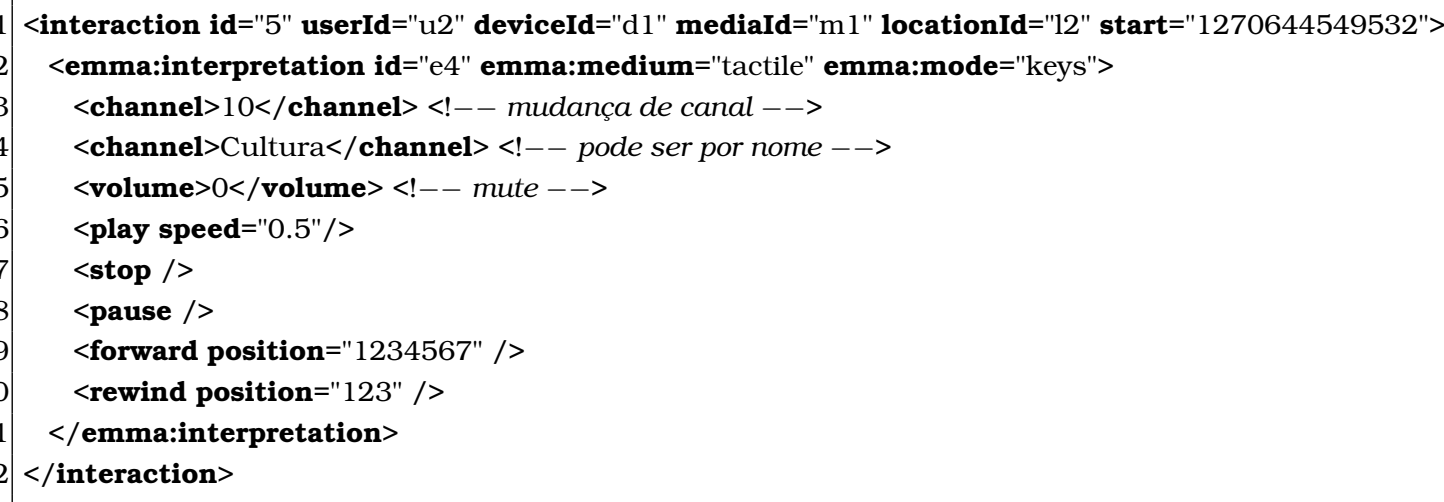

Quadro 5.8: Exemplo de ações possíveis do usuário em interaction.

O Guadro 5.8 apresenta elementos disponiveis para o registro de ações que o usuário pode realizar e que não estão relacionadas diretamente com o ato de anotar um vídeo. O exemplo do quadro, apesar de válido, é confuso por conter todos os elementos disponíveis para ações no interpretation, sendo o ideal que cada elemento seja representado por um único elemento de interpretação (emma: interpretation). As linhas 3 e 4 descrevem uma mudança de canal do usuário, descrevendo o número do canal e o nome, respectivamente. No caso, mudança de canal é mais comum para uso em TVDI. A linha 5 apresenta alteração no nível de volume sonoro, que no caso o usuário optou por deixar mudo (valor zero).

As linhas 6 a 10 representam ações do usuário na mídia, que no caso são para tocar ( play, com atributo de velocidade em que "0.5" representa câmera lenta de 50\% da velocidade normal), parar (stop), adiantar ( forward $>$ ) e voltar (rewind). No caso de adiantar e voltar, o parâmetro marca em nanossegundos a posição destino da mídia.

Com os elementos de interação apresentados, é interessante ressaltar ainda que há a possibilidade não só de se compartilhar as anotações do usuário, como também de inferir informações de preferências e criar um vídeo interativo com a sequência do que foi realizado.

\subsection{Ontologias}

Ontologias podem ser usadas como uma ferramenta apropriada para reduzir o intervalo semântico entre dados e a interpretação desses dados. Desse modo, o modelo CAPPA utiliza um modelo ontológico para representar dados capturados, permitindo a identificação de novas informações por meio de inferências. O modelo ontológico descreve as informações de contexto em uma 
atividade de assistir a um vídeo e comentá-lo, como proposto no paradigma WaC.

Para construir o modelo ontológico, foram reutilizadas ontologias de informação de contexto do modelo SeCoM (Bulcão Neto, 2006), com uma extensão e adaptação para o domínio de anotação de vídeo e da ontologia Programmes da BBC (Raimond et al., 2008). A ontologia Programmes descreve um vocabulário para a descrição de programas de TV enquanto que o modelo SeCoM é independente de domínio e composto por um conjunto modular de ontologias que descrevem informações de contexto.

O modelo SeCoM explora cinco dimensões: as ontologias Spatial, Time, Activity, Actor e Device, que modelam respectivamente informações de contexto de espaço (onde), tempo (quando), atividade (o que), usuário (quem) e dispositivo (como) (Abowd; Mynatt, 2000).

O modelo da ontologia de Furtado (2010) e de Maximino (2009) foi integrado ao modelo CAPPA com duas adaptações: o elemento principal, Wat$c h T V$, transformou-se no Wac, e o elemento de canal Channel transformou-se em Source, pois pode se tratar tanto de um canal de TV como de vídeos locais ou em repositórios Web. Foram removidas também as distinções de interações implícitas e explícitas, além do registro de controle remoto por não ser o único dispositivo que registra ações no modelo CAPPA.

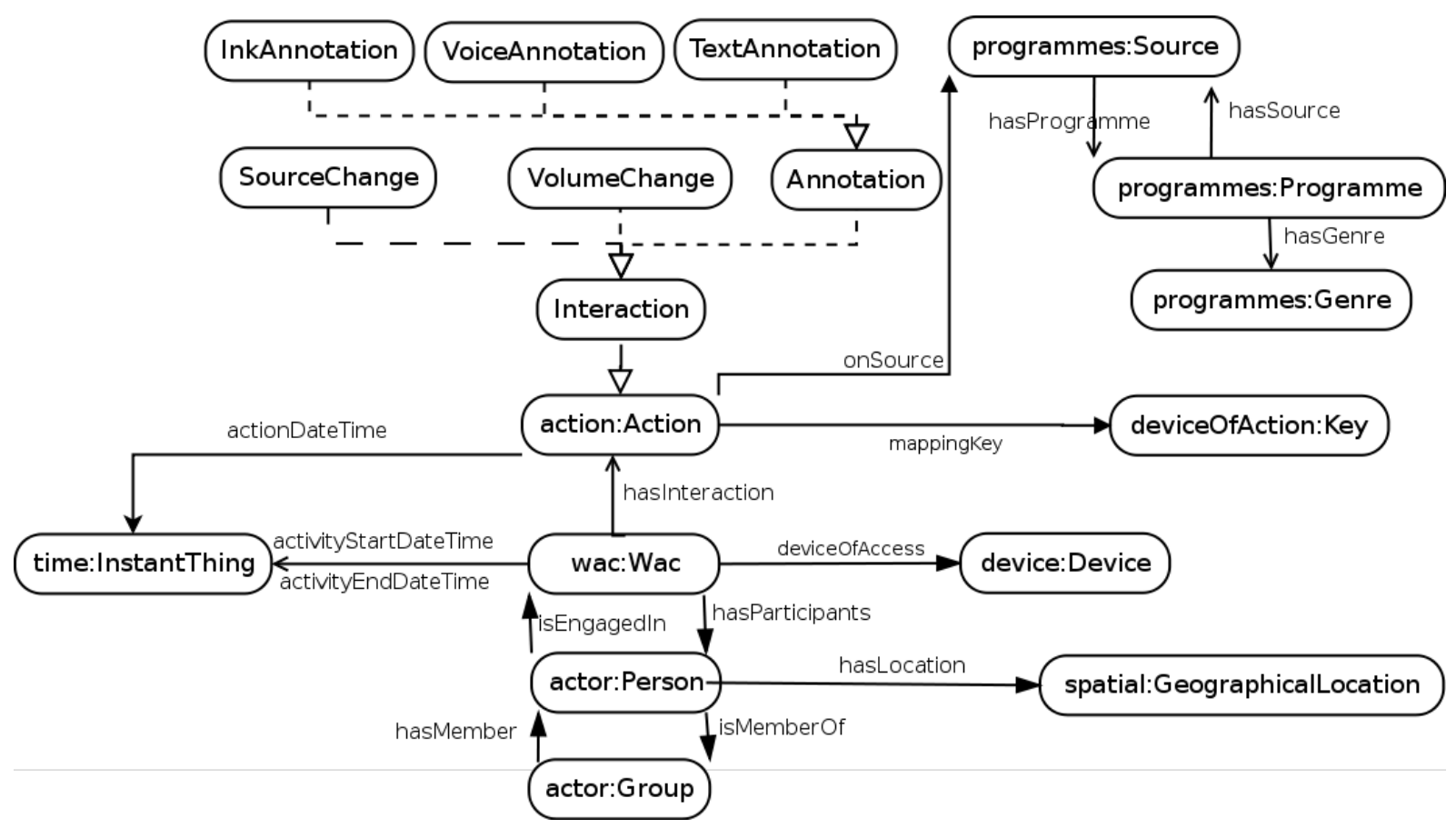

Figura 5.4: Ontologias utilizadas no modelo CAPPA.

A Figura 5.4 mostra as ontologias utilizadas no modelo CAPPA, que refletem parcialmente a estrutura do formato XML do modelo. Os principais itens presentes na ontologia são: 
- A ontologia Programme, que descreve o vídeo em questão como um programa televisivo ou um vídeo na Web. Essa ontologia está associada a um gênero (Genre) e a uma mídia (Source), a qual varia entre um canal de televisão, um vídeo na Web ou um vídeo local.

- A ontologia Action, que descreve alguma interação realizada pelo usuário com o sistema de vídeo, a qual pode variar entre alterações na fonte do vídeo (SourceChange), no volume do vídeo (VolumeChange) e realização de anotações (Annotation). Essa ontologia também tem as propriedades onSource, que determina qual a mídia em que se realiza a ação, e mappingKey, que determina qual a tecla ou recurso utilizado para se realizar a ação (deviceOfAction:Key).

- A ontologia Device, estendida da ontologia de mesmo nome do modelo SeCoM, a qual determina os dispositivos computacionais de acesso, como set-top-box ou um notebook, por exemplo.

- A ontologia Actor, também estendida de mesmo nome do SeCoM, que modela o conjunto de entidades, os atores, os quais assistem a um vídeo e o comentam. Todo ator possui uma localização espacial GeographicLocation e pode estar associado a vários grupos de usuários (Group).

- A ontologia Spatial do modelo SeCoM, que descreve qualquer tipo de entidade que contenha uma dimensão espacial. No modelo CAPPA é descrita a localização física dos atores.

- A ontologia Time, a qual descreve qualquer tipo de entidade que contenha uma dimensão temporal. No modelo CAPPA, essa ontologia descreve os instantes de tempo (InstantThing) iniciais e finais da atividade de assistir TV, bem como o momento de uma interação.

- A ontologia Wac, que descreve a atividade de um usuário (Actor) de assistir a um vídeo. Essa ontologia é uma extensão da ontologia Activity do modelo SeCoM.

O World Wide Web Consortium (W3C) propôs a Web Ontology Language (OWL) (Dean et al., 2004) como uma linguagem padrão para representar ontologias. Uma vantagem da linguagem OWL, quando comparada a XML, é de permitir a inserção mais expressiva e semântica ao vocabulário.

O principal modo de se instanciar ontologias no modelo CAPPA a partir de informações em formato XML, que podem ter sido originadas de diferentes dispositivos e fontes de informação, como descrito anteriormente. A extração 
das informações de XML para OWL pode ser realizada com uso de XML Stylesheets (XSLT), como relatado por Bohring e Auer (2005), ou como um serviço da aplicação que processa XML para gerar o formato OWL, com uso de APIs de programação.

Com o objetivo de permitir o aprendizado de ontologias no modelo, é possível o uso de Formal Concept Analysis (FCA). Uma FCA é um formalismo para, a partir de um contexto formal, derivar um reticulado de conceitos (concept lattice). Um concept lattice é uma representação composta por um ou mais contextos formais parcialmente ordenados por inclusão, ou seja, há uma relação de subjunção entre conceitos. Em um concept lattice, em cada par de conceitos, para quaisquer dois elementos de um lattice, há sempre um que é Supremo e um Ínfimo, que correspondem uma relação de subconceito e superconceito entre esses dois elementos (Priss, 2006).

Bendaoud et al. (2008) utilizam FCA para extrair uma ontologia a partir de um concept lattice. O processo de aprendizado consiste em elaborar um contexto formal, a partir de um conjunto de dados, construir um concept lattice a partir do contexto formal e representá-lo como uma ontologia. Esse processo de aprendizagem é incremental, tornando possível a geração de ontologias sem que haja a necessidade da repetição de todo o processo.

Pelo processo de aprendizagem incremental, a geração de concept lattices para se extrair ontologias no modelo CAPPA pode trazer melhorias em performance para um sistema quando este processa grande quantidade de informações de contexto. Isso pode tornar possível o uso de ontologias em dispositivos com poder de processamento limitado.

Outro benefício para o modelo CAPPA do uso de FCA e de concept lattices é o suporte a novos elementos no formato XML, pois, por ser um processo de aprendizagem, permite que alterações e novos elementos no XML deem origem a novas ontologias. Com isso é possível, por exemplo, permitir que um outro padrão diferente de SVG seja representado pela ontologia sem a reconstrução do modelo ontológico apresentado anteriormente.

Gomes (2010) investiga a integração de FCA com Análise Conceitual Relacional e propõe uma adaptação do formato XML do modelo CAPPA como parte do estudo de permitir uma mineração em uma base dinâmica de ontologias.

\subsection{Raciocínio}

As ontologias do modelo CAPPA têm como um de seus principais propósitos auxiliar no processo de inferir diferentes ações sobre os dados de interação 
do usuário. A Máquina de Inferência (MI) atua juntamente um processo de mineração de dados em que as informações das ontologias são processadas para permitir a inferência de alguma ação. Esse processo forma o raciocínio do modelo (reasoning) que gera recomendações a um usuário.

Para a realização da mineração de dados, o modelo CAPPA pode fazer uso da plataforma WEKA (Weka, 2010), uma coleção de algoritmos de aprendizado de máquina e ferramentas de processamento de dados (Witten; Frank, 2005). Essa plataforma pode fornecer regras de associação do usuário, para classificá-los em grupos por exemplo. Outra possibilidade é a de analisar dados para realizar recomendações na interface de captura de anotações, buscando por exemplo semelhanças entre as anotações dos usuários para sugerir uma palavra de anotação.

\subsection{Plataforma WEKA}

A plataforma WEKA prevê a descrição dos dados de entrada em um formato Attribute-Relation File Format (ARFF) ${ }^{5}$. Realizando a construção de um modelo de documento, é possível descrever o modelo ontológico do modelo CAPPA em atributos do formato $\mathrm{ARFF}$ e as instâncias, que no caso referem-se às interações do usuário.

O Quadro 5.9 apresenta um exemplo de um documento ARFF gerado a partir da ontologia do modelo CAPPA. O documento apresenta apenas alguns atributos do modelo ontológico, descrevendo nas linhas 2 a 18 os atributos que serão utilizados na WEKA e nas linhas 20 a 32 os dados de interação que serão processados.

\footnotetext{
1 @relation ontoCAPPA

2 @attribute actionContent\{sourceChange,red,blue,green,cat,link,very funny, cat falling again, nice jumping\}

3 @attribute action\{voiceAnnot,inkAnnot,textAnnot,volumeChange,sourceChange\}

4 @attribute deviceOfAction\{PC,TouchScreen\}

5 @attribute actorPersonAge $\{21,24\}$

6 @attribute actorPersonGender\{male,female\}

7 @attribute actorGroup $\{$ Comedy,Pets\}

8 @attribute actorSLLong $\{52.05151723\}$

9 @attribute actorSLLat $\{69.98037992\}$

$10 @$ attribute timeMonth $\{8\}$

$11 @$ attribute timeDay $\{26,28,29\}$

$12 @$ attribute timeYear\{2009\}

$13 @$ attribute timeHour $\{14,21\}$

14 @attribute timeMinute $\{3,20,21,23,25,55,58\}$

15 @attribute timeSecond $\{1,2,4,7,9,14,16,32,39,49,55\}$

$16 @$ attribute programme\{nTasT5hOLEg,JAMkggHmRUw,a4cmrMJullg\}

$17 @$ attribute programmeSource\{youtube\}

$18 @$ attribute programmeGender\{Comedy, Pets\}

19

20 @ata
}

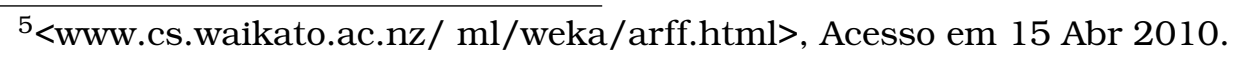


21 youtube,sourceChange,PC,24,male,Pets,52.05151723,69.98037992,8,26,2010,21,20,9,nTasT5hOLEg,youtube,Pets

22 blue,inkAnnot,PC,24,male,Pets,52.05151723,69.98037992,8,26,2010,2 1,2 1,1,nTasT5hOLEg,youtube,Pets

23 blue,inkAnnot,PC,24,male,Pets,52.05151723,69.98037992,8,26,2010,2 1,2 1,14,nTasT5hOLEg,youtube,Pets

24 red,inkAnnot,PC,24,male,Pets,52.05151723,69.98037992,8,26,2010,2 1,21,16,nTasT5hOLEg,youtube,Pets

25 blue,inkAnnot,PC,24,male,Pets,52.05151723,69.98037992,8,26,2010,21,21,32,nTasT5hOLEg,youtube,Pets

26 cat falling,textAnnot,PC,24,male,Pets,52.05151723,69.98037992,8,26,2010,2 1,23,7,nTasT5hOLEg,youtube,Pets

27 link,voiceAnnot,PC,24,male,Pets,52.05151723,69.98037992,8,26,2010,21,23,49,nTasT5h0LEg,youtube,Pets

28 very funny,textAnnot,PC,24,male,Pets,52.05151723,69.98037992,8,26,2010,2 1,23,55,nTasT5hOLEg,youtube,Pets

29 cat falling again,textAnnot,PC,24,male,Pets,52.05151723,69.98037992,8,26,2010,21,25,2,youtube,Pets

30 youtube,sourceChange,a4cmrMJul1g,PC,2 1,female,Comedy,52.05151723,69.98037992,8,28,2009, 14,55,4, youtube, Comedy

31 nice jumping,textAnnot,a4cmrMJul1g,PC,2 1,female,Comedy,52.05151723,69.98037992,8,28,2009, 14,58,39, youtube,Comedy

32 youtube,sourceChange,JAMkggHmRUw,TouchScreen,24,male,Pets,52.05151723,69.98037992,8,29,2009,21,3,2, youtube,Pets

Quadro 5.9: Documento ARFF para entrada na plataforma WEKA.

Os atributos descritos nas linhas 2 a 18 são extraídos da ontologia do modelo CAPPA, tendo sido selecionados quais campos serão utilizados e os valores disponíveis de acordo com os dados presentes no documento ARFF. A seleção dos campos pode ser realizada de modo automático, se possível, mas pode exigir também uma pré-definição manual dos campos.

Dos atributos presentes no Quadro 5.9, destacam-se: (i) a linha 3 representa o conteúdo da ação de acordo com o tipo de ação - qual a cor no caso de anotação de tinta, qual o texto em anotação textual e "sourceChange" para mudança de fonte de vídeo; (ii) a linha 7 apresenta o grupo do usuário mais apropriado à anotação; e (iii) a linha 16 define cada programa como um código de identificação (id) do vídeo no qual são realizadas as anotações.

As linhas 21 a 32 do Quadro 5.9 descrevem dados de instâncias de ontologia do modelo CAPPA: cada linha é uma interação e cada valor (separados por vírgulas em cada linha) é relativo ao atributo descrito anteriormente, seguindo a mesma ordem. A linha 22, por exemplo, descreve uma mudança de fonte de vídeo para o Youtube, em um computador (PC) de um homem de 24 anos e que pertence a um grupo de proteção a animais de estimação, por exemplo, mesma categoria do vídeo (Pets). Já a linha seguinte, a 23, descreve uma anotação de tinta eletrônica no mesmo vídeo, pelo mesmo usuário.

\footnotetext{
1 actorPersonAge=24 ==> actorPersonGender=male timeHour=2 1 actorGroup=Pets

2 actorPersonGender $=$ male $==>$ actorPersonAge $=24$ timeHour $=21$ actorGroup $=$ Pets

3 timeHour=21 ==> actorPersonAge $=24$ actorPersonGender=male actorGroup=Pets

4 actorGroup $=$ Pets $==>$ actorPersonAge $=24$ actorPersonGender $=$ male timeHour $=21$

5 actorPersonAge $=24$ actorPersonGender $=$ male $==>$ timeHour $=21$ actorGroup $=$ Pets
} 
O algoritmo Apriori ${ }^{6}$, presente na plataforma WEKA, pode ser utilizado para extrair relações entre as informações de contexto do modelo CAPPA. O Quadro 5.10 mostra uma possivel saída resultante do processamento de informações do Quadro 5.9, que apresenta algumas relações de atributos, como, por exemplo, na linha 5 que determina que a idade de 24 anos e o gênero sendo masculino, há uma tendência do horário e do grupo de uso pelos usuários analisados.

Outros algoritmos podem ser utilizados para a geração de relações, de modo a identificar regras da Máquina de Inferência.

\subsubsection{Máquina de Inferência}

No modelo CAPPA, o componente Máquina de Inferência (Inference Engine, Figura 5.2) é usada para recomendar uma ação ou classificação ao usuário, gerenciando as Regras de Classificação ou as Regras de Ação. O conhecimento extraído por mineração dos dados do usuário é utilizado para uma tomada de decisão, que pode resultar na recomendação implícita ou explícita de algum conteúdo ou ação.

Uma alternativa para a integração de ontologias e da criação de regras é o uso do framework Jena (Jena, 2010). O framework, dentre outras características, suporta o uso de ontologias em OWL, possui uma biblioteca para operações em ontologias e também permite o uso de SPARQL ${ }^{7}$ e de um formato próprio para manuseio de regras. O Quadro 5.11 exibe como seriam as relações do Quadro 5.10 em formato próprio do Jena.

1 [rule1:(rdf:type WatchTV)(actorPersonAge:24) -> (actorPersonGender:male)(timeHour:21)(actorGroup:Pets)] 2 [rule2:(rdf:type WatchTV)(actorPersonGender:male) -> (actorPersonAge:24)(timeHour:21)(actorGroup:Pets)] 3 [rule3:(rdf:type WatchTV)(timeHour:21) -> (actorPersonAge:24)(actorPersonGender:male)(actorGroup:Pets)] 4 [rule4:(rdf:type WatchTV)(actorGroup=Pets) $\rightarrow$ (actorPersonAge:24)(actorPersonGender:male)(timeHour:21)] 5 [rule5:(rdf:type WatchTV)(actorPersonAge:24)(actorPersonGender:male) -> (timeHour:21)(actorGroup:Pets)]

Guadro 5.11: Regras de Associação no formato para Jena

As Regras de Classificação possibilitam que o componente Máquina de Inferência possa classificar, ou não, um usuário em um determinado grupo de usuários. O Quadro 5.11 apresenta cinco regras de classificação, nas quais a Máquina de Inferência deve determinar se podem ser ou não recomendadas implicitamente ou explicitamente. No caso de recomendação implícita, o usuário automaticamente recebe as recomendações que o componente Má-

\footnotetext{
${ }^{6}<\mathrm{http}: / /$ weka.sourceforge.net/doc/weka/associations/Apriori.html>, Acesso em $25 \mathrm{Abr}$ 2010.

${ }^{7}$ SPARQL é uma linguagem de queries de ontologias. Maiores informações em www.w3. org/TR/rdf-sparql-query/, Acesso em 20 Mai 2010.
} 
quina de Inferência determinar relevantes, enquanto que as recomendações explícitas devem ter autorização do usuário para serem efetivadas.

As Regras de Ação permitem ao componente Máquina de Inferência determinar recomendações para ações do usuário, sendo elas sugestões de alternativas no modo de anotação e de alternativas no modo de interação do usuário com um vídeo. Para as Regras de Ação, as recomendações implícitas tomam ações automaticamente, enquanto que as explícitas sugerem tais ações sem serem realizadas automaticamente (por exemplo exibindo alternativas à anotação ou a outros vídeos).

O componente Máquina de Inferência deve ter a capacidade de utilizar determinados padrões para julgar recomendações relevantes ou não. É interessante que se utilize um modelo estatístico, ainda que simples, para avaliar se as recomendações são ou não relevantes, e que se divulgue o resultado dessa avaliação para os outros peers. Com isso, uma recomendação ruim pode ser mal avaliada por diversos $e$ nem chegar a ser realizada em um usuário. Para realizar a avaliação, o componente Máquina de Inferência pode, por exemplo, considerar recomendações explícitas e registrando quantas foram utilizadas e quantas não foram.

O modelo CAPPA não determina o tipo de máquina de inferência, podendo também, por exemplo, usar análises estatísticas das informações do usuário, mineradas com extração direta das informações dos usuários e gerando as Regras de Ação e de Classificação. Em resumo, os componentes de raciocínio do modelo CAPPA podem utilizar técnicas de mineração de dados do nível mais simples (como extração direta das informações em XML) às mais complexas (usando por exemplo a Weka), além de poder também utilizar um método mais complexo para gerenciamento das regras de classificação de de ação (com Jena).

\subsection{Rede P2P}

Na estrutura proposta no modelo CAPPA, cada usuário participa de diversas redes $\mathrm{P} 2 \mathrm{P}$, de acordo com suas preferências. Ou seja, uma rede P2P pode ser composta por torcedores de um determinado time de futebol, outra por quem gosta de assistir a programas esportivos, e outra por amigos do usuário, como em uma comunidade de relacionamentos.

O usuário é automaticamente ou manualmente convidado para as comunidades criadas para compartilhamento de comentários e de informações de contexto de cada usuário, provendo anotações compartilhadas e novas infor- 
mações de contexto. Quando o usuário assiste a um vídeo ou a um determinado programa na TV, por exemplo, os grupos $\mathrm{P} 2 \mathrm{P}$ associados ao programa ou vídeo são selecionados e mostrados como opção para o usuário, que pode participar de um ou mais grupos simultaneamente. É recomendado que a participação dos usuários em grupos P2P seja voluntária e explícita.

A plataforma JXTA pode ser utilizada em implementação do modelo CAPPA por conter elementos fundamentais no modelo, como a troca de informações síncronas, replicação de conteúdo alheio e independência de servidores ou super-nós. A plataforma é recomendada para a aplicação que tenha disponibilidade da biblioteca própria da JXTA, entretanto o uso de servidores de replicação para dispositivos que não suportem o uso de rede P2P é especificado pelo modelo CAPPA. A impossibilidade de um dispositivo utilizar uma rede $\mathrm{P} 2 \mathrm{P}$ pode ocorrer por diversos motivos, como falta de suporte a biblioteca JXTA, conectividade limitada com a Internet ou mesmo baixo poder de processamento.

Os servidores de replicação atuam como peers na rede, interligando em uma conexão direta dispositivos com a rede P2P do modelo CAPPA. Com isso, os servidores atuam como supernodes ${ }^{8}$, de modo que cada servidor conectese a um total de $N$ grupos P2P diferentes. $N$ grupos corresponde à soma dos diferentes grupos presentes entre os usuários conectados nesse servidor.

Como pode haver muitos dispositivos que não suportem o uso de rede $\mathrm{P} 2 \mathrm{P}$, a utilização de muitos usuários em um mesmo servidor pode tornar a arquitetura P2P inutilizável. É recomendado à aplicação ou ao sistema que implementa o modelo CAPPA estabelecer um limite máximo de usuários por servidor de acordo com a escalabilidade do sistema. Pode-se ainda estabelecer um limite dinâmico de usuários e servidores, utilizando balanceamento de carga.

\subsection{Considerações Finais}

Este capítulo apresentou o modelo arquitetural CAPPA, o qual tem por objetivo fazer uso de informações de contexto em aplicações de anotações de vídeo. $O$ modelo CAPPA apresenta definições de componentes necessários para uma aplicação, bem como o funcionamento e interação desses componentes.

Considerando os módulos apresentados no capítulo, é possível notar que os módulos de comunicação e de conhecimento são mais definidos e deta-

\footnotetext{
${ }^{8}$ supernodes, ou super-nós, conectam diversos usuários a um subgrupo de outros.
} 
lhados do que o módulo de raciocínio. Este possui uma abordagem menos complexa para facilitar a implementação do modelo em uma aplicação.

A seguir serão apresentados os protótipos resultante da integração do modelo arquitetural na aplicação WaCTool. 


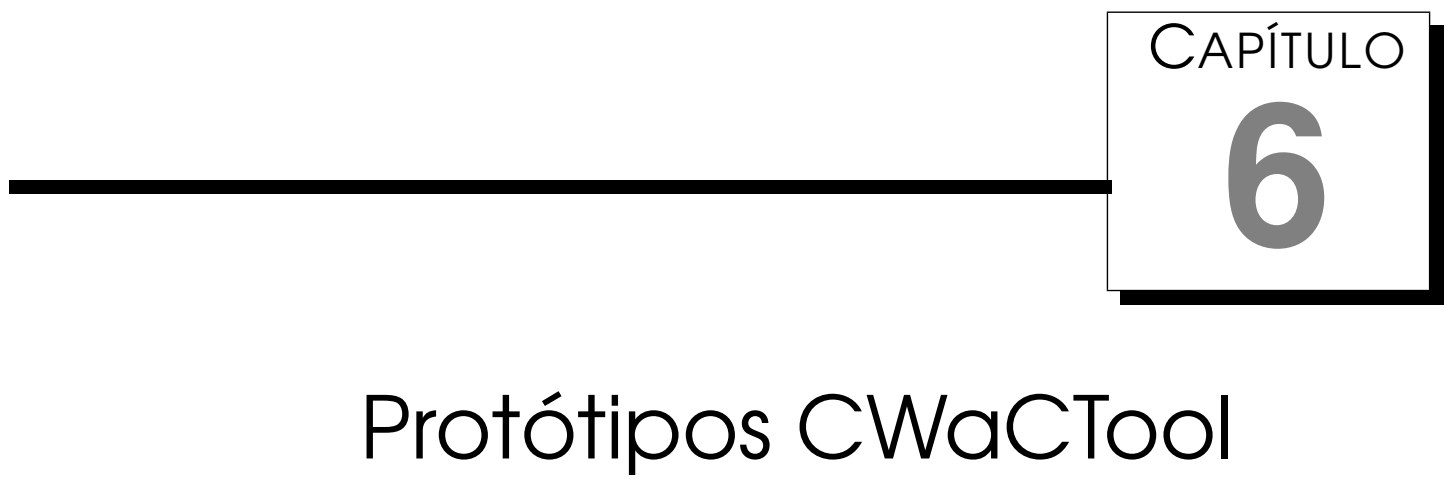

Para prova de conceito do modelo CAPPA, redefinição do modelo (detalhado no capítulo anterior na Seção 5.1) e avaliação dos conceitos do modelo CAPPA, foram construídos dois protótipos: a ferramenta Collaborative Watch-and-Comment Tool (CWaCTool) e o serviço Context Aware Peer-to-Peer Architecture Service (CAPPAS).

A ferramenta CWaCTool é o principal protótipo, baseado na WaCTool descrita no Capítulo 4. A CWaCTool é descrita a partir da Seção 6.3 deste capítulo.

O serviço CAPPAS é uma implementação parcial do modelo CAPPA, projetado para ser independente da aplicação e para permitir a aplicações de anotações em vídeo o uso dos recursos do modelo CAPPA. O serviço, por ser uma implementação parcial, acabou se integrando a ferramenta CWaCTool, tornando os dois protótipos em um só, a CWaCTool versão 3.

Este capítulo apresenta um histórico do serviço CAPPAS na Seção 6.1. A Seção 6.2 detalha as duas versões anteriores da CWaCTool. A Seção 6.3 descreve a arquitetura da terceira versão da CWaCTool. Em seguida são descritos o funcionamento de aspectos diversos da aplicação em uso, como o funcionamento das anotações, da conexão de rede e de integração com redes sociais na Seção 6.4. A Seção 6.5 apresenta as avaliações realizadas nas três versões da CWaCTool. A Seção 6.6 apresenta as considerações finais sobre este capítulo. 


\subsection{Serviço CAPPAS}

O serviço Context Aware Peer-to-Peer Architecture Service (CAPPAS) implementa alguns recursos do modelo CAPPA para aplicações de anotações de vídeo, como a CWaCTool. Apesar da CWaCTool integrar o serviço CAPPAS como parte da aplicação em um único protótipo, esta seção apresenta os módulos não integrados à CWaCTool na versão atual.

A implementação do CAPPAS utilizou a plataforma Java ${ }^{1}$, por ser a mesma da CWaCTool. Inicialmente, a CWaCTool utilizava o serviço CAPPAS como uma biblioteca de aplicação, com recursos posteriormente integrados à CWaCTool e dois não integrados: Jena e Weka.

\subsubsection{Recurso Jena}

Como apresentado no capítulo anterior, o framework Jena permite o uso de aplicações com a Web Semântica, permitindo o uso de RDF, OWL e SPARQL, além de permitir o uso de uma máquina de regras (rule engine) (Jena, 2010). No serviço CAPPAS, são usados o formato OWL para definição das ontologias e a Rule Engine do Jena.

A Jena Ontology API oferece classes e propriedades para instanciar as ontologias em objetos Java. O CAPPAS utiliza dois pacotes (packages) Java para agrupar as classes necessárias: o pacote "br.fapesp.tidia.ae.cappas.ontology" com uma classe para gerenciar as ontologias e um Reasoner(para a máquina de inferência), e o pacote "br.fapesp.tidia.ae.cappas.ontology.vocabulary" com as classes que representam as ontologias principais do modelo CAPPA.

A Rule Engine do Jena permite que se construa regras de associação, que podem ser definidas por um objeto Java da classe Rule. O pacote "br.fapesp.tidia.ae.cappas.ontology" do CAPPAS possui uma classe para gerenciamento das regras, criando-as de modo manual (pelo desenvolvedor, diretamente no código Java). A API de regras é detalhada em http://jena.sourceforge. net/inference (Acesso em 26 Abr 2010).

O uso do Jena possibilita que a aplicação trabalhe diretamente com ontologias de modo abstrato, por permitir acesso aos elementos através de classes e métodos em Java. Como o modelo CAPPA utiliza um formato XML para transição de informação de contexto, o recurso Jena realiza a conversão das informações para instâncias da ontologia do modelo CAPPA.

\footnotetext{
${ }^{1}$ http: //www.java.com/pt_BR/, Acesso em 26 Abr 2010.
} 


\subsubsection{Recurso Weka}

A plataforma Weka é uma coleção de algoritmos de aprendizado de máquina para tarefas de mineração de dados (Weka, 2010). Seu uso no serviço CAPPAS tem como objetivo extrair informações utilizando mineração de dados para se obter relações das informações, como por exemplo regras de associação.

A integração com a biblioteca fornecida pelo projeto Weka, em Java, com o serviço CAPPAS ocorre no pacote "br.fapesp.tidia.ae.cappas.mining”. O pacote contém uma classe para leitura de ontologias (WekaModule) e outra para funcionamento do algoritmo Apriori, este para geração de regras (RulesManager).

Apesar do uso do Jena para geração de regras, a plataforma Weka oferece não só a possibilidade de criação de regras (Witten; Frank, 2005), mas também de árvores de decisão (Witten; Frank, 2005), ou ainda de uma modelagem estatística (Witten; Frank, 2005). Uma futura implementação da Weka independente do Jena e integrada a CWaCTool pode gerar resultados de melhor desempenho tanto na busca por informações de contexto como na criação de recomendações.

\subsubsection{Análise do Serviço CAPPAS}

Apesar dos recursos não integrados a CWaCTool, o desenvolvimento do serviço auxiliou na especificação de fontes de informações de contexto na CWaCTool. O serviço possibilitou também construir uma prova de conceito do módulo de raciocínio utilizando Jena e Weka, tendo como resultado o modelo do capítulo anterior. Os resultados são detalhados em Furtado (2010), Maximino (2009) e Gomes (2010), que auxiliaram na construção e integração desses recursos ao serviço CAPPAS.

A decisão da integração do serviço CAPPAS foi após o término da versão 2 da CWaCTool, detalhada por Fagá Jr. et al. (2009a), quando o serviço CAPPAS tornou-se desnecessário por só considerar a CWaCTool. Ocorreram também problemas para integrar as diferentes bibliotecas (Jena e JXTA) quanto a duplicidade de instâncias da ontologia do modelo CAPPA. Outro motivo pela remoção do serviço é a complexidade dos módulos Jena e Weka, tendo sido priorizado outros módulos mais importantes que resultem em um protótipo funcional do modelo CAPPA. 


\subsection{Versões Iniciais da CWaCTool}

A CWaCTool foi construída em três versões, sendo que cada uma explorou diferentes aspectos. A primeira versão não utilizava informações de contexto, tendo como objetivo explorar o aspecto social e o tema Social TV. A segunda versão teve como principais objetivos a renovação da interface gráfica, da infra-estrutura e o uso de informações de contexto em um ambiente de TVDI interativa. A última versão focou no uso de informações de contexto com colaboração em repositórios de vídeos na Internet.

Apesar de cada versão ter objetivos distintos, o desenvolvimento foi incremental e os recursos produzidos em uma versão foram reutilizados na versão seguinte. Nesta seção serão descritas algumas particularidades das versões anteriores à versão final, a qual é explorada neste capítulo a partir da Seção 6.3 .

\subsubsection{CWaCToolv1}

O primeiro protótipo da CWaCTool é apresentado por Motti et al. (2009), explorando a colaboração dos usuários e a discussão de Social TV na CWaCTool. A principal nova funcionalidade que a ferramenta implementa, em relação a WaCTool, é o quadro colaborativo, que permite aos usuários anotarem sincronamente um mesmo quadro de um vídeo.

A arquitetura do paradigma WaC com aspecto colaborativo pode ser analisada pelo fluxo das informações na Figura 6.1, quando diferentes categorias de usuários utilizam a ferramenta CWaCTool enquanto assistem a um mesmo programa de TV. Cada círculo representa um usuário diferente com formas de captura diferentes, gerando e visualizando anotações na rede P2P. As setas representam o fluxo dos diferentes tipos de anotações, seja de tinta digital, de texto ou de áudio.

Na Figura 6.1, o usuário em A) utiliza um televisor e um PDA, ou algum dispositivo que suporte tinta digital, para realizar anotações com tinta eletrônica ou com áudio, já que seu dispositivo pode conter um microfone. O usuário em B) utiliza um Computador Pessoal (PC) e pode realizar qualquer tipo de anotação, como por exemplo anotação de tinta eletrônica, anotações de texto com o teclado ou de áudio caso seu computador possua um microfone. O usuário em C) não possui instrumentos de captura, apenas o controle remoto que, em um sistema de TVDI, pode visualizar os comentários que são realizados no mesmo instante. O usuário em D) também possui um televisor, 


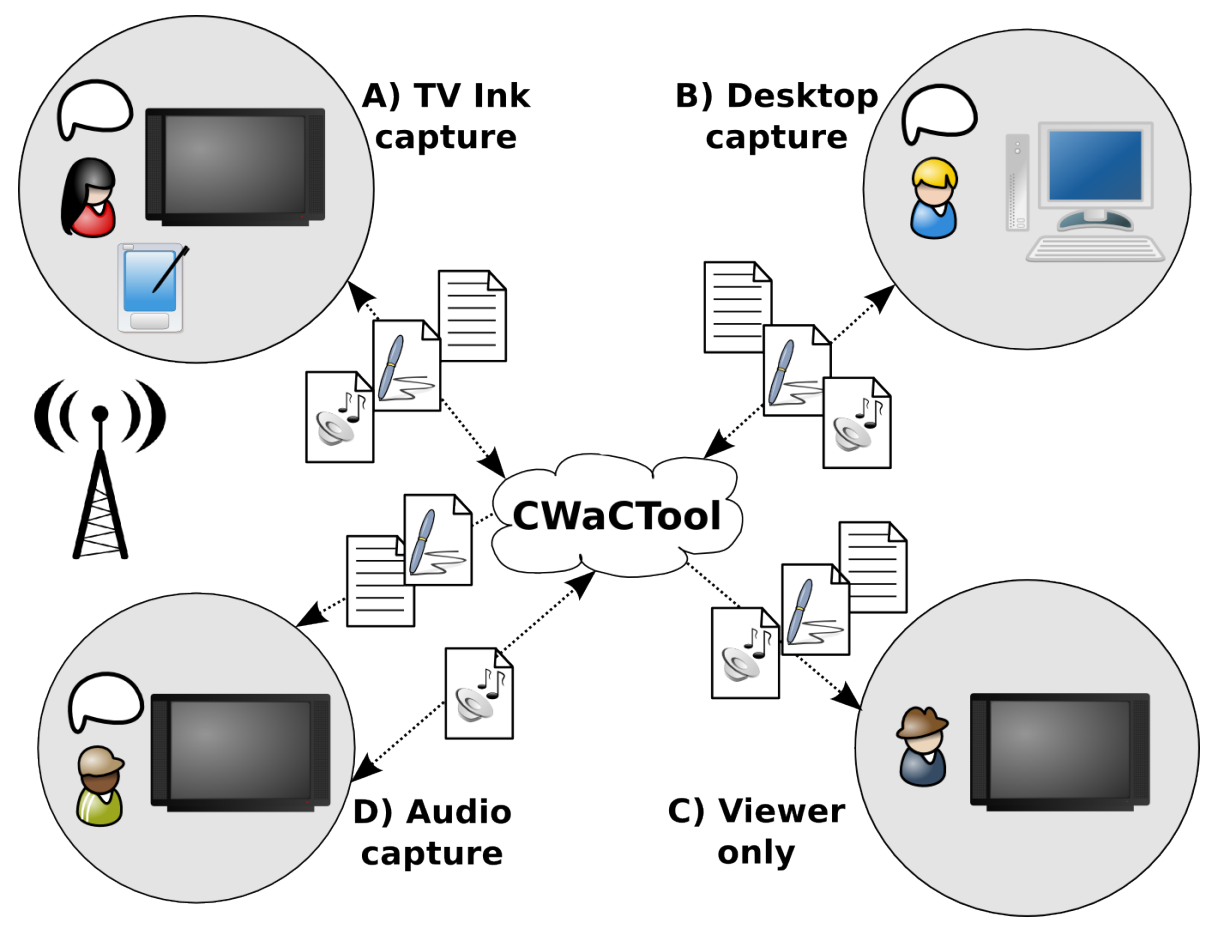

Figura 6.1: Diagrama com o fluxo das informações no processo de anotação da CWaCTool $v 1$ sobre um mesmo programa de TV (Motti et al., 2009).

mas com um microfone, e por isso pode interagir com comentários de áudio e visualizar os comentários dos outros usuários.

Cada usuário da Figura 6.1 que utilize algum dispositivo com suporte a tinta digital, como é o caso dos usuários A) e B), pode anotar em tinta sincronamente ou assincronamente. Os outros comentários são compartilhados sincronamente, mas somente quando concluídos, como é o caso das anotações de áudio.
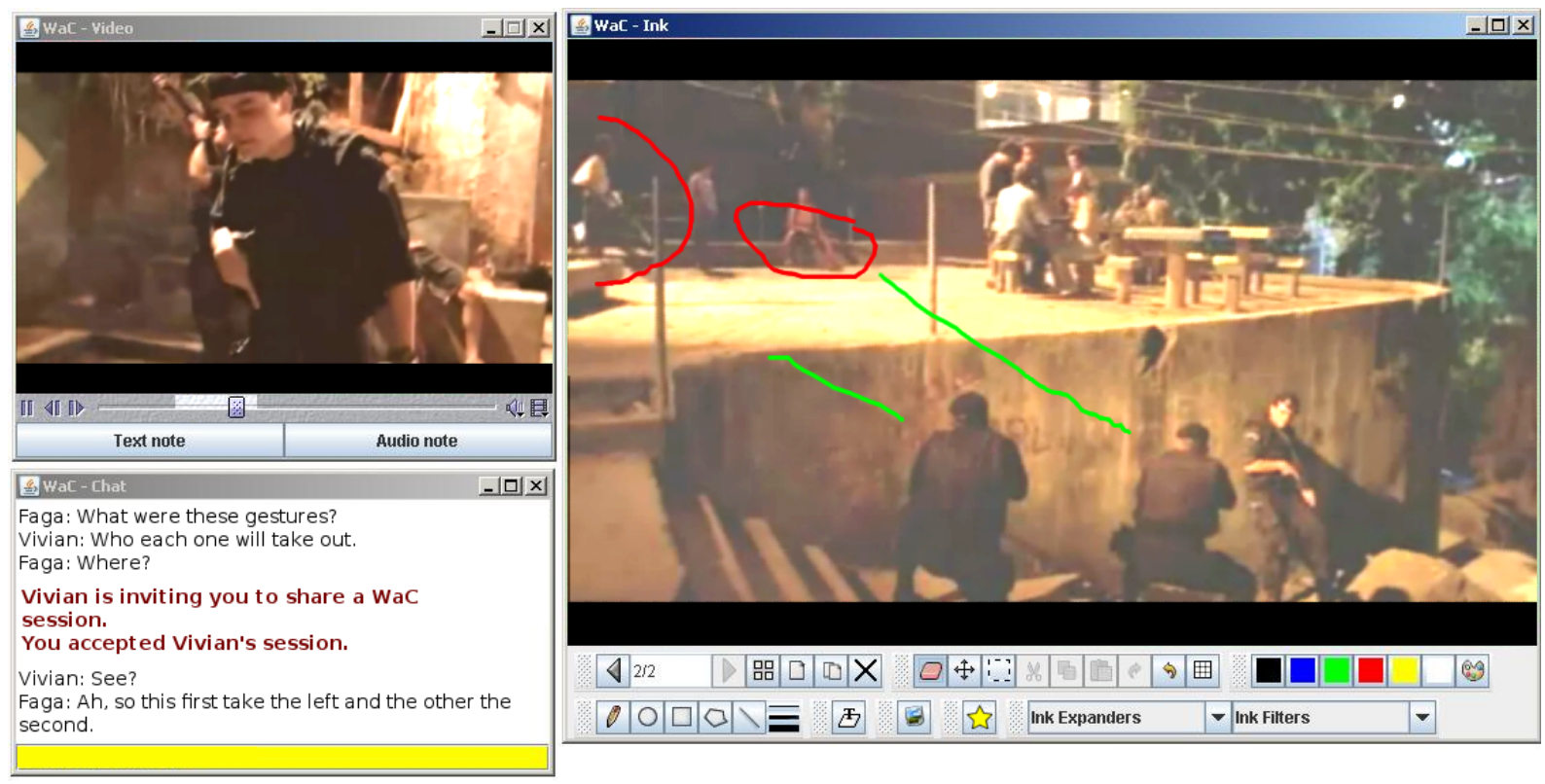

Figura 6.2: CWaCTool v1: ferramenta em funcionamento realizando anotação colaborativa (Motti et al., 2009). 
Uma captura de tela da CWaCTool v1 é apresentada na Figura 6.2. Existem três janelas, já existentes na WaCTool, entretanto com a janela de bate-papo exibindo um convite, realizado por um dos usuários para compartilhar anotação de tinta eletrônica. Aceitando o convite, quando um usuário realizar alguma anotação em tinta, o outro usuário pode visualizá-lo no mesmo instante. Essas anotações são armazenadas para todos os usuários envolvidos no compartilhamento após o término da sessão, e podem ser visualizadas como existente na WaCTool. Quando há o término da anotação de um quadro ou a inserção de um comentário de áudio ou texto, estes podem ser compartilhados com outros usuários.

\subsubsection{CWaCTool v2}

A segunda versão foi caracterizada por uma grande reforma da arquitetura original da ferramenta. Como reportado em Fagá Jr. et al. (2009a) e Fagá Jr. et al. (2009b), os principais objetivos da nova versão foram de explorar o uso e captura de informações de contexto (considerando ambiente de TVDI), de renovar a interface gráfica, e de incluir novos componentes na arquitetura, além de substituir alguns componentes.

Para oferecer um mecanismo de gerenciamento de informações de contexto, um modelo preliminar ao modelo CAPPA foi definido, acompanhado da prototipação do serviço CAPPAS.

Para viabilizar a CWaCTool em cenário de TVDI, a interface gráfica foi redefinida de modo a integrar as janelas da WaCTool em apenas uma, além desse recurso ter sido requisitado por usuários em avaliação da primeira versão da CWaCTool. Algumas interações da aplicação foram redefinidas para permitir o uso de teclado, com o objetivo de simular um controle remoto para, como por exemplo, a reprodução de vídeos e de anotações de texto e áudio.

A Figura 6.3 apresenta a captura de tela da segunda versão da CWaCTool durante a anotação com tinta eletrônica na Whiteboard. Em (B) o usuário realiza uma anotação de tinta, juntamente com outro usuário, como apontado no botão pressionado relativo a colaboração em (D). Enquanto o usuário faz a anotação em (C), é possível acompanhar em uma janela em miniatura, em (A), o vídeo correspondente, podendo ou não pausar sua reprodução. A janela da Figura 6.3 aparece quando o usuário realiza um clique na área do vídeo, o qual é reproduzido em toda a tela.

O usuário pode também utilizar o bate papo, que aparece em um quadro em cima do vídeo como mostrado na Figura 6.4. Outra possibilidade de inte- 


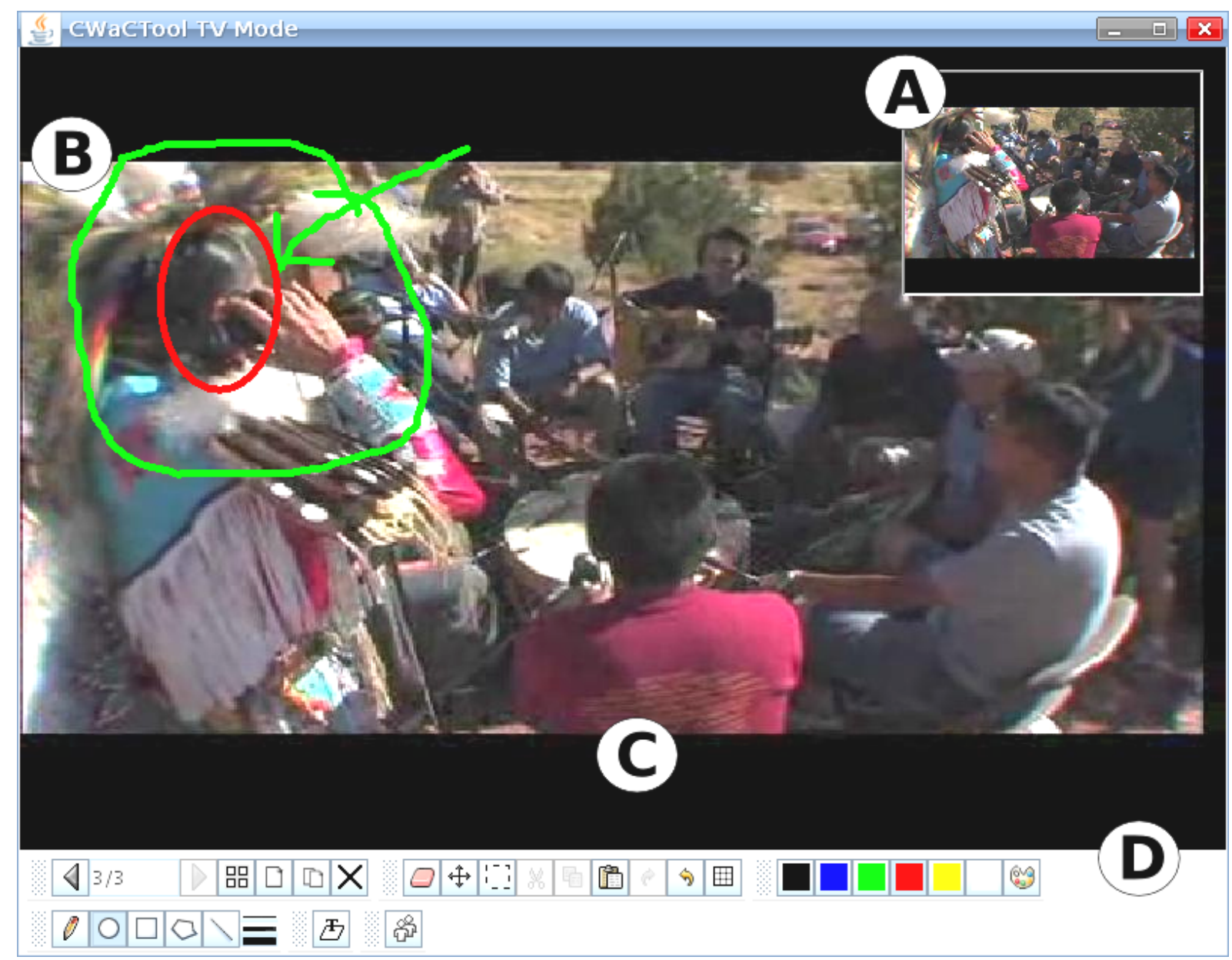

Figura 6.3: CWaCTool v2: usuário realizando anotação de tinta enquanto assiste ao vídeo correspondente em (A) (Fagá Jr. et al., 2009a).

ração é realizar anotações de texto e de áudio (Figura 6.5), podendo ocorrer sugestões de como completar o texto.

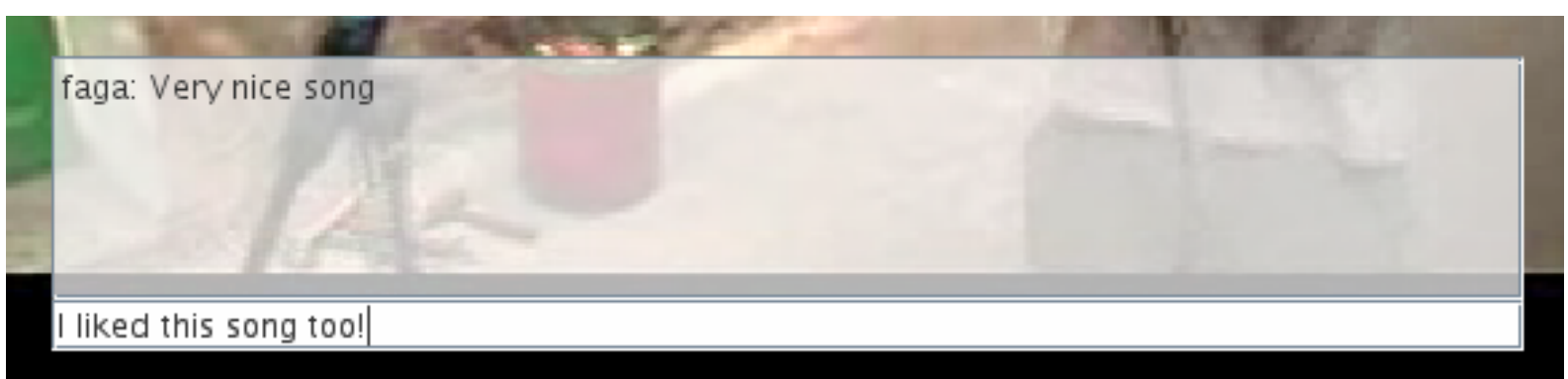

Figura 6.4: CWaCTool v2: janela de bate-papo sobreposta ao video em reprodução.

Outra mudança na segunda versão da CWaCTool foi a reestruturação do código fonte e dos componentes de software, destacando o uso do framework Gstreamer ao invés da Java Media Framework, o uso de canais P2P ao invés de redes P2P para cada vídeo e o compartilhamento de informações de contexto. Destaca-se que a segunda versão não foi testada com possíveis usuários reais do sistema pois o protótipo lançado não possuía todos os novos componentes 


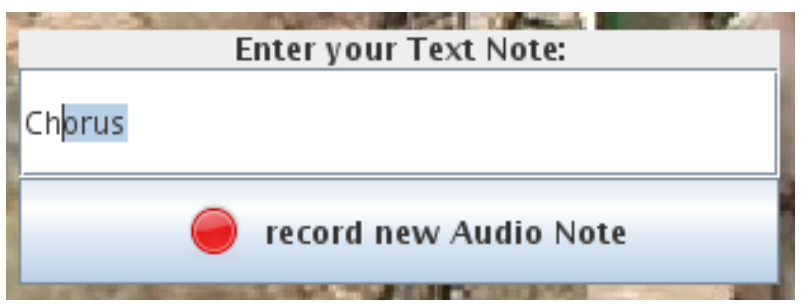

Figura 6.5: CWaCTool v2: durante a realização de uma anotação de texto, um possível modo de sugerir uma anotação auto-completando o texto digitado pelo usuário.

integrados. Os componentes e conceitos da segunda versão foram reutilizados na terceira e última versão da CWaCTool, a versão atual, que é descrita no restante deste capítulo.

\subsection{Arquitetura CWaCTool}

A arquitetura da CWaCTool foi construída com base na arquitetura da WaCTool, detalhada anteriormente no Capítulo 4. Seu principal objetivo é permitir a implementação das principais características do modelo CAPPA.

Para a construção da arquitetura, foram modificados módulos originais da WaCTool e adicionados outros novos, além de ter sido descrito o fluxo das informações de contexto na CWaCTool. Essas duas visões da arquitetura são apresentadas a seguir.

\subsubsection{Módulos}

Os módulos da arquitetura da CWaCTool podem ser observados na Figura 6.6. Em relação a arquitetura da WaCTool, a região de Colaboração passa a ser de Colaboração e Contexto, já que possui módulos com esses dois objetivos e os mesmos possuem vários módulos interligados.

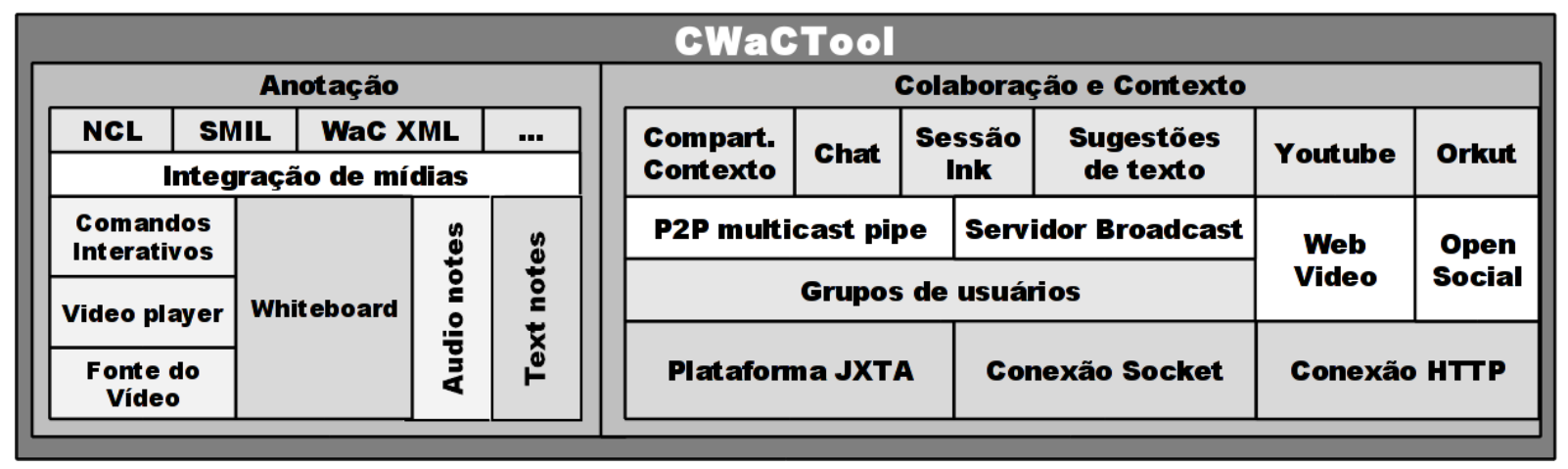

Figura 6.6: Arquitetura da CWaCTool. 


\subsubsection{Módulos de Anotação}

- NCL, SMIL e WaC XML: São responsáveis pela geração de documentos interativos, como na WaCTool, com a diferença do módulo WaC XML que, ao invés de gerar um documento interativo, produz um documento no formato XML do modelo CAPPA para representar e transitar informações de contexto. A CWaCTool, assim como a WaCTool, permite que novos formatos de documentos sejam produzidos com a adição de novos módulos nessa mesma camada (representado pelo módulo “...” na Figura 6.6, uma vez que essa camada é ligada diretamente com o módulo de Integração de mídias).

- Integração de mídias: Realiza a integração dos módulos produtores de documentos e a captura de interações, como na WaCTool.

- Comandos Interativos: Também sem mudanças em relação a WaCTool, permite o manuseio de comandos interativos sobre a mídia do vídeo, como replay e salto em um trecho do vídeo.

- Video player: Originalmente utilizando o Java Media Framework (JMF), utiliza agora o framework Gstreamer ${ }^{2}$. Dentre os principais motivos pela troca estão a descontinuidade de manutenção da JMF, o melhor suporte a codecs de vídeos (inclusive disponiveis a uma maior variedade de sistemas operacionais) e suporte a legendas de texto. O uso do Gstreamer possibilitou também o uso de recurso PiP (Picture-in-Picture), com vários vídeos na mesma janela, bem como o suporte de vídeos do Youtube.

- Fontes de vídeo: Permite o acesso aos vídeos remotamente em streaming (como no Youtube), ou localmente. Pode ocorrer acesso simultâneo de mais de uma fonte de vídeo (como no uso de PiP), sendo o motivo da alteração no nome de Fonte de Vídeo para Fontes de Vídeo, em relação a WaCTool.

- Whiteboard: Possibilita o funcionamento de anotações em tinta digital como na WaCTool, com adaptações para funcionamento em colaboração.

- Audio notes: Trata as anotações de áudio realizadas pelo usuário, com modificações para utilizar a Gstreamer e registrando as anotações em formato MP3 (MPEG-1 Audio Layer 3).

- Text notes: Manipula as anotações textuais dos usuários, permitindo o armazenamento e o compartilhamento em formato de informações de contexto. O módulo conta também com uma classe para o gerenciamento

\footnotetext{
${ }^{2}$ http://code.google.com/p/gstreamer-java/, Acesso em 26 Abr 2010.
} 
das anotações de texto em um banco de dados, possibilitando o registro e o acesso às anotações de diferentes vídeos e usuários.

\subsubsection{Módulos de Colaboração e Contexto}

- Compartilhamento de Contexto: Representado na Figura 6.6 como "Compart. Contexto", esse módulo originou-se do módulo da WaCTool "Compartilhamento de Conteúdo”. A principal diferença é que, ao invés de compartilhar conteúdo gerado pelo usuário, são compartilhadas informações de contexto obtidas implicitamente, como informações e preferências pessoais, além do compartilhamento de conteúdo.

- Chat: Oferece aos usuários a possibilidade de conversa por texto sincronamente. O módulo de bate-papo possibilita que o usuário escolha uma sala de bate-papo por vez, na qual cada "sala de bate-papo" é associada a um grupo P2P. Diferente da WaCTool que considera um canal de batepapo por vídeo, a CWaCTool utiliza vários canais, uma para cada grupo $\mathrm{P} 2 \mathrm{P}$, mas não para cada vídeo.

- Sessão Ink: Permite que, durante o uso da Whiteboard, as anotações em tinta sejam realizadas sincronamente com outros usuários. Um usuário que está anotando um quadro de vídeo envia o convite aos usuários de seu grupo para colaborarem com a anotação desse quadro. Durante a anotação os outros participantes visualizam cada traço ou operação na Whiteboard no mesmo instante, e podem utilizar a ferramenta de bate papo.

- Sugestões de texto: É o módulo que compartilha as anotações de texto (Text notes) realizadas por todos os usuários. As anotações de texto são repassadas a todos os outros usuários, e então essas informações são utilizadas para sugerir anotações possíveis em determinados vídeos. As sugestões são apenas para cada vídeo, mas em alguns grupos é possível que as sugestões sejam em relação a categoria de um vídeo. Utiliza o framework Gstreamer para renderizar os textos em legendas, além de utilizar os módulos Timebars e jaretutil da plataforma jaret.de ${ }^{3}$.

- P2P multicast pipe: É um canal de comunicação multicast em rede P2P, isso é, cada peer se comunica com todos os outros, seja em conexão direta ou com intermédio de outros peers que distribuem os pacotes de dados. Atua de modo semelhante a WaCTool, com a diferença que na

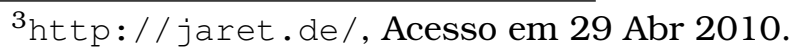


CWaCTool utiliza uma implementação própria para transmissão de pacotes de tamanho grande, uma vez que a implementação original de multicast da JXTA não permite tal transmissão.

- Servidor Broadcast: É uma alternativa ao multicast e ao uso de P2P. $\mathrm{O}$ objetivo é atuar como um serviço auxiliar à rede $\mathrm{P} 2 \mathrm{P}$, oferecendo um servidor que replique os dados aos outros usuários quando a rede P2P não estiver disponível. Utiliza o módulo Socket Connection para realizar conexão com o servidor. Junto com o P2P multicast pipe, permite a comunicação dos módulos Compart. Contexto, Chat, Sessão Ink e Sugestões de texto.

- Grupos de usuários: Permite o agrupamento de usuários de modo semelhante a WaCTool, mas considera grupos de usuários ao invés de peers. $\mathrm{Na}$ CWaCTool os grupos de usuários são baseados em informações de contexto e escolha do usuário.

- Plataforma JXTA: Com o objetivo de oferecer conexão P2P a aplicações e sistemas computacionais, esse módulo permite que os diferentes módulos da CWaCTool utilizem a rede P2P. Do mesmo modo que a Conexão Socket, é baseada na classe de interface CommunicationLayer, que modela as possibilidades de transmissão e recebimento de pacotes de dados para a CWaCTool. Para a troca de informações em tempo real, os dois módulos utilizam objetos Java definidos em XML.

- Conexão Socket: Faz conexão simples via Socket ${ }^{4}$ do sistema operacional. O servidor da CWaCTool, responsável pelo Broadcast das informações e utilizando a linguagem Python, conecta-se com os clientes e distribui as informações entre todos da rede, podendo haver necessidade de diversos servidores de acordo com a demanda de usuários da aplicação.

- Youtube: Realiza o intercâmbio de informações entre a CWaCTool e o site Youtube. É responsável por parte da aquisição de informações de contexto, extraindo dos vídeos palavras-chave, descrições e notas dos usuários. É também esse módulo o responsável por baixar os fluxos (streams) de vídeo, bem como buscar vídeos. Utiliza a biblioteca GData Java ${ }^{5}$, responsável por integrar serviços da Google a programas de terceiros.

- Orkut: Atua na rede social Orkut ${ }^{6}$ para extrair informações de contexto do usuário. Utiliza para isso o módulo Open Social, que permite também que outros sites de relacionamento, ou outras redes sociais, possam

\footnotetext{
${ }^{4}$ http://java.sun.com/docs/books/tutorial/networking/sockets/, Acesso em 29 Abr 2010.

${ }^{5}$ http: //code.google.com/p/gdata-java-client/, Acesso em 29 Abr 2010.

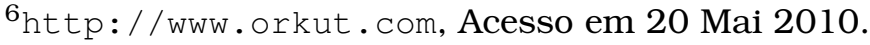


ser utilizadas. Se comparado ao módulo Youtube, o módulo Orkut extrai informações de contexto do usuário, enquanto que o Youtube extrai informações dos vídeos aos quais o usuário assiste.

- Web Video: Manipula as informações do módulo Youtube, bem como de algum outro possível módulo, para extração de informações em repositórios de vídeo. Para um determinado vídeo, é possível extrair diversas outras informações com a construção de outros módulos, como, por exemplo, detalhes sobre a produção do vídeo consultando a base de dados www. imdb. com (Acesso em 29 Abr 2010).

- Open Social: Conjunto de APIs para desenvolvimento de aplicações sociais $^{7}$. Suporta diversas redes sociais, como Orkut, Friendster, LinkedIn, MySpace, dentre outras.

- Conexão HTTP: Conecta os módulos Youtube e Orkut diretamente à Web, pelo protocolo HTTP.

\subsubsection{Fluxo de Informações}

A Figura 6.7 descreve a arquitetura CWaCTool quanto ao fluxo das informações e aos componentes participantes do uso da ferramenta. Os componentes são: (A) o usuário, (B) a ferramenta, (C) a rede P2P e (D) outros sistemas disponiveis online ou por TV.

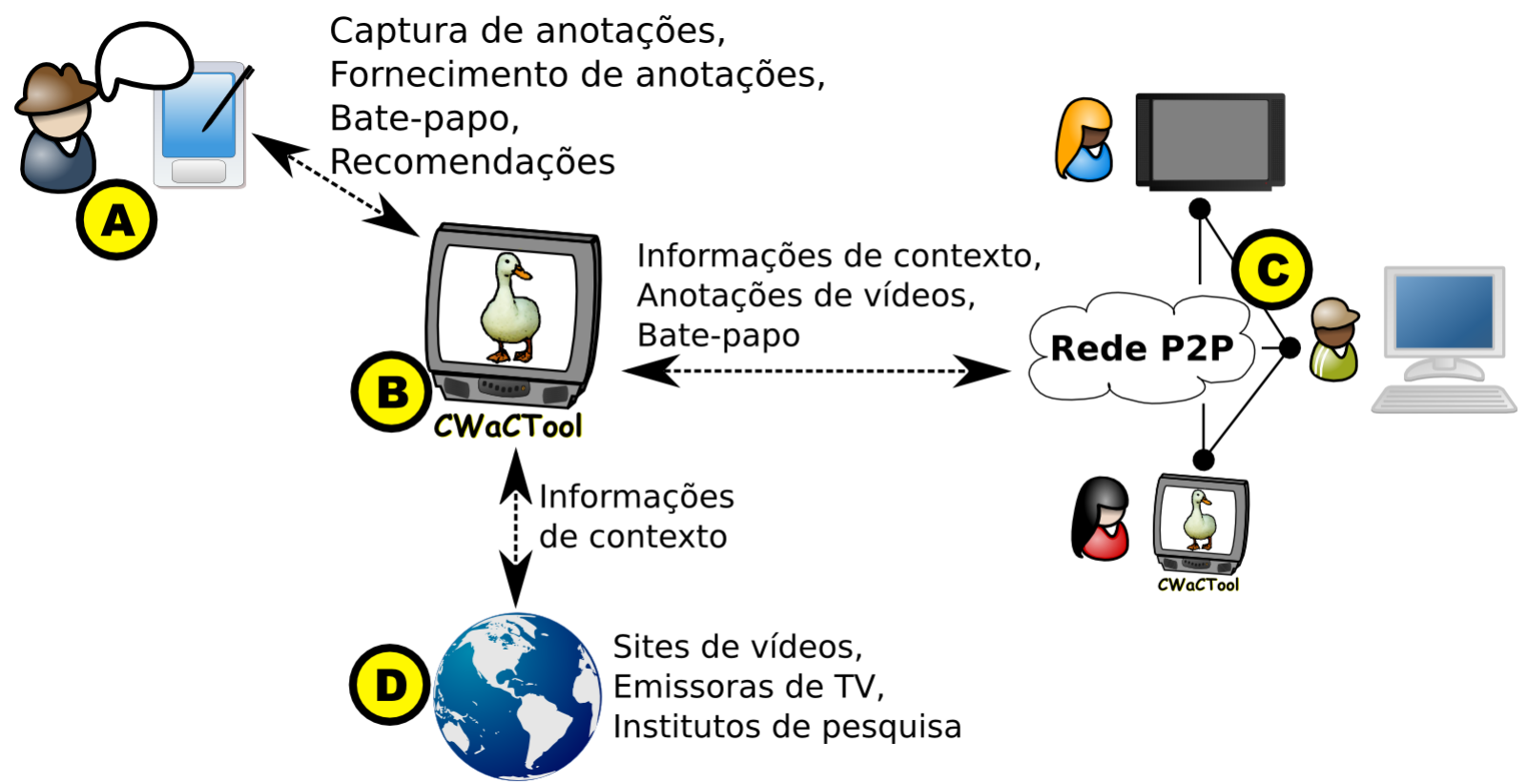

Figura 6.7: Fluxo de informações na arquitetura da CWaCTool.

${ }^{7}$ http://code.google.com/apis/opensocial/, Acesso em 29 Abr 2010. 
O usuário, representado na Figura 6.7(A), interage com a CWaCTool realizando anotações e operações no vídeo ou na TV e usando o bate-papo. A CWaCTool, representada por (B), retorna para o usuário recomendações (de anotações ou de canais de bate-papo) e mensagens de outros usuários.

A rede P2P, na Figura 6.7(C), realiza a troca de informações de contexto, anotações de vídeos e mensagens de bate-papo. As anotações e as interações capturadas por um usuário (A) são processadas em informações de contexto pela CWaCTool (B) e compartilhadas com a rede $\mathrm{P} 2 \mathrm{P}$ (C). A rede pode ser composta (i) por outros usuários de CWaCTool, promovendo os três tipos de trocas, (ii) por usuários de TVDI, que apenas visualizam as anotações dos outros usuários (sem retornar qualquer informação) ou (iii) por usuários de outras aplicações de vídeo.

Outro exemplo de um possível usuário na rede $\mathrm{P} 2 \mathrm{P}$ é alguém utilizar um repositório de vídeos na Internet, como o Youtube, e realizar, pelo site, anotações ou comentários. Nesse caso, a CWaCTool (Figura 6.7.B) se comunica com outras fontes, como sites de vídeos, emissoras de TV ou institutos de pesquisa (D).

\subsection{CWaCTool em Uso}

A terceira versão da CWaCTool apresenta uma interface gráfica reformulada em relação às versões anteriores, porém aproveita os componentes desenvolvidos anteriormente. Essa mudança ocorreu para possibilitar o uso de sites de vídeos, como o Youtube.

Considerando apenas o código fonte da CWaCTool, o total de linhas de código de todas as classes é de pouco mais de 16 mil linhas de código e mais 13659 linhas de comentários em 172 arquivos de classes Java. Ao todo, foram 115 versões enviadas ao repositório de desenvolvimento entre o final da segunda versão e o final da terceira.

A CWaCTool versão 3 pode ser baixada em http: / / cwactool . googlecode. com/ (Acesso em 03 Mai 2010). Quando executada, a ferramenta apresenta uma janela como mostrada na Figura 6.8, requisitando um nome de usuário. Essa janela é responsável não somente por requisitar o nome de usuário, mas também de inicializar a conexão de rede e as bibliotecas de software necessárias para a execução da CWaCTool de acordo com o sistema operacional do usuário. 


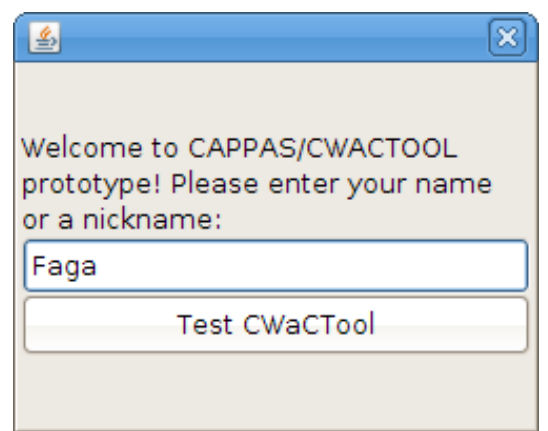

Figura 6.8: Tela de abertura para a CWaCTool, requisitando um nome de usuário.

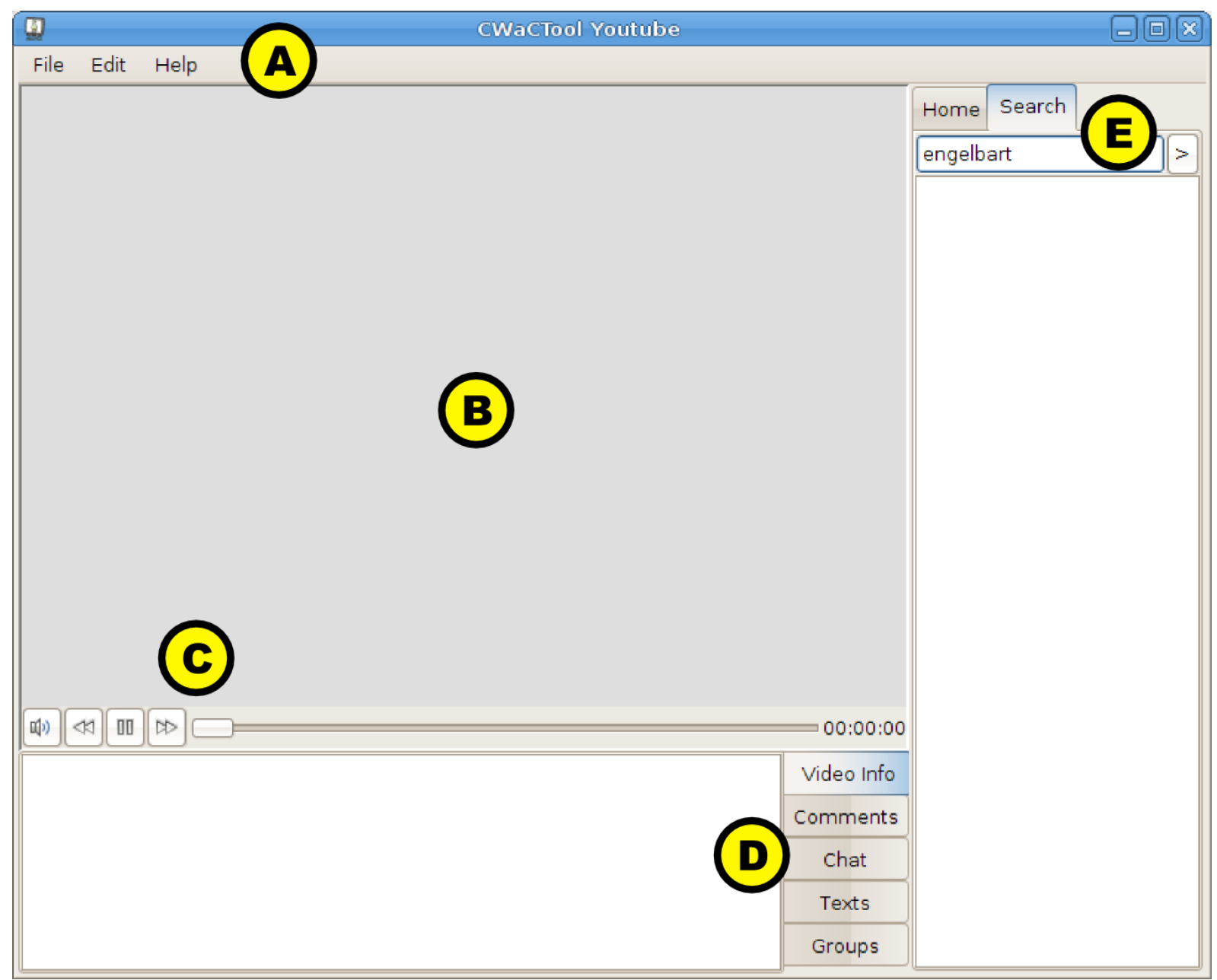

Figura 6.9: Tela inicial da CWaCTool, mostrando os diferentes elementos presentes na ferramenta.

A Figura 6.9 apresenta uma captura de tela da ferramenta em funcionamento, na primeira vez que um usuário está utilizando-a. As regiões destacadas na figura são:

- Em (A), a ferramenta exibe uma barra de menus, com as opções File (para abrir um vídeo do Youtube com a URL ou sair da aplicação), Edit (para editar configurações da ferramenta e ir para o modo de anotação de tinta) e Help, disponibilizando ajuda ao usuário. 
- Em (B), é exibida a área principal de reprodução de vídeos. Diferente da versão anterior, a janela do vídeo não ocupa toda a tela, permitindo a exibição dos painéis lateral e inferior. Quando há um vídeo em reprodução, ao clicar nessa região (B) (no vídeo), é aberta uma janela de opções de anotações ao usuário.

- Em (C), há uma barra de interação padrão de reprodutores de vídeo na Internet, com opções de alterar o volume, retroceder, pausar ou reproduzir e adiantar o vídeo, além de uma barra para deslocar para algum determinado trecho do vídeo. Há ainda um relógio na direita marcando o total de tempo do vídeo.

- Em (D), situa-se o painel inferior, que contém alguns recursos de interatividade. A opção selecionada inicialmente, Video Info, apresenta as informações do vídeo de acordo com o que é extraído do Youtube. A opção Comments exibe os comentários dos usuários no vídeo, relativo ao que está presente no Youtube, e permite a adição de novos comentários. A opção Chat contém uma ferramenta de bate papo em que o usuário lê as mensagens dos outros usuários e escreve o que desejar, além de poder ou não aceitar convites para assistir a um determinado vídeo ou participar de uma sessão de anotação de tinta colaborativa. A opção Texts exibe as anotações de texto dos outros usuários na rede e as realizadas pelo usuário em uma linha do tempo, permitindo também salvar as anotações em um arquivo de legendas. A opção Groups mostra os grupos que o usuário está e os sugeridos para que o mesmo participe.

- Em (E), está o painel lateral, em que estão presentes as abas Home, contendo os vídeos que o usuário possui localmente em sua biblioteca de vídeos, e Search, que tem por objetivo realizar uma busca de vídeos no site do Youtube. Quando uma busca é realizada, o vídeo pode ser selecionado para ser baixado e em seguida reproduzido em (B).

A seguir a CWaCTool é detalhada quanto à sequência de interação, ao uso com redes sociais, às anotações e à conexão de rede.

\subsection{Sequência de Interação para Anotações}

Uma parte importante da CWaCTool é a formalização da interação do usuário no processo de anotação, considerando o usuário, a CWaCTool e a rede. A Figura 6.10 descreve um diagrama de sequência sobre a interação de um usuário reproduzindo um vídeo e realizando anotações colaborativas. A seguir são descritas as etapas dessa interação: 


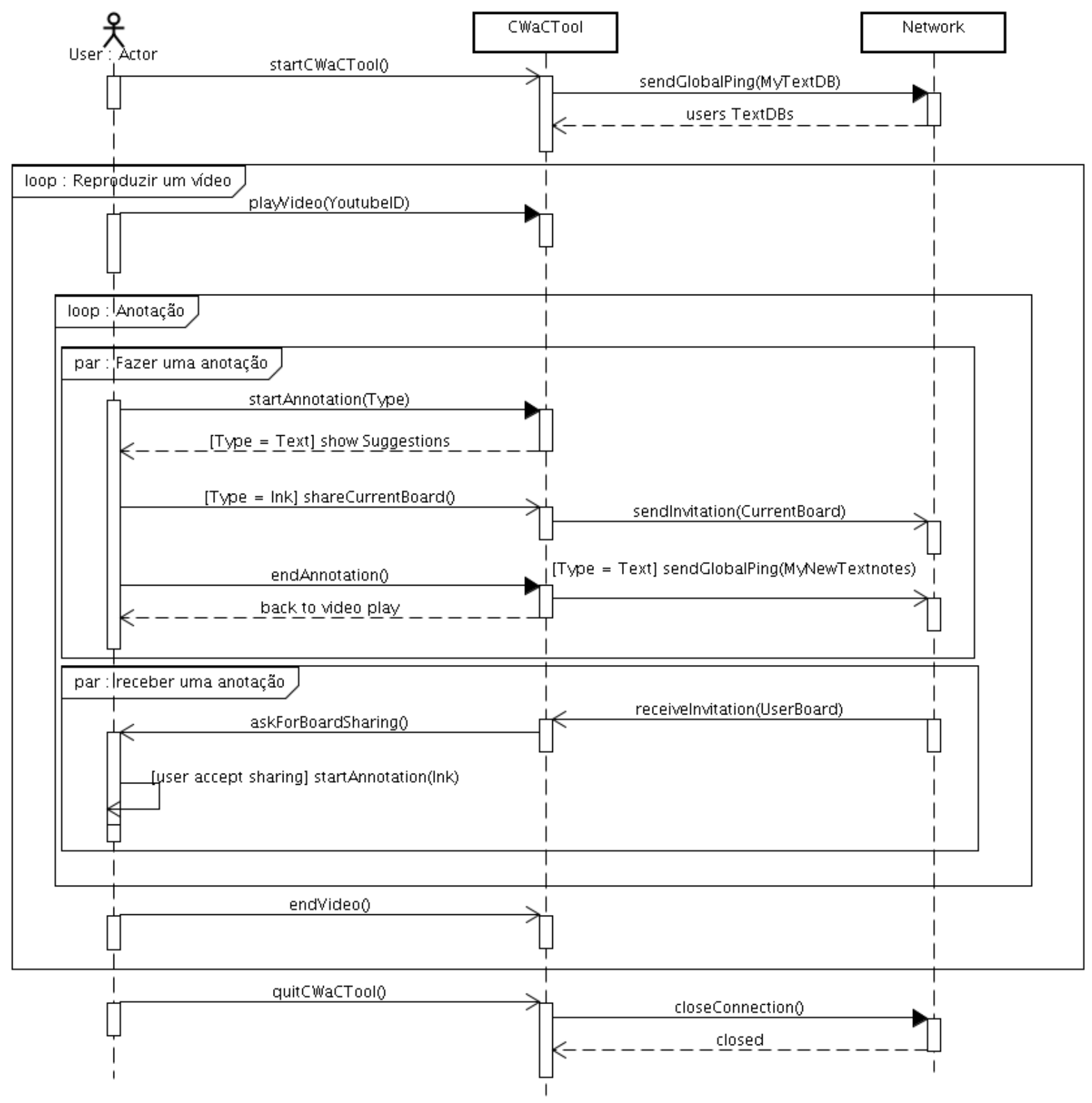

Figura 6.10: Diagrama de sequência sobre um usuário utilizando a CWaCTool para anotação.

- Guando o usuário (User : Actor) inicializa a CWaCTool, a aplicação envia a base de dados de anotações de texto para todos os outros usuários na rede, com o método sendGlobalPing. Como retorno, os outros usuários enviam a base de dados correspondente, podendo ou não realizar cortes do que pode ser relevante (como por exemplo retornar só as anotações associadas a vídeos do mesmo grupo P2P).

- Inicia-se então o bloco loop: Reproduzir um vídeo, a partir da reprodução de um vídeo no Youtube. Antes dessa etapa pode ocorrer a busca de um vídeo. Dentro do bloco, o usuário pode realizar anotações e receber convites para compartilhar anotações de tinta. O laço finaliza quando o 
vídeo acaba ou o quando usuário manda-o parar explicitamente (ambos enviando o método endVideo()).

- Quando iniciado um processo de anotação, no bloco Par: Fazer uma anotação, a CWaCTool pode enviar as sugestões de texto para o usuário, se o tipo de anotação for de texto (show Suggestions). Se for de tinta eletrônica, o usuário pode enviar um convite para compartilhar a sessão (shareCurrentBoard), o qual é enviado para a rede. Quando é encerrada a anotação (endAnnotation()), a CWaCTool envia a nova anotação de texto para a rede, caso a anotação realizada tenha sido de texto (sendGlobalPing).

- Outra possibilidade no processo de anotação é do usuário receber um convite de compartilhamento de anotação de tinta (receivedInvitation e askForBoardSharing). O bloco par: receber uma anotação prossegue então com a anotação caso o usuário aceite, ou ignora caso o usuário recuse o convite.

- Um usuário pode realizar diversas anotações do vídeo e reproduzir quantos vídeos desejar, até finalizar a ferramenta (quitCWaCTool), momento em que a CWaCTool finaliza a conexão com a rede $\mathrm{P} 2 \mathrm{P}$.

Outras opções de interação além da apresentada no diagrama também são possíveis, como buscar outros vídeos, participar do bate-papo ou conferir anotações realizadas anteriormente.

\subsubsection{Integração com Redes Sociais}

Para se obter informações de contexto, a CWaCTool integra-se com redes sociais na Internet, provendo também colaboração entre os usuários. Para tanto, o protótipo foi integrado com duas redes sociais de propósitos diferentes: o Orkut, com o objetivo de se obter informações de contexto do usuário, e o Youtube, com o intuito principal de colaboração e de se obter informações do vídeo.

\subsubsection{Integração com Orkut}

A integração com o Orkut é através da OpenSocial API, que permite a conexão não só com o Orkut mas com diversas outras redes sociais. O objetivo dessa integração é extrair informações de contexto do usuário. Primeiramente, 
o usuário adiciona a aplicação no próprio Orkut, denominada "CAPPAS", obtendo com isso um código, denominado UID. Inserindo esse código na CWaCTool, os dados do usuário são automaticamente adicionados.

As informações de contexto são extraídas no momento em que o usuário insere seu código do Orkut nas preferências do programa. A Figura 6.11 mostra a aplicação Web sendo executada pelo usuário no Orkut, em que é fornecido apenas um código. Além desse código, tal aplicação é necessária para habilitar o acesso de informações do usuário à CWaCTool.

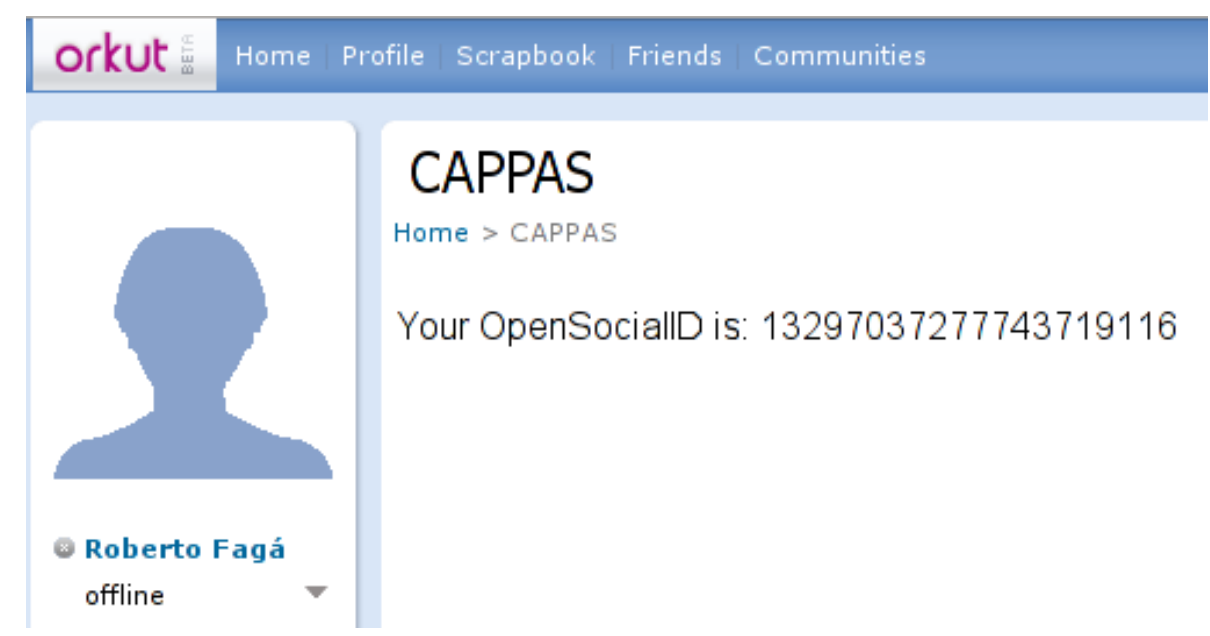

Figura 6.1 1: Aplicação no Orkut exibindo o código UID do usuário.

Em seguida, o usuário deve informar o código gerado, o Orkut UID, na ferramenta CWaCTool, em Edit- > Settings. A Figura 6.12 mostra a tela em que o usuário digita o código e, assim que é clicado em outro lugar da janela de configurações, o código é validado e as informações do usuário são lidas. Nesse momento, as informações já estão armazenadas localmente no usuário.

Quando extraídas as informações de contexto do Orkut do usuário, a CWaCTool obtém, pela classe em Java OrkutOpenSocial, o nome inteiro do usuário, endereço (cidade e país), sexo e a lista de contatos. Com a lista de contatos é possível criar um grupo de amigos, caso os mesmos estejam também na CWaCTool.

\subsubsection{Integração com Youtube}

A CWaCTool v3 permite que vídeos do Youtube sejam visualizados e comentados por diversos usuários na rede da CWaCTool. Com tal adaptação algumas modificações foram necessárias, dentre elas:

- Disponibilidade dos vídeos: Os vídeos estão disponíveis online, ou seja, não seria necessário salvar os vídeos em disco local. Entretanto, a ferramenta está focada para uso em desktops e laptops, que normalmente 


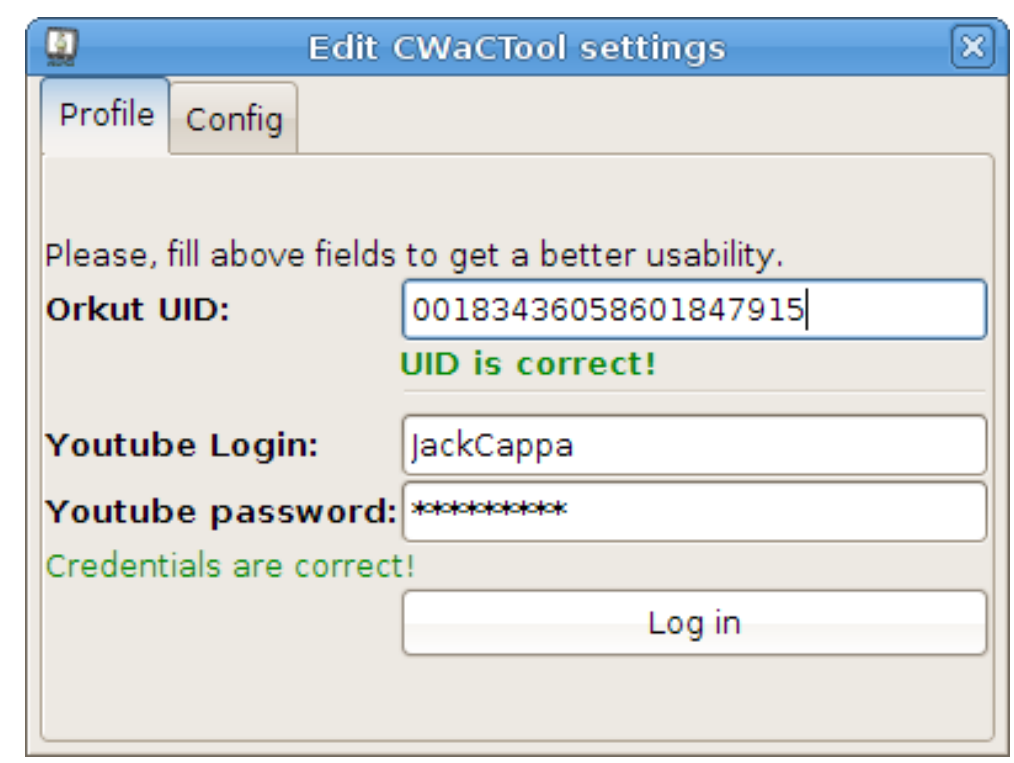

Figura 6.12: Captura de tela da caixa de seleção do Orkut UID, código fornecido quando instalado a aplicação na Web.

dispõem de uma razoável capacidade de disco. Ainda, os vídeos presentes no Youtube costumam ser de curta duração, portanto o espaço de armazenamento necessário é baixo. E por último, o armazenamento em disco permite que usuários possam visualizar os vídeos no Youtube não somente adquirindo a mídia do servidor principal, mas também pela rede P2P.

- Integração de buscar vídeos: Foi incorporado na CWaCTool um serviço de busca de vídeos, podendo ser buscados e baixados diretamente da ferramenta CWaCTool. É possivel ainda compartilhar um vídeo no Chat com outros usuários e abrir um vídeo dado uma URL do Youtube.

- Integração com comentários e informações do vídeo: Outra mudança ocorreu com a incorporação de um visualizador das informações disponíveis no vídeo para o usuário, bem como a integração de comentários do Youtube com a CWaCTool, permitindo o usuário visualizar e realizar comentários sobre o vídeo como um todo.

A busca de vídeos no Youtube pode ser observada na Figura 6.13, que traz uma compilação passo a passo do funcionamento dessa busca. Em (A) o usuário digita uma ou mais palavras-chave para realizar a busca e clica no símbolo >, ou aperta o Enter do teclado para iniciar a busca. A query é então enviada ao Youtube (B) e são retornados os resultados um a um em formato de lista, como mostrado em (C). Quando o usuário clica em um dos resultados, são exibidas em (E) as informações do vídeo, como título, descrição e duração, além de parte do título e duração em (C). 


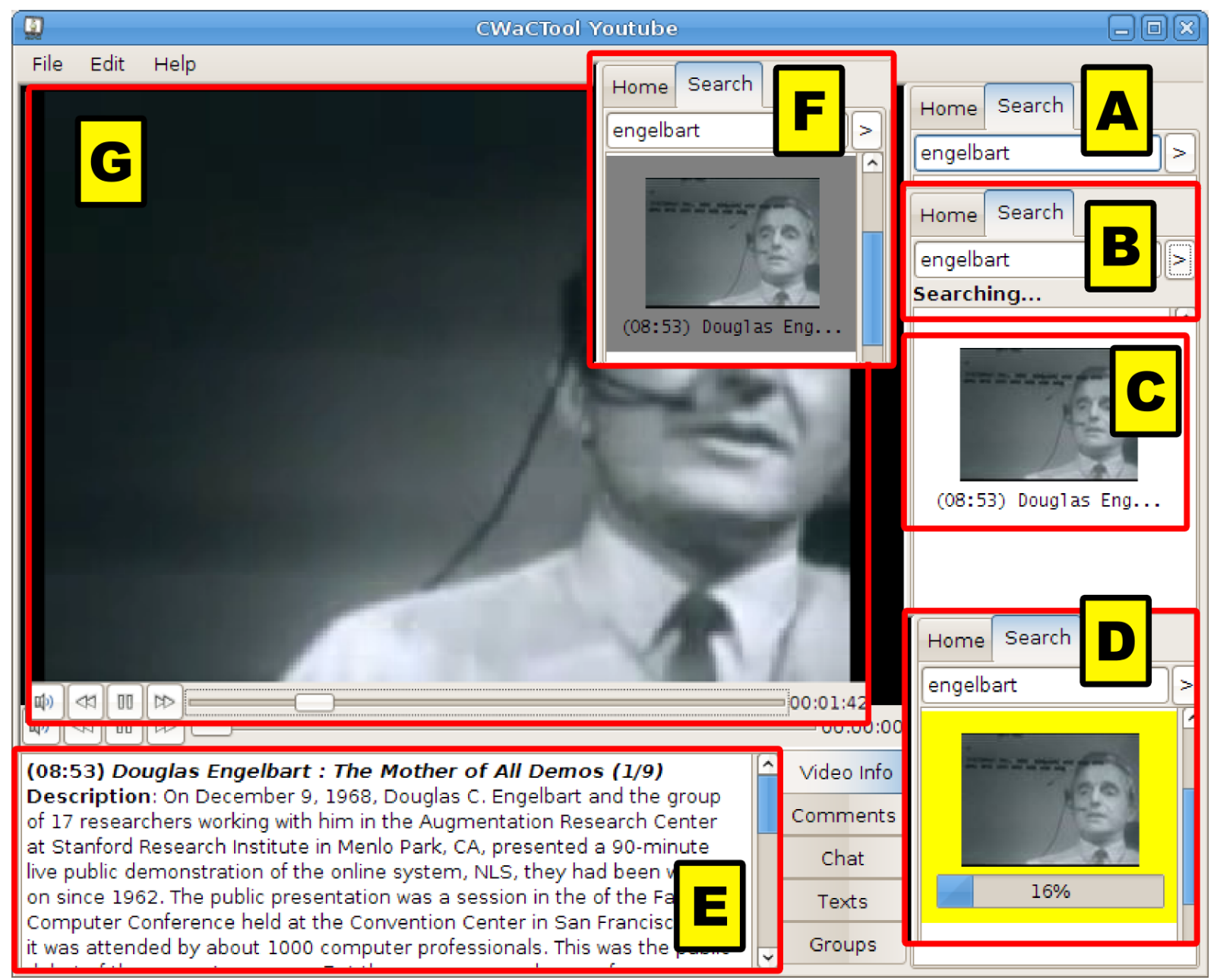

Figura 6.13: Usuário realizando uma busca na CWaCTool, com capturas de tela em etapas: do início da busca em (A) a reprodução final em (G).

Quando em um resultado (Figura 6.13.C) o usuário realiza dois cliques, inicia-se então o processo de copiar o vídeo para o disco local (download), exibindo uma barra de progresso em (D), além da mudança do da cor do fundo do vídeo para o tom amarelo. Enquanto o vídeo é copiado, o usuário pode realizar novamente dois cliques para reproduzir o vídeo (no caso só é reproduzido o trecho que está copiado para o disco local), ou clicar com o direito e cancelar o download.

Quando a cópia é finalizada, a cor do fundo torna-se cinza (F) e o vídeo aparece na Home (biblioteca de vídeos) do usuário. O vídeo pode então ser reproduzido $(G)$, compartilhado no bate-papo ou excluído (essas duas últimas opções são realizadas com o clique direito).

Outro recurso presente é a integração de comentários do Youtube, que permite que o usuário visualize os comentários de outros usuários ou realize seus próprios comentários. A Figura 6.12, apresentada anteriormente, mostra os campos que o usuário pode, opcionalmente, entrar com seus dados de acesso do Youtube. Quando autenticado, a aba do painel inferior relacionada 
aos comentários (Comments) habilita o botão de realizar comentários, como exibido na Figura 6.14.

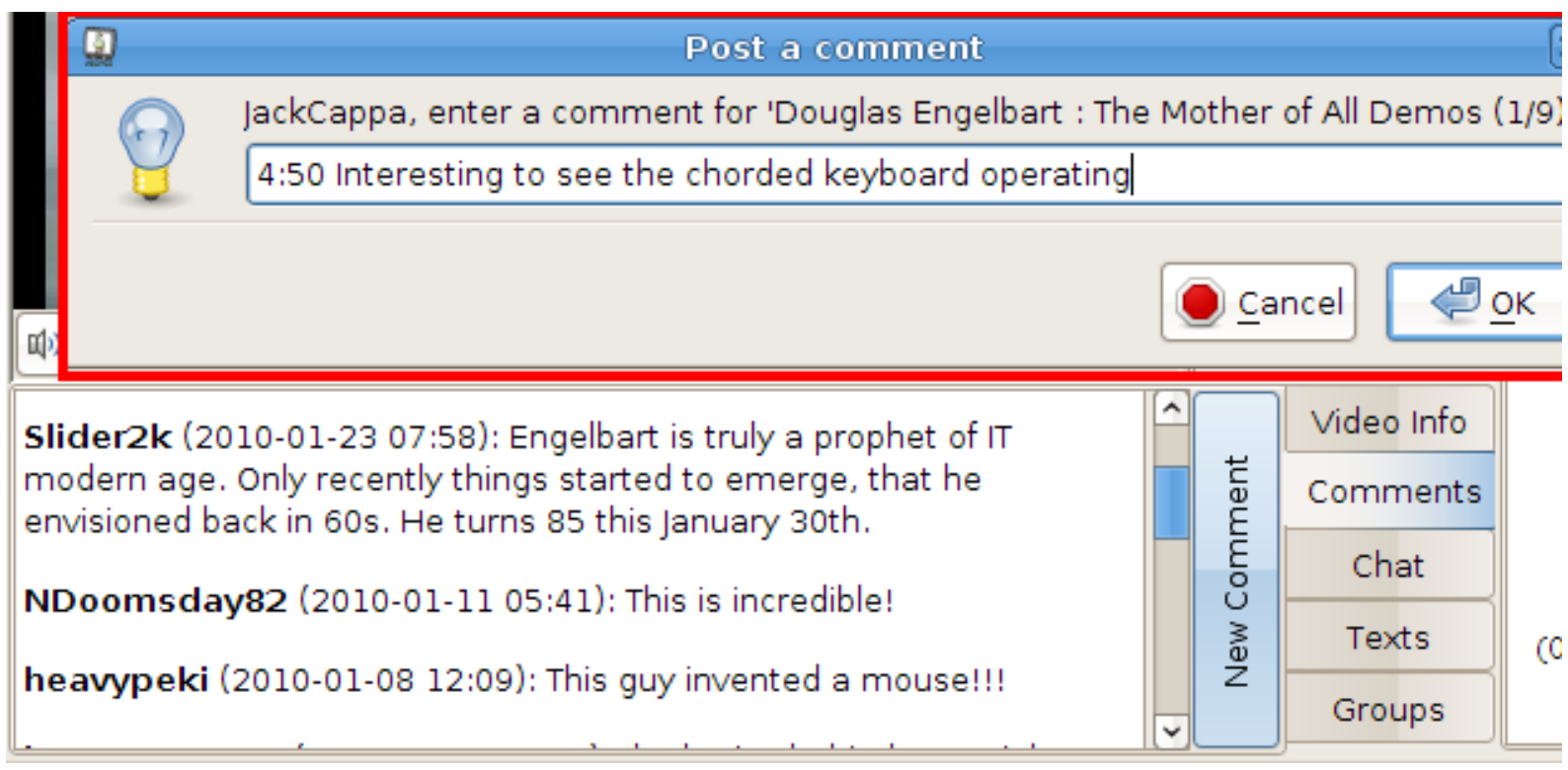

Figura 6.14: Parte da CWaCTool exibindo o painel inferior com os comentários do atual vídeo em reprodução e uma janela pop-up com uma anotação sendo realizada.

Os comentários de um vídeo são sempre recarregados quando o usuário o reproduz do início, ou seja, quando efetua dois cliques em um vídeo. A Figura 6.14 mostra na região superior uma janela pop-up com um espaço para o usuário digitar um determinado comentário. O começo do comentário pode ser já preenchido pela CWaCTool. A região inferior da Figura 6.14 mostra os comentários de outros usuários e o botão para realizar um comentário (New Comment).

Quando realizado um comentário, o mesmo fica disponivel no site do Youtube, permitindo que mesmo pessoas sem a CWaCTool possam, de algum modo, interagir, como apresentado na Figura 6.15.

A integração com uma rede social de vídeos é interessante pois permite que, diferentemente de como ocorre atualmente no Youtube e em outras redes, haja o compartilhamento de anotações em torno de vídeos na Web. Atualmente alguns desses Websites já oferecem sistemas de anotações de vídeos, entretanto se limitam a anotações de texto e não colaborativo.

\subsubsection{Anotações}

A CWaCTool oferece as anotações de tinta, texto e voz, sendo as duas primeiras de modo colaborativo. A anotação de voz não é colaborativa, e é iniciada e 


\section{Douglas Engelbart : The Mother of All Demos (1/9)}

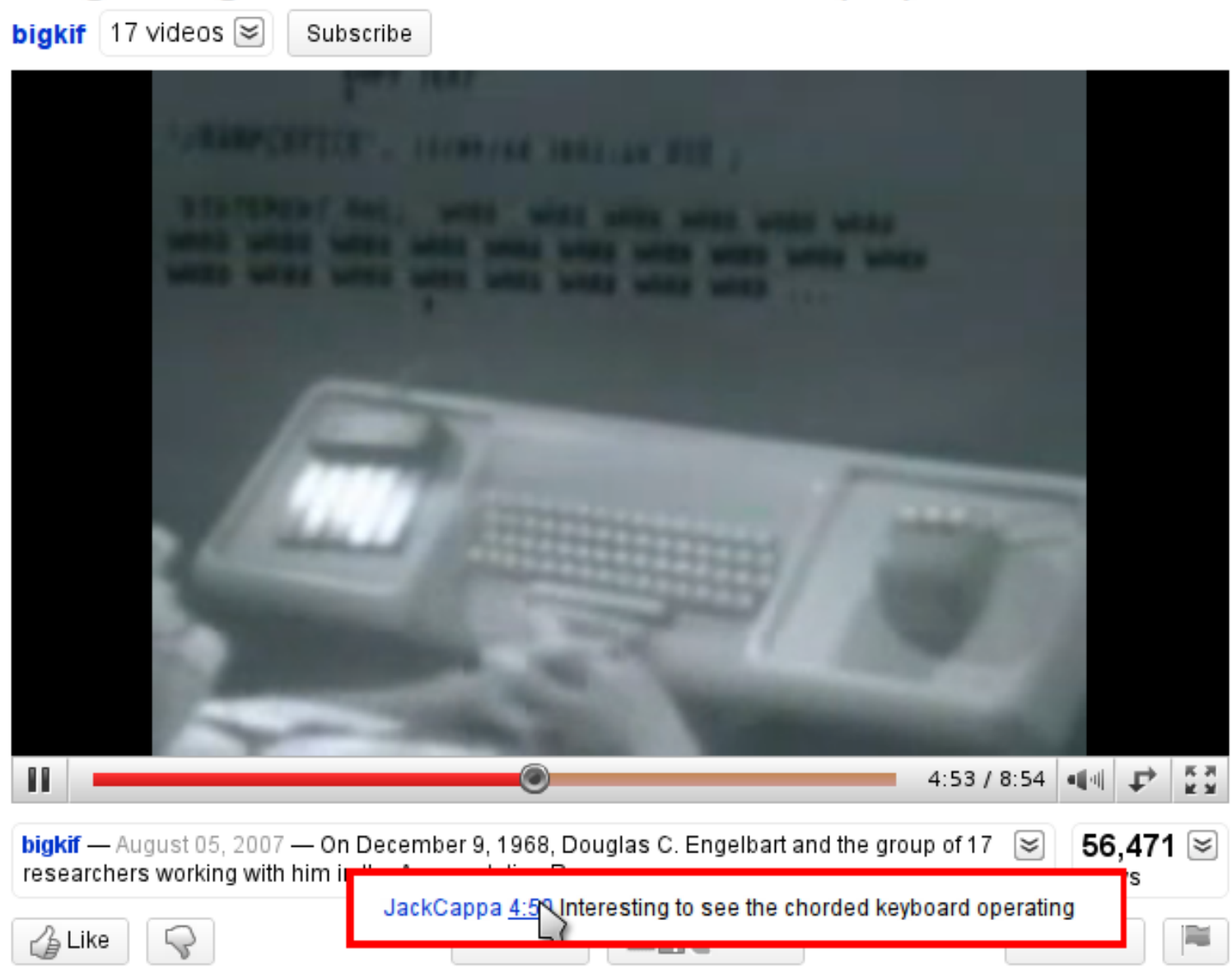

Figura 6.15: Site do Youtube com o novo comentário inserido pela CWaCTool, referenciando o tempo da anotação para o vídeo saltar ao ponto correspondente no vídeo.

finalizada na mesma janela de anotações, semelhante ao funcionamento na WaCTool. A seguir são detalhados os processos de anotação de tinta e texto.

\subsubsection{Anotações de Tinta}

As anotações de tinta funcionam do mesmo modo que a CWaCTool v2, incluindo o suporte a anotações colaborativas. Conta apenas com algumas mudanças, como mostradas na Figura 6.16.

Quando um usuário escolhe um vídeo para reproduzir, como mostrado na Figura 6.16(A), ele pode realizar uma anotação com um clique na região do vídeo e escolher InkNote (F). Outra opção é receber um convite de sessão, como exibido em (B). Uma vez iniciada a Whiteboard, o vídeo continua a reprodução em miniatura (E) enquanto que uma barra de ferramentas (C) e uma superfície de desenho (D) aparecem na ferramenta. 


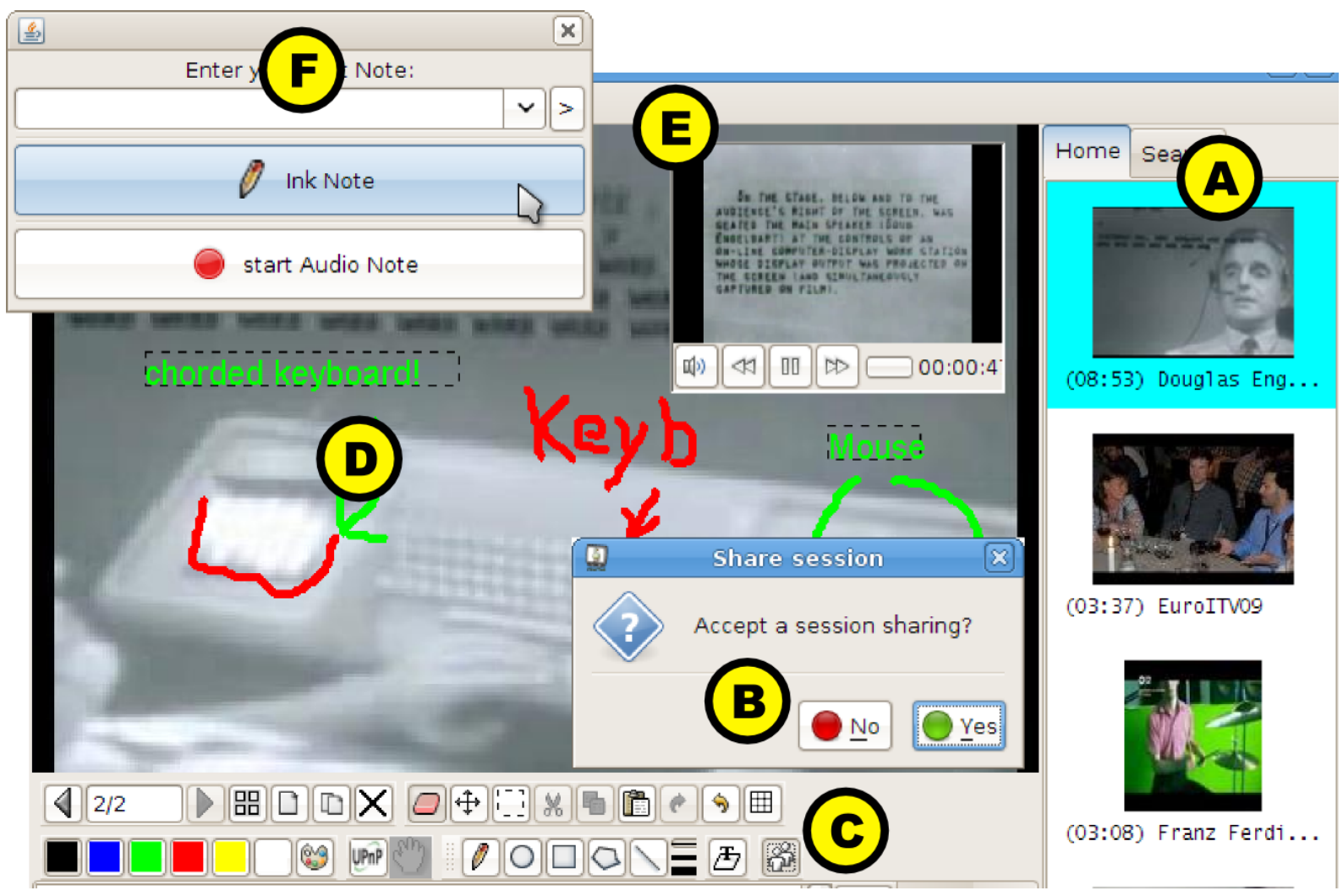

Figura 6.16: Anotação de tinta, em que o usuário compartilha um vídeo (A) ou aceita um convite $(B)$ e realiza anotações de tinta em (D).

Quando a Whiteboard está em modo colaborativo, ou seja, em compartilhamento com algum outro usuário, o ícone presente da Figura 6.16(C) mantémse como um botão pressionado. O mesmo botão pode ser utilizado para encerrar uma sessão compartilhada ou enviar o convite aos usuários do grupo.

\subsubsection{Anotações de Texto}

As anotações de texto ocorrem em relação a uma determinada posição no vídeo, e podem ser análogas a legendas de vídeos. Entretanto, a ideia não é escrever as falas presentes nos vídeos (legendas), mas sim anotar momentos relevantes do vídeo. As anotações dos usuários são compartilhadas com todos os outros de um mesmo grupo, e permite que um usuário realize anotações de texto com sugestões das anotações de outros usuários, bem como visualize as anotações destes e incorpore-as às suas.

A Figura 6.17 mostra o processo de anotação de texto de um usuário e a visualização das anotações realizadas. Quando um usuário clica na janela do vídeo (B), em qualquer momento da reprodução do vídeo, é aberta a janela (C), enquanto que o vídeo permanece em reprodução ${ }^{8}$. O usuário então pode

\footnotetext{
${ }^{8} \mathrm{O}$ vídeo era antes pausado quando o usuário clicava para realizar uma anotação. Entretanto houveram várias reclamações dos usuários requisitando que o vídeo não pausasse enquanto se anotava.
} 


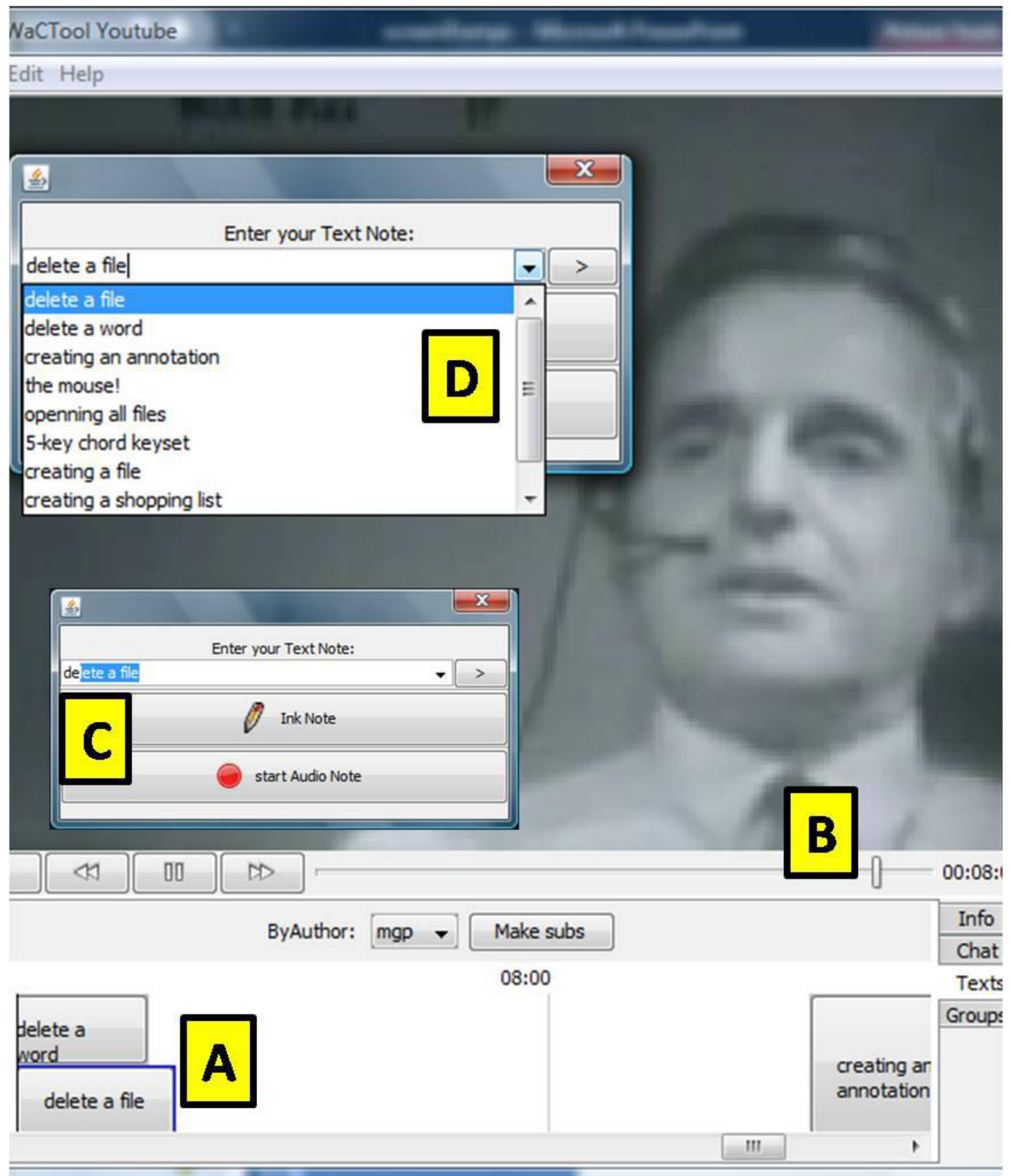

Figura 6.17: Anotação de texto, em que o usuário digitou apenas as duas primeiras letras e o restante é sugerido de acordo com o trecho do vídeo e anotações de outros usuários (C). Uma seta, na direita do campo de texto, permite selecionar outras sugestões (D) e ainda ver na linha do tempo (A) o vídeo (B).

começar a digitar uma anotação de texto e esta ser auto completada, caso haja algum registro de outro usuário ou do mesmo usuário em outro momento (D).

A sugestão de novas anotações é realizada com base em uma contagem do total de anotações realizadas no mesmo vídeo de todos os usuários. Quanto mais vezes uma mesma anotação é realizada em um vídeo e quanto mais 
próxima do instante em que se deseja anotar, maior a classificação dessa anotação e mais acima ela vai aparecer na lista de sugestões. Quando o usuário digita uma letra, a CWaCTool cria uma lista de possibilidades que se encaixem iniciando-se com as letras já digitadas, sugerindo auto completar a frase ou uma lista com outras sugestões. Na CWaCTool, as classes Java do pacote "br.fapesp.tidia.ae.wac.cappas” são as responsáveis por esse processamento.

As anotações realizadas por todos os usuários de um grupo que o usuário faça parte são exibidas na timeline, na Figura 6.17(A). É possível utilizar um filtro para visualizar as anotações por autor (na figura são mostradas as anotações do usuário "mgp”), criar legendas em um arquivo separado ${ }^{9}$ e manipular as anotações. Quando as legendas são criadas em arquivo separado, é possivel visualizar as anotações em forma de legendas na própria CWaCTool, sendo exibidas no canto superior direito do vídeo.

Ao clicar em uma anotação, selecionando o retângulo correspondente (como o selecionado delete a file da Figura 6.17), o usuário pode clicar novamente para pular para o trecho correspondente à anotação ou clicar com o direito para remover o comentário.

As anotações de tinta ocorrem em um determinado quadro do vídeo quando o usuário clica sobre o vídeo, este é congelado e o quadro congelado é o de anotações por tinta. Utilizando um dispositivo com suporte a captura de tinta eletrônica, como um Tablet PC, é possível então compartilhar tal quadro com outros usuários, em que todos podem realizar as anotações em um mesmo slide de modo síncrono.

\subsubsection{Conexão de Rede}

Semelhante ao funcionamento da WaCTool, a CWaCTool utiliza uma rede P2P para realizar conexão entre os usuários, como previsto pelo modelo CAPPA, além de uma arquitetura de servidores de Broadcast. Cada uma dessas arquiteturas contribuem para permitir que a CWaCTool possa gerenciar grupos, possibilitando ao usuário participar de Grupos P2P, de acordo com afinidades com outros usuários.

Um Grupo P2P é formado por usuários com algum interesse em comum, seja pela rede $\mathrm{P} 2 \mathrm{P}$ ou pelos servidores de Broadcast, cujo interesse pode ser explícito (o usuário escolhe o grupo) ou recomendado pela ferramenta. Cada

\footnotetext{
${ }^{9} \mathrm{O}$ formato de saída é denominado SRT, compatível com diversos reprodutores de vídeo. Mais informações em http://www. matroska.org/technical/specs/subtitles/srt. html, Acesso em 03 Mai 2010.
} 
usuário pode participar de diversos grupos P2P, em que suas informações de contexto são compartilhadas com todos os grupos.

\begin{tabular}{|c|c|c|}
\hline \multirow{4}{*}{$\begin{array}{l}\text { Faga: hi everyone, I'm here } \\
\text { mgp: hi faga, check this video } \\
\text { mgp: * sharing video: } 3 \text { D Medical Animation: Antibody Immune } \\
\text { Response } \\
\text { Faga: got it... checking your notes } \\
\text { ** mgp wants to share a session with you. ** } \\
\text { Faga: cool }\end{array}$} & $\hat{n}$ & Video Info \\
\hline & & Comments \\
\hline & & Chat \\
\hline & & Texts \\
\hline & & Groups \\
\hline
\end{tabular}

Figura 6.18: Chat da ferramenta, com um usuário compartilhando um vídeo e em seguida compartilhando uma sessão de anotação de tinta.

No bate papo da CWaCTool (Chat), um usuário pode compartilhar algum vídeo que esteja em sua Home (clique direito -> share this video) ou compartilhar uma sessão de tinta, além de poder enviar mensagens de texto. A Figura 6.18 mostra um exemplo em que o usuário "mgp" envia o convite para compartilhar um vídeo primeiro e cada usuário pode clicar para receber ou ignorar. Depois, o mesmo usuário envia um convite para compartilhar sessão de anotação de tinta.

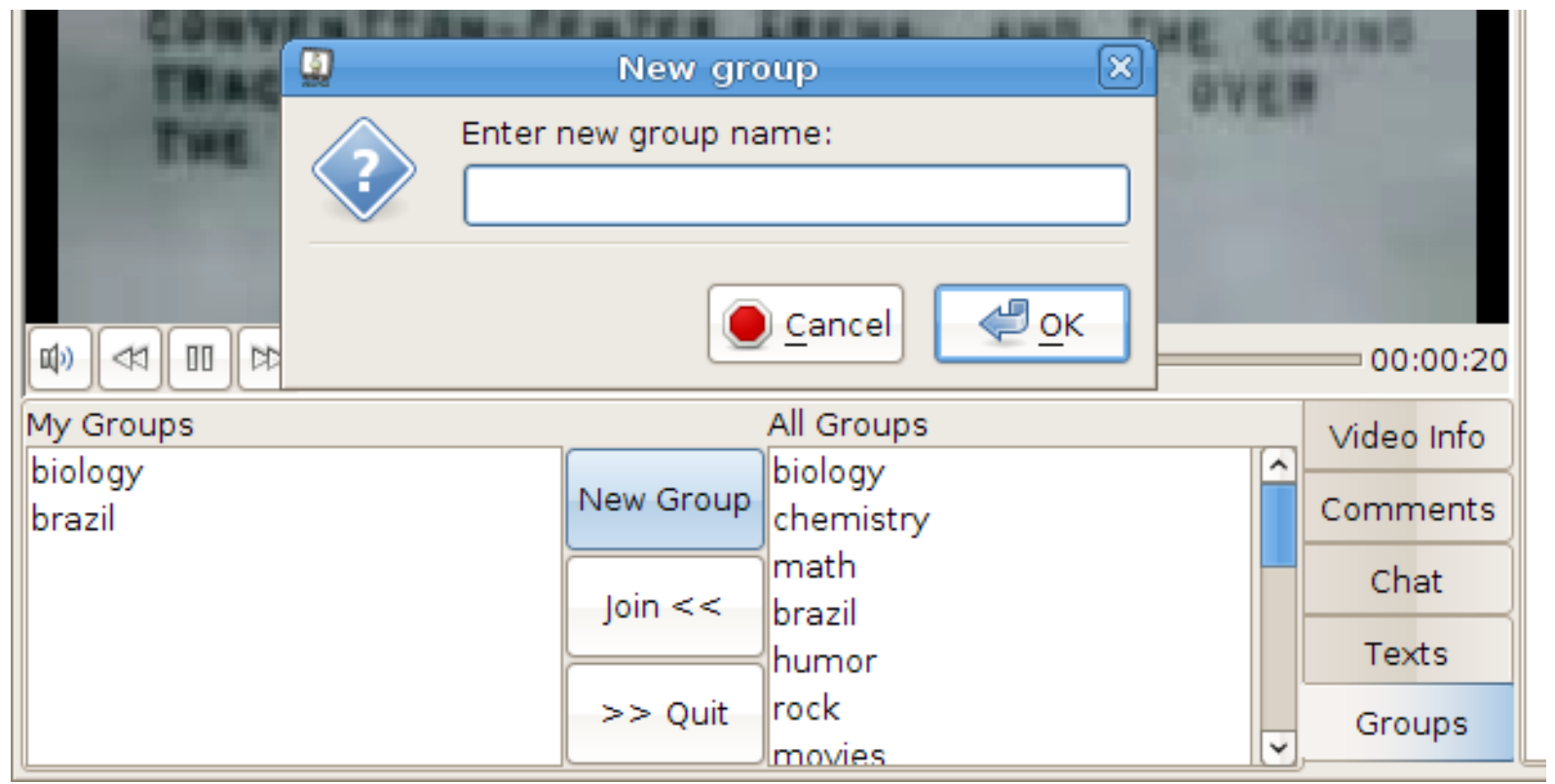

Figura 6.19: Seleção e gerenciamento dos grupos participantes pelo usuário.

Outro recurso presente na interface gráfica é a escolha dos grupos participantes e disponíveis ao usuário, com uso do componente Groups. Na Figura 6.19 é possível selecionar, à esquerda (My Groups), qual o grupo participante do bate-papo, dentre os grupos que o usuário atualmente faz parte. $\mathrm{Na}$ direita, o usuário pode selecionar um grupo de uma lista de outros disponíveis (All Groups), ordenados de acordo com a recomendação. Há também uma 
janela em pop-up requisitando um novo nome para um grupo, caso o usuário prefira criar um novo que não esteja na lista.

Para classificar os grupos em ordem de recomendação, a CWaCTool considera as categorias dos vídeos mais reproduzidos pelo usuário. A lista de grupos disponíveis é atualizada de acordo com o que é recebido dos outros usuários.

O último recurso presente na interface gráfica que utiliza diretamente a rede é o compartilhamento de sessões de tinta, como já detalhado anteriormente.

Um elemento adicionado na CWaCTool é um servidor de Broadcast. Seu objetivo é registrar as interações e colaborações dos usuários, para análise estatística e de uso, bem como para atuar como conexão entre peers quando a rede P2P não está disponível.

Cada interação que o usuário realiza no protótipo é enviada ao servidor apenas, e não à rede P2P também. Esse recurso foi adicionado aplicação nas avaliações, possibilitando que se realize análises diversas como tempo de uso, anotações realizadas, sugestões de texto utilizadas, dentre outras ações apresentadas na Seção 6.5.

Outra utilidade desse servidor é atuar quando a rede P2P não estiver disponível. Problemas como firewalls ou outros de conectividade podem impedir o usuário de se conectar por essa rede, podendo assim utilizar um servidor de Broadcast para conectar-se a outros usuários.

Como previsto no modelo CAPPA, a aplicação deve dimensionar os servidores de Broadcast de acordo com a demanda. No caso da CWaCTool, apenas um servidor foi utilizado. O servidor replica as mensagens para todos os outros usuários independente dos grupos participantes, entretanto os usuários consideram os grupos para aceitar ou não tais mensagens.

\subsection{Avaliação CWaCTool}

Existem diversas técnicas específicas para se avaliar interfaces de TVDI, como as apontadas por Piccolo e Baranauskas (2006). Os autores apontam ainda que, apesar de existirem diversas diferenças no uso de TV e um PC, as interfaces gráficas compartilham muitos elementos em comum.

Cattelan et al. (2008a) aponta uma avaliação heurística e uma avaliação Think Aloud realizadas com usuários na WaCTool, em que foram encontrados alguns problemas de uso, como (i) o status dos botões que deveriam ser 
alterados quando são pressionados, (ii) os ícones que deveriam ter textos descrevendo o que realizam e (iii) mais atalhos para as ações. Outros problemas menores também foram identificados, e foram considerados para a construção da CWaCTool.

Como a CWaCTool é uma ferramenta com objetivos de aumentar a socialização e melhorar o uso em anotações de vídeo e TVDI, foram aplicados testes de usabilidade com usuários e especialistas, como discutidos a seguir. Os testes foram aplicados em grupos de usuários, com uso de colaboração nas anotações, reforçando alguns benefícios como os apontado por Shrimpton-Smith et al. (2008).

\subsubsection{Avaliações com Usuários}

As primeiras avaliações realizadas na CWaCTool são detalhadas por Motti et al. (2009), considerando três avaliações diferentes: uma avaliação de Percurso Cognitivo, uma avaliação de Think Aloud e um questionário de avaliação, aplicado duas vezes. Os formulários aplicados são apresentados no Apêndice A.

Com o lançamento do primeiro protótipo da CWaCTool, foi aplicado o Percurso Cognitivo em cinco usuários. Cada usuário analisou cinco funcionalidades no processo de anotação, detectando problemas que resultaram em cinco principais sugestões e alterações: (i) é necessário um atalho visível para a Whiteboard, que não só clicando no vídeo, (ii) o botão de compartilhamento de tinta é pouco visível, (iii) a faixa amarela presente no bate papo chama muito a atenção do usuário, (iv) falta um botão ou menu de ajuda e (v) falta um menu geral.

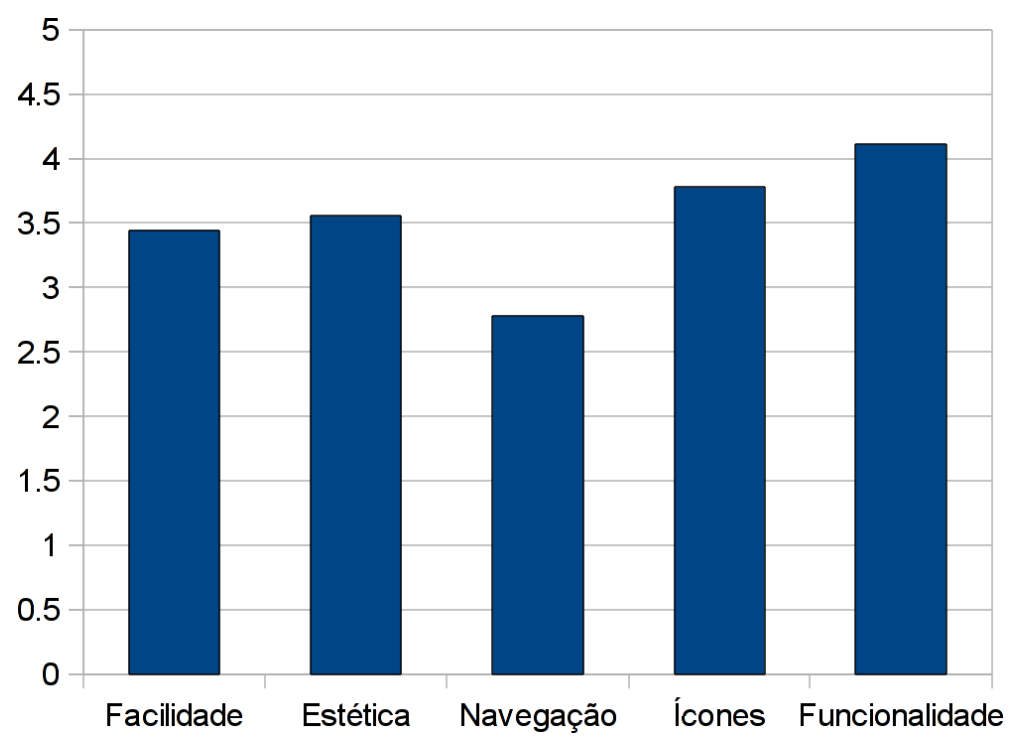

Figura 6.20: Médias das pontuações relativas a avaliação Likert com 10 usuários. 
Outro teste realizado foi um questionário de avaliação, contando com cinco perguntas em uma escala Likert de cinco pontos. O usuário pôde então determinar em uma escala de 1 a 5 o quão útil, bom ou fácil era cada item. As cinco perguntas são referentes a facilidade de uso, estética do sistema, facilidade de navegação, design dos ícones e funcionalidade da ferramenta. O teste foi realizado primeiramente na versão preliminar da CWaCTool v1, obtendo-se os resultados apresentados na Figura 6.20. Os dez usuários avaliaram com notas altas, mas apontaram problemas na navegação e facilidade, que obteve nota inferior a 3,5.

Após alterações na navegação e contando com um guia de ajuda para o uso da ferramenta, foi lançada a CWaCTool v1 e avaliada novamente pelo mesmo questionário de avaliação Likert, dessa vez com 22 potenciais usuários de diferentes áreas (incluindo Guímica, Ciência da Informação e Física), além de especialistas em TVDI e em computação. Os resultados são apresentados na Figura 6.21, que aponta melhora em relação ao teste anterior, principalmente na facilidade e nos ícones.

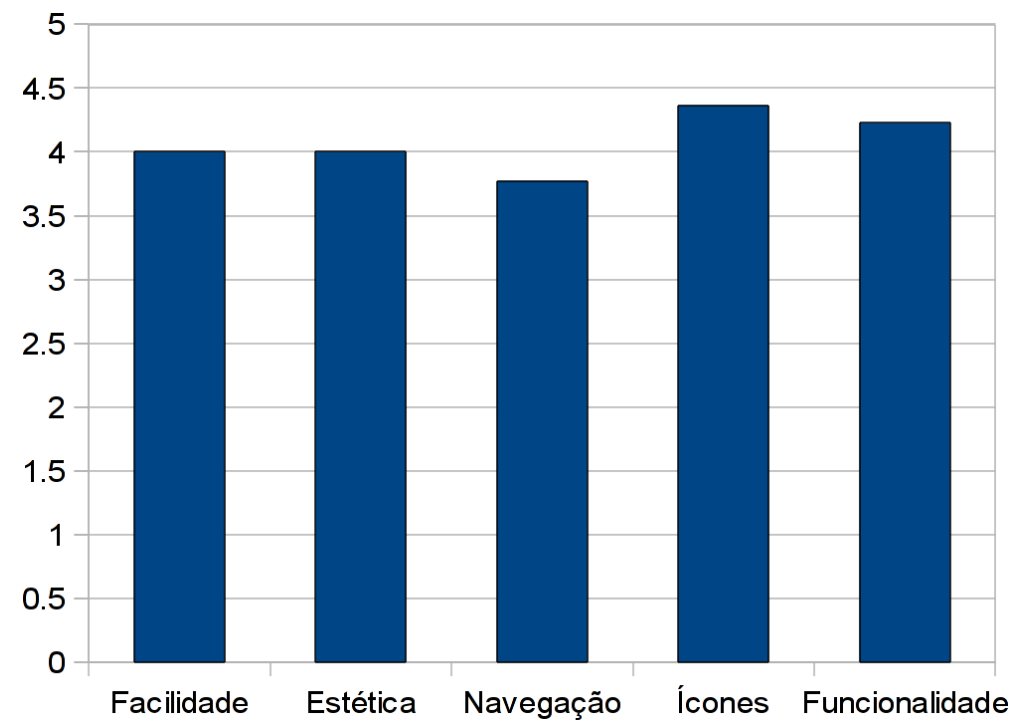

Figura 6.21: Médias das pontuações relativas a avaliação Likert com 22 usuários na CWaCTool $v 1$.

Dentre algumas sugestões fornecidas nessas primeiras avaliações, constam a integração das janelas da CWaCTool em uma única janela, um menu de opções de interação e aviso de quando um usuário entra na sala de bate-papo. Essas sugestões foram implementadas na CWaCTool nas versões posteriores.

\subsubsection{Estudo de Caso}

Com a conclusão da segunda versão da CWaCTool, foi observada a dificuldade de se realizar testes com usuários, uma vez que a simulação de TVDI 


\begin{tabular}{|c|c|}
\hline Ação & Quantidade \\
\hline \hline Anotações em texto & 49 \\
\hline Sugestões de texto utilizadas & 19 \\
\hline Mensagens no Chat & 9 \\
\hline Anotações em tinta & 28 \\
\hline Anotações em tinta compartilhadas & 4 \\
\hline Anotações em voz & 12 \\
\hline Reproduzir um vídeo & 167 \\
\hline Total de anotações & 89 \\
\hline Usuários online & 18 \\
\hline
\end{tabular}

Tabela 6.1: Ações dos usuários realizadas no estudo de caso da CWaCTool.

requereria diversas alterações na aplicação, como tornar o uso de dispositivo apontador facultativo. Perante os esforços e discussões com outros pesquisadores (Gomes, 2010; Furtado, 2010; Maximino, 2009), a terceira versão foi implementada, considerando ainda os aspectos das avaliações anteriores e trabalhos relacionados.

Estudo de caso, segundo Yin (2008), é uma investigação empírica que tem por objetivo investigar um fenômeno inserido em um contexto da vida real. Para a avaliação final do protótipo, foi escolhido um estudo de caso por ser um método qualitativo de análise, o que é apontado como mais apropriado para sistemas computacionais ubíquos por Neely et al. (2008).

Para aferir a qualidade das sugestões de texto e sua utilidade, foi realizado um estudo de caso com 18 alunos de graduação em Ciências da Computação da Universidade de São Paulo, na disciplina de Interação UsuárioComputador. Os alunos utilizaram ao mesmo tempo a CWaCTool v3 em um laboratório de computação, onde costumam ter aulas práticas. Os usuários também não possuíam caneta para anotação em tinta eletrônica, pelas limitações do laboratório, mas alguns possuíam microfones.

Nesse contexto, os alunos tiveram como tarefa utilizar a CWaCTool para avaliar quatro vídeos, presentes no Youtube, sobre usabilidade. Dois deles eram gravações de algum usuário realizando percurso cognitivo e os outros dois realizando think aloud. Os alunos foram instruídos a então analisar os vídeos para encontrar os momentos em que o usuário apresentasse alguma dúvida ou dificuldade e, se desejado, marcar o momento com alguma anotação. A ferramenta não foi explicada aos detalhes, apenas foi demonstrado como se buscar, baixar um vídeo e que um clique no vídeo abriria uma janela de anotações, com o objetivo de se analisar se a curva de aprendizado da CWaCTool é pequena.

Ao todo, os 18 usuários realizaram 89 anotações em um intervalo de tempo de 40 minutos. A Tabela 6.1 apresenta ações dos usuários e algumas esta- 


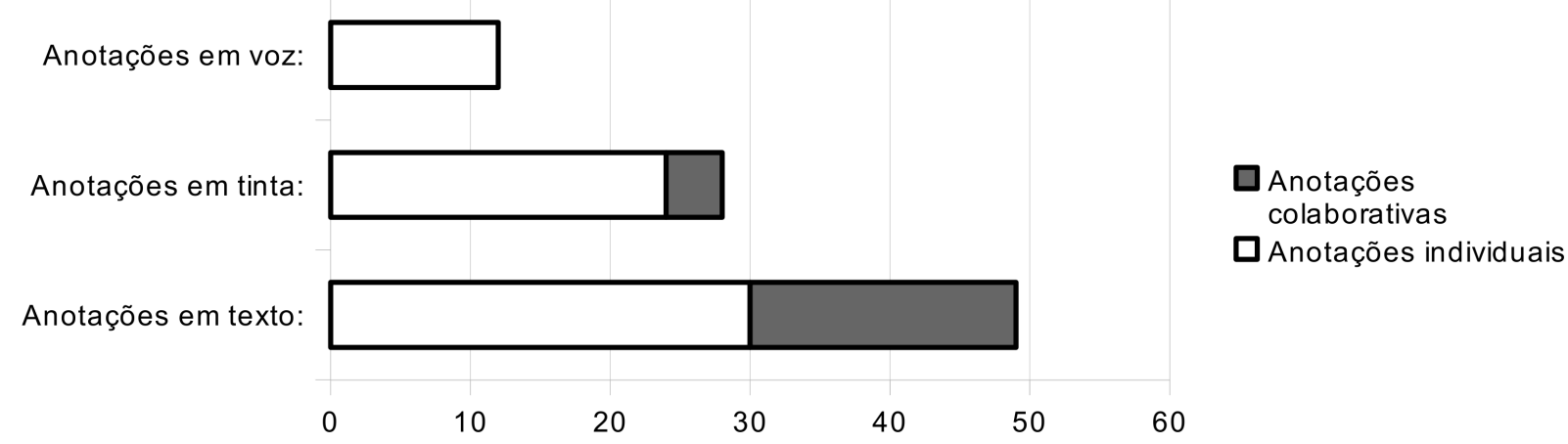

Figura 6.22: Anotações realizadas classificadas por tipo (voz, texto e tinta) e se foi colaborativa ou individual.

tísticas, capturadas automaticamente pelo servidor de Broadcast durante o uso da CWaCTool. Por exemplo, é possível analisar que a maior quantidade de anotações foi realizada por texto, seguida de tinta e voz. Também é possível notar um baixo número de mensagens no bate-papo (Chat), possivelmente pelo experimento ter sido realizado com os usuários se comunicando verbalmente por estarem na mesma sala.

A Figura 6.22 apresenta os três tipos de anotações classificadas como colaborativas ou individuais, isso é, sincronas de tinta eletrônica na Whiteboard ou utilizando sugestões de textos de anotações de outros usuários. É possível notar, analisando a tabela e a figura, que 38.78\% dos usuários utilizaram sugestões de outros usuários ao realizarem anotações de texto, enquanto que 14.29\% utilizaram sessões de tinta compartilhadas. O número de anotações por voz (12) também é considerável, e mostra que os três tipos de anotações foram bem utilizados.

Após os alunos utilizarem a ferramenta, foi aplicado um questionário com perguntas sobre o conteúdo na primeira parte, isso é, métodos de avaliação com usuários, uma vez que o estudo de caso considerou vídeos nesse assunto. A outra parte do questionário foi relativa ao uso da ferramenta, sendo possível também retirar outras conclusões sobre a CWaCTool. O questionário possuía as seguintes questões relativas à CWaCTool:

- Durante o processo de anotação nos vídeos, foi utilizada alguma sugestão de texto?

- Quais os métodos de anotação que foram utilizados no processo de anotação?

- No caso de ter ocorrido anotações com tinta, foi utilizado sessão compartilhada? A colaboração influenciou no processo de comentários? 
- Foram visualizados os comentários de outros autores na "timeline"? Isso influenciou nos seus comentários?

- Descreva, sob seu ponto de vista, qual a influência que anotar sobre um vídeo teve quanto a analisar os dois experimentos com usuário. Procure responder o que considerou cômodo, incômodo e alternativas para o uso da ferramenta CWaCTool.

A segunda questão sobre a CWaCTool dava ao usuário as opções de quais tipos de anotações foram realizadas. A maior parte dos usuários realizaram apenas anotações de texto (14 usuários), sendo que foram poucos os que realizaram os três tipos de anotações (voz, tinta e texto - apenas dois usuários). Outro fato interessante é que 10 usuários informaram ter utilizado anotações por voz, o que conclui-se que o uso de voz pode ter sido apenas experimental ou de uma a duas anotações por usuário, e que assim torna-se menor que as anotações de texto (média de 3.5 anotações de texto por usuário).

A maior parte dos usuários também informou não ter utilizado anotações por tinta, sendo que alguns ainda desconheciam tal opção. Um fator provável foi o posicionamento do botão de anotações de tinta e o símbolo, que apresentava apenas uma captura do quadro do vídeo e sem escrita. A interface gráfica para escolher a anotação foi redefinida, como apresentada nas capturas de tela da CWaCTool v3 anteriormente, utilizando um pincel e legenda do significado.

Sobre os comentários de texto e sugestões, boa parte dos usuários visualizaram as anotações dos outros usuários, mas relatam que não foram influenciados por isso. Ainda assim, alguns utilizaram as sugestões dos outros usuários, como apresentado na Tabela 6.1.

Quando os alunos foram perguntados sobre o que foi cômodo e incômodo no uso da ferramenta, a maior parte relatou que consideraram a ferramenta de boa qualidade e que era interessante anotar em vídeos para se analisá-lo. Dentre o que consideraram cômodo, citaram as sugestões de comentários e a recuperação as anotações em um vídeo. Como incômodo, os usuários citaram o fato de ter de parar o vídeo para realizar uma anotação como o principal problema.

Como avaliações, conclui-se que o uso de informações de contexto, ainda que apenas sugerindo anotações de texto aos usuários, foi de considerável uso, já que mais de um terço das anotações de texto realizadas foram por sugestões de outros usuários. Esse número poderia ser maior, caso houvessem mais usuários, ou se os mesmos utilizassem a ferramenta por mais tempo, 
gerando desse modo mais anotações de texto e mais possibilidades de sugestões.

\subsection{Considerações Finais}

Este capítulo detalhou os protótipos construídos, para prova do modelo e dos conceitos estudados, além de apresentar as avaliações realizadas com usuários da CWaCTool. Os protótipos foram construídos utilizando abordagem incremental, em que cada protótipo foi construído com base no anterior, realizando modificações com base nas avaliações com usuários e de trabalhos relacionados pesquisados.

As três versões da CWaCTool apresentadas neste capítulo coincidem com as três iterações do modelo CAPPA, apresentado na Seção 5.1 do capítulo anterior, e foram construídas para auxiliar no desenvolvimento do modelo. Com os resultados obtidos nas avaliações, foi possivel concluir que o uso de colaboração e recomendações melhorou a usabilidade, uma vez que foram utilizadas anotações de tinta colaborativas e sugestões de textos.

A seguir serão apresentadas algumas conclusões sobre esta dissertação. 



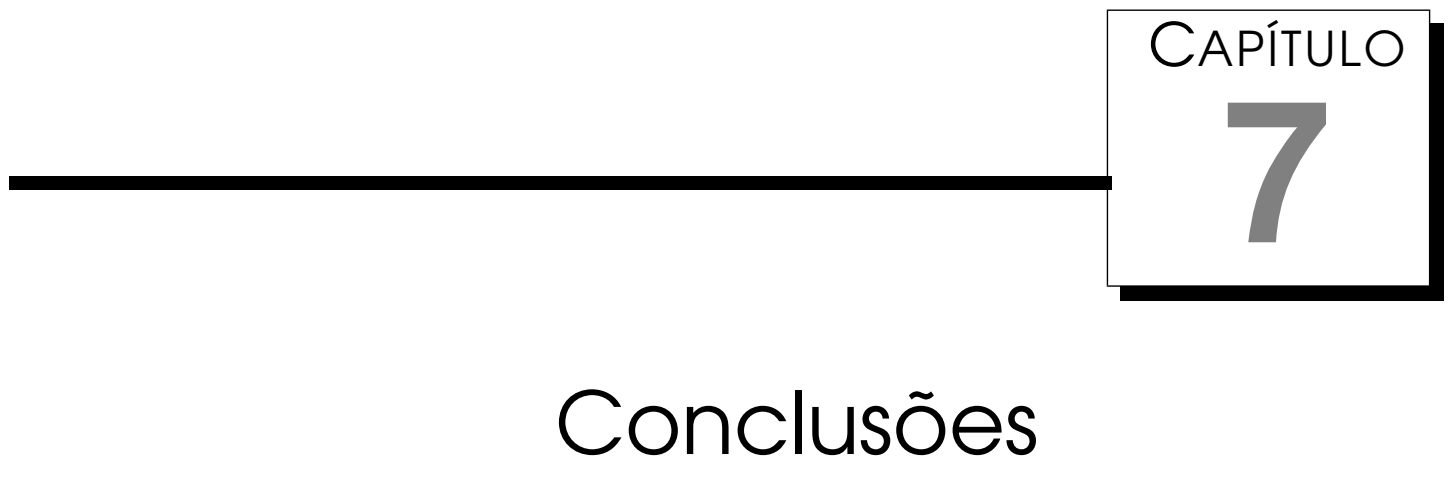

Nesta dissertação foram apresentados um levantamento bibliográfico, uma síntese de trabalhos relacionados ao modelo CAPPA, o paradigma WaC, o modelo CAPPA e os protótipos construídos.

O levantamento bibliográfico identificou alguns conceitos importantes para o trabalho. Foram considerados os conceitos de Computação Ubíqua, sob os aspectos de captura automática e acesso de dados e de computação ciente de informações de contexto; Sistemas de Recomendação, considerando ontologias e extração de conhecimento de dados; Colaboração, enfatizando Social TV e redes P2P; e TV Digital Interativa.

Em paralelo ao levantamento bibliográfico, foi realizado um levantamento de trabalhos relacionados ao modelo CAPPA. Foram consideradas quatro grande áreas: (i) Sistemas e modelos cientes de contexto que exploram o uso de ciência de contexto para qualquer finalidade; (ii) Sistemas de recomendação multimídia que utilizam algum mecanismo para fornecer recomendações em aplicações que envolvam mídias, especialmente vídeos; (iii) Sistemas colaborativos de vídeo que exploram a colaboração dos usuários para alguma finalidade em aplicações de vídeos; e (iv) Sistemas Peer-to-Peer, que explorem o uso de redes P2P principalmente relacionadas a anotações ou a vídeos.

O modelo CAPPA foi baseado no paradigma WaC, que estuda o processo de usuários anotarem vídeos enquanto assistem ao mesmo. O protótipo construído para prova de conceito do paradigma WaC, a WaCTool, foi base para os protótipos construídos para validação do modelo CAPPA. 
O modelo arquitetural CAPPA foi criado com o objetivo de prover ciência de informações de contexto e maior colaboração no paradigma WaC, permitindo outras abordagens ao paradigma além dos originais estudados por Pimentel et al. (2007), Cattelan et al. (2008a). O modelo CAPPA define uma arquitetura de componentes necessários para prover tais serviços, além de também definir um formato de informações do usuário para transição, uma ontologia, o modo de se extrair ações e recomendações dessas informações de contexto e o uso de uma rede $\mathrm{P} 2 \mathrm{P}$.

Para validar as ideias propostas no modelo, foram construídos protótipos de modo incremental. Os protótipos, construídos em três etapas, possibilitaram evoluir os conceitos do modelo CAPPA bem como avaliar com usuários cada componente do modelo, considerando colaboração, usabilidade e utilidade das recomendações.

A seguir são sumarizados os resultados e as contribuições obtidos, as limitações do modelo e dos protótipos atuais e lista possíveis trabalhos futuros.

\section{1 Resultados e Contribuições}

As avaliações apresentadas no capítulo anterior mostram que o uso de informações de contexto e de colaboração trouxe benefícios aos usuários, ainda que com algumas limitações. O uso das sugestões de texto e de sessões de anotação de tinta eletrônica compartilhada mostraram que a implementação do modelo CAPPA na CWaCTool, ainda que parcialmente, trouxe alternativas nas sugestões e maior integração entre usuários comentando um mesmo vídeo. O uso da CWaCTool com o Youtube permitiu ainda que os usuários pudessem colaborar não só com usuários da aplicação, mas também com outros usuários.

A privacidade dos usuários pode ser comprometida dependendo dos propósitos e das informações a serem compartilhadas. O compartilhamento automático de informações do usuário, como endereço residencial, pode ser inviável em cenários reais, sendo por este motivo que a CWaCTool não compartilha informações pessoais que identifiquem uma pessoa (endereço, nome, localização exata).

O modelo arquitetural CAPPA e os protótipos foram construídos com auxílio de trabalhos de outros pesquisadores, que exploram linhas complementares ao apresentado nesta dissertação (Maximino, 2009; Furtado, 2010; Gomes, 2010; Cattelan, 2009). 


\subsection{Limitações}

O modelo CAPPA tem como limitações o fato de utilizar um modelo fixo de ontologias. Outra limitação é a integração das informações de contexto com o módulo de Raciocínio, pois considera uma entrada de dados de mesmo formato para a análise.

Por definição, o modelo CAPPA também utiliza uma rede P2P. Mas é possível que seja utilizada apenas uma conexão cliente-servidor padrão, como no caso de aplicação do modelo em uma aplicação Web.

Quanto às limitações dos protótipos, a CWaCTool v3, última versão prototipada, considera apenas o uso no site Youtube e o uso de informações de redes sociais do Orkut, apesar de ser facilmente estendido para permitir o uso com outras fontes de vídeo e de redes sociais. A ferramenta também não é compativel com o middleware de TVDI brasileiro, o Ginga, sendo necessária uma reimplementação do código para o correto funcionamento. Outra incompatibilidade é o uso como aplicação Web, em que a CWaCTool seria executada em um navegador de Internet, sem a necessidade de instalação, e que não é possivel pela quantidade e tipo de bibliotecas de Software utilizadas.

A CWaCTool também implementa somente alguns métodos colaborativos de anotação e de compartilhamento, não possuindo por exemplo um canal de voz para bate-papo ou anotações colaborativas por voz. Outros meios de anotação e compartilhamento podem ser implementados integrando novos componentes à arquitetura da ferramenta. A CWaCTool também é limitada quanto ao processamento de recomendações, que oferece apenas a sugestão de textos, mas que também pode ser expandido com uma outra prototipação da ferramenta com esse foco.

O estudo da CWaCTool como aplicativo gerador de vídeos interativos e do processo de interação para se realizar anotações foram detalhados e estudados por Cattelan (2009).

\subsection{Trabalhos Futuros}

É possível estender tanto o modelo como os protótipos para que sejam utilizados em TVDI e na Web. Cada um desses dois cenários apresenta requisitos como suporte a vídeo transmitidos por emissoras da TVDI ou possibilidade de ser executado em um navegador Web. 
O modelo pode ainda ser estendido para ter suporte integral a concept lattices e para utilizar outras técnicas de mineração de dados e de extração de conhecimento. Com isso, pode ser possível realizar outras recomendações e sugestões, além das já citadas nos cenários de uso e presentes nos trabalhos relacionados.

Alguns pesquisadores do laboratório Intermidia exploram conceitos relacionados com o paradigma $\mathrm{WaC}$ ou a captura automática e acesso, como os trabalhos em andamento de Gomes (2010), Oliveros (2010) e Pedrosa (2010). No trabalho de Gomes (2010), por exemplo, é possivel que haja uma contribuição do modelo CAPPA e da CWaCTool para a análise de mineração de dados em vídeos e TVDI. 


\section{Referências Bibliográficas}

ABOWD, G. D.; MYNATT, E. D. Charting past, present, and future research in ubiquitous computing. ACM Transactions on Computer-Human Interaction, New York, v. 7, n. 1, p. 29-58, Mar. 2000. ISSN 1073-0516. Disponível em: $<$ http://doi.acm.org/10.1145/344949.344988>. Acesso em: 16 Mai. 2010.

ABOWD, G. D.; MYNATT, E. D.; RODDEN, T. The human experience. IEEE Pervasive Computing, Los Alamitos, v. 1, n. 1, p. 48-57, Jan./Mar. 2002. ISSN 1536-1268. Disponível em: <http://doi.ieeecomputersociety.org/10.1109/MPRV.2002$.993144>$. Acesso em: 16 Mai. 2010.

ANDROUTSELLIS-THEOTOKIS, S.; SPINELLIS, D. A survey of peer-to-peer content distribution technologies. ACM Computing Surveys, New York, v. 36, n. 4, p. 335-371, Dez. 2004. ISSN 0360-0300. Disponível em: <http://doi.acm.org/10$.1145 / 1041680.1041681>$. Acesso em: 16 Mai. 2010.

AROYO, L.; BELLEKENS, P.; BJORKMAN, M.; HOUBEN, G.-J.; AKKERMANS, P.; KAPTEIN, A. SenSee framework for personalized access to TV content. In: EUROPEAN CONFERENCE ON INTERACTIVE TV. Proceedings... Springer Berlin / Heidelberg, 2007a. p. 156-165. ISBN 978-3-540-72558-9. Disponível em: <http://www.springerlink.com/content/m1502x19g2857m30/>. Acesso em: 17 Mai. 2010.

AROYO, L.; NACK, F.; SCHIPHORST, T.; SCHUT, H.; KAUWATJOE, M. Personalized ambient media experience: move.me case study. In: INTERNATIONAL CONFERENCE ON INTELLIGENT USER INTERFACES, 12., 2007, Honolulu. Proceedings... New York: ACM, 2007b. p. 298-301. ISBN 1-59593-481-2. Disponível em: <http://doi.acm.org/10.1145/1216295.1216351>. Acesso em: 18 Mai. 2010.

BALDAUF, M.; DUSTDAR, S.; ROSENBERG, F. A survey on context-aware systems. International Journal of Ad Hoc and Ubiquitous Computing, Geneva, v. 2, n. 4, p. 263-277, Jun. 2007. ISSN 1743-8225. Disponivel em: <http:- 
//dx.doi.org/10.1504/IJAHUC.2007\% -.014070>. Acesso em: 16 Mai. 2010.

BARGERON, D.; GUPTA, A.; GRUDIN, J.; SANOCKI, E. Annotations for streaming video on the web. In: CONFERENCE ON HUMAN FACTORS IN COMPUTING SYSTEMS, 17., 1999, Pittsburgh. Proceedings... New York: ACM, 1999. p. 278-279. ISBN 1-58113-158-5. Disponivel em: < http://doi.acm.org/10.1145/632716.632887>. Acesso em: 18 Mai. 2010.

BELlEKENS, P.; HOUBEN, G.-J.; AROYO, L.; SCHAAP, K.; KAPTEIN, A. User model elicitation and enrichment for context-sensitive personalization in a multiplatform tv environment. In: EUROPEAN CONFERENCE ON INTERACTIVE TELEVISION, 7., 2009, Leuven. Proceedings... New York: ACM, 2009. p. 119-128. ISBN 978-1-60558-340-2. Disponível em: <ttp://doi.acm.org/10.1145/1542084.1542106>. Acesso em: 18 Mai. 2010.

BENDAOUD, R.; NAPOLI, A.; TOUSSAINT, Y. Formal concept analysis: A unified framework for building and refining ontologies. In: INTERNATIONAL CONFERENCE ON KNOWLEDGE ENGINEERING AND KNOWLEDGE MANAGEMENT KNOWLEDGE PATTERNS, 16., 2008, Acitrezza. Proceedings... Springer Berlin / Heidelberg, 2008. p. 156-171. ISBN 978-3-540-87695-3. Disponivel em: <http://www.springerlink.com/content/g4830n5643522u43/>. Acesso em: 18 Mai. 2010.

BERGLUND; ASEEL; JOHANSSON; PONTUS. Using speech and dialogue for interactive tv navigation. Universal Access in the Information Society, v. 3, n. 3-4, p. 224-238, Out. 2004. ISSN 1615-5289. Disponível em: <http://dx.doi.org/10.1007/s10209-004-0106-x>. Acesso em: 16 Mai. 2010.

BOCCONI, S.; NACK, F.; HARDMAN, L. Automatic generation of matter-of-opinion video documentaries. Web Semantics: Science, Services and Agents on the World Wide Web, v. 6, n. 2, p. 139 - 150, Abr. 2008. ISSN 1570-8268. Disponivel em: <http://www.sciencedirect.com/science/article/B758F4S2VG0N-1/2/ad84fce4b15e2f62576b7d877ee4df53>. Acesso em: 16 Mai. 2010.

BOHRING, H.; AUER, S. Mapping xml to owl ontologies. In: LEIPZIGER INFORMATIKTAGE, 13., 2005, Leipziger. Proceedings... Verlag: Bonner Köllen, 2005. p. 147-156. ISBN 3-88579-401-2.

BROTHERTON, J. A.; ABOWD, G. D. Lessons learned from eClass: assessing automated capture and access in the classroom. ACM Transactions on Computer-Human Interaction, New York, v. 11, n. 2, p. 121-155, Jun. 2004. ISSN 1073-0516. Disponível em: <http://doi.acm.org/10.1145/1005361$.1005362>$. Acesso em: 16 Mai. 2010.

Bulcão Neto, R. F.; PIMENTEL, M. d. G. C. Performance evaluation of inference services for ubiquitous computing. In: BRAZILIAN SYMPOSIUM ON 
MULTIMEDIA AND THE WEB, 12., 2006, Natal, RN. Proceedings... New York: ACM, 2006. p. 27-34. ISBN 85-7669-100-0. Disponivel em: <http://doi.acm.org/10.1145/1186595.1186600>. Acesso em: 18 Mai. 2010.

Bulcão Neto, R. d. F. Um processo de software e um modelo ontológico para apoio ao desenvolvimento de aplicações sensíveis a contexto. 162 p. Tese (Doutorado em Computação) - Instituto de Ciências Matemáticas e da Computação, Universidade de São Paulo, São Carlos, 2006.

CATtElan, R. G. Captura e acesso na produção, distribuição, apresentação e extensão de conteúdo multimídia. 177 p. Tese (Doutorado em Computação) — Instituto de Ciências Matemáticas e da Computação, Universidade de São Paulo, São Carlos, 2009.

CATtelan, R. G.; TeiXeira, C. A. C.; GOUlarte, R.; PiMentel, M. d. G. C. Watch-and-comment as a paradigm toward ubiquitous interactive video editing. ACM Transactions on Multimedia Computing, Communications, and Applications, New York, NY, USA, v. 4, n. 4, p. 1-24, Out. 2008. ISSN 1551-6857. Disponível em: <http://doi.acm.org/10.1145/1412196.1412201>. Acesso em: 16 Mai. 2010 .

CATTElan, R. G.; TEIXEIRA, C. A. C.; RIBAS, H.; MUNSON, E.; PIMENTEL, M. d. G. C. Inkteractors: interacting with digital ink. In: ACM SYMPOSIUM ON APPLIED COMPUTING, 23., 2008, Fortaleza, CE. Proceedings... New York: ACM, 2008b. p. 1246-1251. ISBN 978-1-59593-753-7. Disponível em: $<$ http://doi.acm.org/10.1145/1363686.1363973>. Acesso em: 18 Mai. 2010.

CESAR, P.; BULTERMAN, D. C. A.; JANSEN, A. J. Usages of the secondary screen in an interactive television environment: Control, enrich, share, and transfer television content. In: EUROPEAN CONFERENCE ON INTERACTIVE TV, 6., 2008, Salzburg. Proceedings... Springer Berlin / Heidelberg, 2008. p. 168-177. ISBN 978-3-540-69477-9. Disponivel em: <http://www.springerlink.com/content/p30658353hgj2046/>. Acesso em: 18 Mai. 2010.

CHEN, H.; FININ, T.; JOSHI, A. An ontology for context-aware pervasive computing environments. The Knowledge Engineering Review, New York, v. 18, n. 03, p. 197-207, Set. 2003. ISSN 0269-8889. Disponível em: <http://dx.doi.org/DOI:10.1017/S0269888904000025>. Acesso em: 16 Mai. 2010.

CHEN, H. L. An Intelligent Broker Architecture for Pervasive Context-aware Systems. 129 p. Tese (Doutorado em Computação) - University of Maryland, Baltimore, 2004.

CHIU, P.; BORECZKY, J.; GIRGENSOHN, A.; KIMBER, D. LiteMinutes: an internet-based system for multimedia meeting minutes. In: INTERNATIONAL WORLD WIDE WEB CONFERENCE, 10., 2001, Hong Kong. Proceedings... New York: ACM, 2001. p. 140-149. ISBN 1-58113-348-0. Disponível em: <http://doi.acm.org/10.1145/371920.371971>. Acesso em: 18 Mai. 2010. 
CHORIANOPOULOS, K.; LEKAKOS, G. Learn and play with interactive tv. Computers in Entertainment, New York, v. 5, n. 2, p. 4, Abr./Jun. 2007. ISSN 1544-3574. Disponível em: <http://doi.acm.org/10.1145/1279540.1279544>. Acesso em: 16 Mai. 2010.

COPPENS, T.; TRAPPENIERS, L.; GODON, M. AmigoTV: towards a social TV experience. In: EUROPEAN CONFERENCE ON INTERACTIVE TV, 2., 2004, Brighton. Proceedings... [s.1.], 2004. p. 4. Disponivel em: <http://www.csd.abdn.ac.uk/ jmasthof/EuroITV04/S04.pdf>. Acesso em: 18 Mai. 2010.

COPPOLA, P.; MEA, V. D.; GASPERO, L. D.; LOMUSCIO, R.; MISCHIS, D.; MIZZARO, S.; NAZZI, E.; SCAGNETTO, I.; VASSENA, L. AI techniques in a context-aware ubiquitous environment. In: ABOUL-ELLA HASSANIEN AND JEMAL H. ABAWAJY AND AJITH ABRAHAM AND HANI HAGRAS. Pervasive Computing. London: Springer, 2009. (Computer Communications and Networks), cap. 8, p. 157-180. ISBN 978-1-84882-599-4. Disponível em: $<$ http://www.springerlink.com/content/h36410407vwx430n/>. Acesso em: 17 Mai. 2010.

COUTAZ, J.; CROWLEY, J. L.; DOBSON, S.; GARLAN, D. Context is key. Communications of the ACM, New York, v. 48, n. 3, p. 49-53, Mar. 2005. ISSN 0001-0782. Disponível em: <http://doi.acm.org/10.1145/1047671.1047703>. Acesso em: 16 Mai. 2010.

DAVID, P.-C.; LEDOUX, T. Wildcat: a generic framework for context-aware applications. In: INTERNATIONAL WORKSHOP ON MIDDLEWARE FOR PERVASIVE AND AD-HOC COMPUTING, 3., 2005, Grenoble. Proceedings... New York: ACM, 2005. p. 1-7. ISBN 1-59593-268-2. Disponível em: $<$ http://doi.acm.org/10.1145/1101480.1101483>. Acesso em: 18 Mai. 2010.

DEAN, M.; SCHREIBER, G.; BECHHOFER, S.; HARMELEN, F. van; HENDLER, J.; HORROCKS, I.; MCGUINNESS, D.; PATEL-SCHNEIDER, P.; STEIN, L. OWL Web Ontology Language Reference. W3C, 2004. Disponível em: <http://www.w3.org/TR/owl-ref/>. Acesso em: 18 Mai. 2010.

DEY, A.; ABOWD, G. Towards a better understanding of context and contextawareness. Georgia Institute of Technology, 2000. 12 p. Disponivel em: $<$ http://www.cc.gatech.edu/fce/contexttoolkit/chiws/Dey.pdf $>$. Acesso em: 18 Mai. 2010.

DEY, A. K. Understanding and using context. Personal and Ubiquitous Computing, London, v. 5, n. 1, p. 4-7, Abr. 2001. ISSN 1617-4909. Disponível em: $<$ http://www.springerlink.com/content/1d9grxkjvquhpwkw/>. Acesso em: 16 Mai. 2010.

ELTING, C. Orchestrating output devices: planning multimedia presentations for home entertainment with ambient intelligence. In: SMART OBJECTS 
AND AMBIENT INTELLIGENCE, 1., 2005, Grenoble. Proceedings... New York: ACM, 2005. p. 153-158. ISBN 1-59593-304-2. Disponível em: <http://doi.acm.org/10.1145/1107548.1107589>. Acesso em: 18 Mai. 2010.

FAGÁ JR., R.; FURTADO, B. C.; MAXIMINO, F.; CATTELAN, R. G.; PIMENTEL, M. d. G. C. Context information exchange and sharing in a peer-to-peer community: a video annotation scenario. In: ACM SPECIAL INTEREST GROUP FOR DESIGN OF COMMUNICATION, 27., 2009, Bloomington. Proceedings... New York: ACM, 2009a. p. 265-272. ISBN 978-1-60558-559-8. Disponível em: <http://doi.acm.org/10.1145/1621995.1622048>. Acesso em: 18 Mai. 2010.

FAGÁ JR., R.; MAXIMINO, F. A.; FURTADO, B.; JR, J. A. C. M.; CATTELAN, R. G.; PIMENTEL, M. d. G. C. A peer-to-peer context information structure for TV users. In: BRAZILIAN SYMPOSIUM ON MULTIMEDIA AND THE WEB, 15., 2009, Fortaleza. Proceedings... Fortaleza, CE: Sociedade Brasileira de Computação, 2009b. p. 107 - 114.

FAHY, P.; CLARKE, S. CASS-Middleware for mobile Context-Aware applications. In: INTERNATIONAL CONFERENCE ON MOBILE SYSTEMS, APPLICATIONS, AND SERVICES, 2., 2004, Boston. Proceedings... Usenix, 2004. p. 6. Disponível em: <http://www.sigmobile.org/mobisys/2004/context_awareness/papers/cass12f.pdf $>$. Acesso em: 18 Mai. 2010.

FARIAS, M. C.; CARVALHO, M. M.; ALENCAR, M. S. Digital television broadcasting in brazil. IEEE MultiMedia, Los Alamitos, v. 15, n. 2, p. 64-70, Abr./Jun. 2008. ISSN 1070-986X. Disponivel em: <http://doi.ieeecomputersociety.org/10.1109/MMUL.2008.25>. Acesso em: 16 Mai. 2010.

FENSEL, D. Ontologies: A Silver Bullet for Knowledge Management and Electronic Commerce. 2. ed. New York: Springer-Verlag, 2003. 170 p. ISBN 3540003029.

FERNANDEZ, Y.; ARIAS, J.; NORES, M.; SOLLA, A.; CABRER, M. Avatar: an improved solution for personalized tv based on semantic inference. IEEE Transactions on Consumer Electronics, v. 52, n. 1, p. 223-231, Fev. 2006. ISSN 0098-3063.

FOKKER, J.; RIDDER, H. de; WESTENDORP, P.; POUWELSE, J. Psychological backgrounds for inducing cooperation in peer-to-peer television. In: EUROPEAN CONFERENCE ON INTERACTIVE TV, 5., 2007, Amsterdam. Proceedings... Springer Berlin / Heidelberg, 2007. p. 136-145. ISBN 978-3-540-72558-9. Disponível em: <http://www.springerlink.com/content/d1w4q08qr721163n/>. Acesso em: 18 Mai. 2010.

FOKKER, J. E.; WESTENDORP, P. H.; POUWELSE, J. A.; RIDDER, H. de. A questionnaire-based study on delayed reciprocity in a p2p-tv system. In: INTERNATIONAL CONFERENCE ON DESIGNING INTERACTIVE USER EXPERIENCES FOR TV AND VIDEO, 1., 2008, Silicon Valley. Proceedings... 
New York: ACM, 2008. p. 151-154. ISBN 978-1-60558-100-2. Disponível em: <http://doi.acm.org/10.1145/1453805.1453836>. Acesso em: 18 Mai. 2010.

FORTIER, A.; CAñIBANO, N.; GRIGERA, J.; ROSSI, G.; GORDILlO, S. An object-oriented approach for context-aware applications. In: INTERNATIONAL SMALLTALK CONFERENCE, 14., 2006, Prague. Proceedings... Springer Berlin / Heidelberg, 2007. p. 23-46. ISBN 978-3-540-71835-2. Disponível em: $<$ http://www.springerlink.com/content/c251ttp62385m537/>. Acesso em: 18 Mai. 2010.

FURTADO, B. C. Captura da interação usuário-Tv interativa: CapTiVa. 2010. 11 p. Relatório técnico de Iniciação Científica - Instituto de Ciências Matemáticas e da Computação, Universidade de São Paulo, São Carlos, 2010.

GENG, B.; YANG, L.; XU, C.; HUA, X.-S. Collaborative learning for image and video annotation. In: INTERNATIONAL CONFERENCE ON MULTIMEDIA INFORMATION RETRIEVAL, 1., 2008, Vancouver. Proceedings... New York: ACM, 2008. p. 443-450. ISBN 978-1-60558-312-9. Disponível em: <http://doi.acm.org/10.1145/1460096.1460168>. Acesso em: 18 Mai. 2010.

GOLDMAN, D. B.; GONTERMAN, C.; CURlESS, B.; SAlESIN, D.; SEITZ, S. M. Video object annotation, navigation, and composition. In: SYMPOSIUM ON USER INTERFACE SOFTWARE AND TECHNOLOGY, 21., 2008, Monterey. Proceedings... New York: ACM, 2008. p. 3-12. ISBN 978-1-59593-975-3. Disponível em: <http://doi.acm.org/10.1145/1449715.1449719>. Acesso em: 18 Mai. 2010.

GOMES, A. K. Aprendizado de Ontologias com Formal Concept Analysis suportado por Usage Mining na TV Digital Interativa. 2010. 86 p. Qualificação (Doutorado em Computação) - Instituto de Ciências Matemáticas e da Computação, Universidade de São Paulo, São Carlos, 2010.

GONZALEZ, A. J.; STENSRUD, B. S.; BARRETT, G. Formalizing context-based reasoning: A modeling paradigm for representing tactical human behavior. International Journal of Intelligent Systems, New York, v. 23, n. 7, p. 822-847, Jul. 2008. ISSN 0884-8173. Disponivel em: <http://dx.doi.org/10.1002/int.v23:7>. Acesso em: 16 Mai. 2010.

GOULARTE, R.; CATTELAN, R. G.; CAMACHO-GUERRERO, J. A.; INÁCIO JR., V. R.; PIMENTEL, M. da G. C. Interactive multimedia annotations: enriching and extending content. In: ACM SYMPOSIUM ON DOCUMENT ENGINEERING, 4., 2004, Milwaukee. Proceedings... New York: ACM, 2004. p. 84-86. ISBN 1-58113938-1. Disponível em: <http://doi.acm.org/10.1145/1030397.1030414>. Acesso em: 18 Mai. 2010.

GOUlARTE, R.; MOREIRA, E. dos S.; PIMENTEL, M. da G. C. Structuring interactive tv documents. In: ACM SYMPOSIUM ON DOCUMENT ENGINEERING, 3., 2003, 
Grenoble. Proceedings... New York: ACM, 2003. p. 42-51. ISBN 1-58113-724-9. Disponivel em: <http://doi.acm.org/10.1145/958220.958229>. Acesso em: 18 Mai. 2010.

GOUlARTE, R.; PIMENTEL, M. da G. C.; MOREIRA, E. dos S. Context-aware support in structured documents for interactive-tv. Multimedia Systems, v. 11, n. 4, p. 367-382, Abr. 2006. ISSN 1432-1882. Disponivel em: <http://www.springerlink.com/content/30271q381q220314/>. Acesso em: 16 Mai. 2010 .

GRAY, P.; SALBER, D. Modelling and using sensed context information in the design of interactive applications. In: ENGINEERING FOR HUMAN-COMPUTER INTERACTION, 8., 2001, Toronto. Proceedings... Springer Berlin / Heidelberg, 2001. p. 317-335. ISBN 978-3-540-43044-5. Disponível em: <http://www.springerlink.com/content/u7fOv4ehpdj82pgr/>. Acesso em: 18 Mai. 2010.

GRUBER, T. R. A translation approach to portable ontology specifications. Knowledge Acquisition, London, v. 5, n. 2, p. 199-220, Jun. 1993. ISSN 1042-8143. Disponível em: <http://dx.doi.org/10.1006/knac.1993.1008>. Acesso em: 16 Mai. 2010.

GU, T.; PUNG, H. K.; ZHANG, D. Q. A middleware for building context-aware mobile services. In: IEEE VEHICULAR TECHNOLOGY CONFERENCE, 60., 2004, Los Angeles. Proceedings... [S.L.]: Vehicular Technology Society, 2004. p. 2656-2660.

GUIMARãES, R. L.; COSTA, R. M. de R.; SOARES, L. G. Composer: Authoring tool for iTV programs. In: EUROPEAN CONFERENCE ON INTERACTIVE TV, 6., 2008, Salzburg. Proceedings... Springer Berlin / Heidelberg, 2008. p. 61-71. ISBN 978-3-540-69477-9. Disponível em: <http://www.springerlink.com/content/274r3802325605m1/>. Acesso em: 18 Mai. 2010.

HANSEN, T. R.; BARDRAM, J. E. ActiveTheatre-A collaborative, Event-Based capture and access system for the operating theatre. In: UBIQUITOUS COMPUTING, 7., 2005, Tokyo. Proceedings... Springer Berlin / Heidelberg, 2005. p. 375-392. ISBN 978-3-540-28760-5. Disponivel em: <http://www.springerlink.com/index/4GKFBN4NF0W6YP57.pdf $>$. Acesso em: 17 Mai. 2010.

HANSEN, T. R.; BARDRAM, J. E.; SOEGAARD, M. Moving out of the lab: Deploying pervasive technologies in a hospital. IEEE Pervasive Computing, Piscataway, v. 5, n. 3, p. 24-31, Jul. 2006. ISSN 1536-1268. Disponível em: <http://dx.doi.org/10.1109/MPRV.2006.53>. Acesso em: 16 Mai. 2010.

HARBOE, G.; METCALF, C. J.; BENTLEY, F.; TULLIO, J.; MASSEY, N.; ROMANO, G. Ambient social tv: drawing people into a shared experience. In: CONFERENCE 
ON HUMAN FACTORS IN COMPUTING SYSTEMS, 26., 2008, Florence. Proceedings... New York: ACM, 2008. p. 1-10. ISBN 978-1-60558-011-1. Disponível em: <http://doi.acm.org/10.1145/1357054.1357056>. Acesso em: 18 Mai. 2010.

HAYES, G. R.; GARDERE, L. M.; ABOWD, G. D.; TRUONG, K. N. Carelog: a selective archiving tool for behavior management in schools. In: CONFERENCE ON HUMAN FACTORS IN COMPUTING SYSTEMS, 26., 2008, Florence. Proceedings... New York: ACM, 2008. p. 685-694. ISBN 978-1-60558-011-1. Disponivel em: <http://doi.acm.org/10.1145/1357054.1357164>. Acesso em: 18 Mai. 2010.

HENRICKSEN, K.; INDULSKA, J.; RAKOTONIRAINY, A. Modeling context information in pervasive computing systems. In: INTERNATIONAL CONFERENCE ON PERVASIVE COMPUTING, 1., 2002, Zurich. Proceedings... Springer Berlin / Heidelberg, 2002. p. 79-117. ISBN 978-3-540-44060-4. Disponível em: $<$ http://www.springerlink.com/index/JBXD2FD5GA045P8W.pdf > . Acesso em: 17 Mai. 2010.

HENRICKSEN, K.; INDULSKA, J.; RAKOTONIRAINY, A. Generating context management infrastructure from high-level context models. In: MOBILE DATA MANAGEMENT, 4., 2003, Melbourne. Proceedings... [s.1.], 2003. p. 6. Disponível em: <http://www.dstc.edu.au/m3/papers/ContextManagement.pdf $>$. Acesso em: 18 Mai. 2010.

HINDUS, D.; SCHMANDT, C. Ubiquitous audio: capturing spontaneous collaboration. In: ACM CONFERENCE ON COMPUTER-SUPPORTED COOPERATIVE WORK, 4., 1992, Toronto. Proceedings... New York: ACM, 1992. p. 210-217. ISBN 089791-542-9. Disponível em: <http://doi.acm.org/10.1145/143457.143481>. Acesso em: 18 Mai. 2010.

HOFER, T.; SCHWINGER, W.; PICHLER, M.; LEONHARTSBERGER, G.; ALTMANN, J.; RETSCHITZEGGER, W. Context-awareness on mobile devices - the hydrogen approach. In: HAWAII INTERNATIONAL CONFERENCE ON SYSTEM SCIENCES, 36., 2003, Hawaii. Proceedings... Washington: IEEE Computer Society, 2003. p. 10. ISBN 0-7695-1874-5. Disponivel em: <http://doi.ieeecomputersociety.org/10.1109/HICSS.2003.1174831>. Acesso em: 18 Mai. 2010.

HOFFMAN, P. J. Computer-supported cooperative work: A book of readings. ACM SIGCHI Bulletin, New York, v. 21, n. 2, p. 125-128, Out. 1989. ISSN 0736-6906. (Revisão). Disponivel em: <http://doi.acm.org/10.1145/70609.1047343>. Acesso em: 16 Mai. 2010.

HUANG, E. M.; HARBOE, G.; TULLIO, J.; NOVAK, A.; MASSEY, N.; METCALF, C. J.; ROMANO, G. Of social television comes home: a field study of communication choices and practices in tv-based text and voice chat. In: INTERNATIONAL 
CONFERENCE ON HUMAN FACTORS IN COMPUTING SYSTEMS, 27., 2009, Boston. Proceedings... New York: ACM, 2009. p. 585-594. ISBN 978-1-60558246-7. Disponível em: <http://doi.acm.org/10.1145/1518701.1518792>. Acesso em: 18 Mai. 2010.

IBGE. Pesquisa Nacional por Amostra de Domicílios: Síntese de Indicadores 2007. Rio de Janeiro: Instituto Brasileiro de Geografia e Estatística, 2008. 248-251 p.

JENA. Jena - A Semantic Web Framework for Java. 2010. Disponível em: <http://www.cs.waikato.ac.nz/ml/weka/>. Acesso em: 16 Mai. 2010.

KELA, J.; KORPIPAA, P.; KALLIO, S.; SAVINO, G.; JOZZO, L.; MARCA, D. Accelerometer-based gesture control for a design environment. Personal and Ubiquitous Computing, London, v. 10, n. 5, p. 285-299, Ago. 2006. ISSN 1617-4909. Disponível em: <http://dx.doi.org/10.1007/s00779-005-0033-8>. Acesso em: 16 Mai. 2010.

KIENTZ, J. A.; ABOWD, G. D. KidCam: Toward an effective technology for the capture of children's moments of interest. In: PERVASIVE COMPUTING, 7. , 2009, Nara. Proceedings... Springer Berlin / Heidelberg, 2009. p. 115-132. ISBN 978-3-642-01515-1. Disponível em: <http://www.springerlink.com/content/u71126r543j60583/>. Acesso em: 18 Mai. 2010.

KIM, S.-H.; OK, J.; KANG, H. J.; KIM, M.-C.; KIM, M. An interaction and product design of gesture based tv remote control. In: CONFERENCE ON HUMAN FACTORS IN COMPUTING SYSTEMS, 22., 2004, Vienna. Proceedings... New York: ACM, 2004. p. 1548-1548. ISBN 1-58113-703-6. Disponível em: <http://doi.acm.org/10.1145/985921.986124>. Acesso em: 18 Mai. 2010.

KLYNE, G.; REYNOLDS, F.; WOODROW, C.; OHTO, H.; HJELM, J.; BUTLER, M. H.; TRAN, L. Composite Capability/Preference Profiles (CC/PP): Structure and Vocabularies 1.0. W3C, 2004. Disponivel em: <http://www.w3.org/TR/CCPPstruct-vocab/>. Acesso em: 18 Mai. 2010.

LUYTEN, K.; THYS, K.; HUYPENS, S.; CONINX, K. Telebuddies: social stitching with interactive television. In: CONFERENCE ON HUMAN FACTORS IN COMPUTING SYSTEMS, 24., 2006, Montréal. Proceedings... New York: ACM, 2006. p. 1049-1054. ISBN 1-59593-298-4. Disponivel em: <http://doi.acm.org/10$.1145 / 1125451.1125651>$. Acesso em: 18 Mai. 2010.

MACEDO, A. A.; JR., L. B.; CAMACHO-GUERRERO, J. A.; CATTELAN, R. G.; PIMENTEL, M. da G. C. Automatically linking live experiences captured with a ubiquitous infrastructure. Multimedia Tools and Applications, v. 37, n. 2, p. 93-115, 2008. ISSN 1573-7721. Disponível em: <http://www.springerlink.com/content/a7h6641752537017/>. Acesso em: 17 Mai. 2010. 
MANTZARI, E.; LEKAKOS, G.; VRECHOPOULOS, A. Social tv: introducing virtual socialization in the tv experience. In: INTERNATIONAL CONFERENCE ON DESIGNING INTERACTIVE USER EXPERIENCES FOR TV AND VIDEO, 1., 200, Silicon Valley. Proceedings... New York: ACM, 2008. p. 81-84. ISBN 978-1-60558-100-2. Disponivel em: <http://doi.acm.org/10.1145/1453805$.1453823>$. Acesso em: 18 Mai. 2010.

MANZATO, M. G.; COIMBRA, D. B.; GOULARTE, R. Multimedia content personalization based on peer-level annotation. In: EUROPEAN CONFERENCE ON INTERACTIVE TV, 7., 2009, Leuven. Proceedings... New York: ACM, 2009. p. 57-66. ISBN 978-1-60558-340-2. Disponivel em: <http://doi.acm.org/10$.1145 / 1542084.1542096>$. Acesso em: 18 Mai. 2010.

MAXIMINO, F. A. Colaboração entre usuários de TV interativa: ColaboraTiVa. 2009. 39 p. Relatório técnico de Iniciação Científica - Instituto de Ciências Matemáticas e da Computação, Universidade de São Paulo, São Carlos.

MCCARTHY, J.; BUVAC, S. Formalizing context (expanded notes). In: ATOCHA ALISEDA AND VAN GLABBEEK,, ROB AND DAG WESTERSTAHL. Computing Natural Language. Stanford: Stanford University, 1997. cap. 2, p. 13-50. Disponivel em: <http://www.formal.stanford.edu/jmc/mccarthy-buvac-98/context.pdf $>$. Acesso em: 20 Mai. 2010.

MEYER, S.; RAKOTONIRAINY, A. A survey of research on context-aware homes. In: AUSTRALASIAN INFORMATION SECURITY WORKSHOP CONFERENCE ON ACSW FRONTIERS, 2003, Adelaide. Proceedings... Darlinghurst: Australian Computer Society, 2003. p. 159-168. ISBN 1-920682-00-7.

MIN, H.-s.; LEE, S.; NEVE, W. D.; RO, Y. M. Semantic concept detection for usergenerated video content using a refined image folksonomy. In: INTERNATIONAL MULTIMEDIA MODELING CONFERENCE, 16., 2010, Chongqing. Proceedings... Springer Berlin / Heidelberg, 2010. p. 511-521. ISBN 978-3-642-11300-0. Disponível em: <http://www.springerlink.com/content/83707k1634p06x08/>. Acesso em: 17 Mai. 2010.

MINNEMAN, S.; HARRISON, S.; JANSSEN, B.; KURTENBACH, G.; MORAN, T.; SMITH, I.; MELLE, B. van. A confederation of tools for capturing and accessing collaborative activity. In: ACM INTERNATIONAL MULTIMEDIA CONFERENCE, 3., 1995, San Francisco. Proceedings... New York: ACM, 1995. p. 523-534. ISBN 0-89791-751-0. Disponível em: <http://portal.acm.org/citation.cfm?doid=217279.215316 $>$. Acesso em: 18 Mai. 2010.

MIZZARO, S.; NAZZI, E.; VASSENA, L. Collaborative annotation for context-aware retrieval. In: WORKSHOP ON EXPLOITING SEMANTIC ANNOTATIONS IN INFORMATION RETRIEVAL, 2009, Barcelona. Proceedings... New York: ACM, 2009. p. 42-45. ISBN 978-1-60558-430-0. Disponivel em: <http://doi.acm.org/10.1145/1506250.1506260>. Acesso em: 18 Mai. 2010. 
MOTTI, V. G.; FAGá JR., R.; CATELLAN, R. G.; PIMENTEL, M. d. G. C.; TEIXEIRA, C. A. Collaborative synchronous video annotation via the watch-and-comment paradigm. In: EUROPEAN CONFERENCE ON INTERACTIVE TV, 7., 2009, Leuven. Proceedings... New York: ACM, 2009. p. 67-76. ISBN 978-1-60558-3402. Disponível em: <http://doi.acm.org/10.1145/1542084.1542097>. Acesso em: 18 Mai. 2010.

NATHAN, M.; HARRISON, C.; YAROSH, S.; TERVEEN, L.; STEAD, L.; AMENTO, B. Collaboratv: making television viewing social again. In: INTERNATIONAL CONFERENCE ON DESIGNING INTERACTIVE USER EXPERIENCES FOR TV AND VIDEO, 1., 2008, Silicon Valley. Proceedings... New York: ACM, 2008. p. 85-94. ISBN 978-1-60558-100-2. Disponivel em: <http://doi.acm.org/10$.1145 / 1453805.1453824>$. Acesso em: 18 Mai. 2010.

NEELY, S.; STEVENSON, G.; KRAY, C.; MULDER, I.; CONNELLY, K.; SIEK, K. A. Evaluating pervasive and ubiquitous systems. IEEE Pervasive Computing, Los Alamitos, v. 7, n. 3, p. 85-88, 2008. ISSN 1536-1268. Disponível em: $<$ http://doi.ieeecomputersociety.org/10.1109/MPRV.2008.47>. Acesso em: 17 Mai. 2010.

OLIVEROS, D. A. V. Operadores de interação multimidia para autoria automática de documentos: audioInteractors. 2010. 73 p. Gualificação (Mestrado em Computação) - Instituto de Ciências Matemáticas e da Computação, Universidade de São Paulo, São Carlos, 2010.

OMOJOKUN, O.; PIERCE, S.; ISBELL, L.; DEWAN, P. Comparing end-user and intelligent remote control interface generation. Personal and Ubiquitous Computing, London, v. 10, n. 2-3, p. 136-143, Abr. 2006. ISSN 1617-4917. Disponivel em: <http://www.springerlink.com/content/72190444nw592107/>. Acesso em: 17 Mai. 2010.

ORAM, A. Peer-to-Peer: Harnessing the Benefits of a Disruptive Technology. illustrated. Senastopol: O'Reilly, 2001. 432 p. ISBN 059600110X.

OUMARD, M.; MIRZA, D.; KROY, J.; CHORIANOPOULOS, K. A cultural probes study on video sharing and social communication on the internet. In: INTERNATIONAL CONFERENCE ON DIGITAL INTERACTIVE MEDIA IN ENTERTAINMENT AND ARTS, 3., 2008, Athens. Proceedings... New York: ACM, 2008. p. 142-148. ISBN 978-1-60558-248-1. Disponível em: $<$ http://doi.acm.org/10.1145/1413634.1413664>. Acesso em: 18 Mai. 2010.

PEDROSA, D. de C. DisposiTVos: infraestrutura para entrada de dados multimodais na TV via múltiplos dispositivos. 2010. 73 p. Qualificação (Mestrado em Computação) - Instituto de Ciências Matemáticas e da Computação, Universidade de São Paulo, São Carlos, 2010.

PESSEMIER, T. D.; DERYCKERE, T.; MARTENS, L. Context aware recommendations for user-generated content on a social network site. In: EUROPEAN 
CONFERENCE ON INTERACTIVE TV, 7., 2009, Leuven. Proceedings... New York: ACM, 2009. p. 133-136. ISBN 978-1-60558-340-2. Disponível em: <http://doi.acm.org/10.1145/1542084.1542108>. Acesso em: 18 Mai. 2010.

PICCOLO, L. S. G.; BARANAUSKAS, M. C. C. Desafios de design para a tv digital interativa. In: BRAZILIAN SYMPOSIUM ON HUMAN FACTORS IN COMPUTING SYSTEMS, 7., 2006, Natal, RN. Proceedings... New York: ACM, 2006. p. 1-10. ISBN 1-59593-432-4. Disponível em: <http://doi.acm.org/10.1145/1298023.1298025>. Acesso em: 18 Mai. 2010.

PIMENTEL, M. d. G.; CATTELAN, R. G.; MElO, E. L.; FREITAS, G. B.; TEIXEIRA, C. A. Watch-and-comment as an approach to collaboratively annotate points of interest in video and Interactive-TV programs. In: ANXO CEREIJO ROIBAS AND AARON MARCUS AND RICCARDO SALA. Mobile TV: Customizing Content and Experience. London: Springer, 2010. (Human-Computer Interaction Series), p. 349-368. ISBN 978-1-84882-701-1. Disponivel em: <http://www.springerlink.com/content/j360331372045v41/>. Acesso em: 17 Mai. 2010.

PIMENTEL, M. d. G. C.; ABOWD, G. D.; ISHIGURO, Y. Linking by interacting: a paradigm for authoring hypertext. In: ACM CONFERENCE ON HYPERTEXT AND HYPERMEDIA, 11., 2000, San Antonio. Proceedings... ACM, 2000. p. 39-48. ISBN 1-58113-227-1. Disponivel em: <http://doi.acm.org/10.1145/336296.336315>. Acesso em: 18 Mai. 2010.

PIMENTEL, M. d. G. C.; GOULARTE, R.; CATTELAN, R. G.; SANTOS, F. S.; TEIXEIRA, C. A. C. Enhancing multimodal annotations with pen-based information. In: IEEE INTERNATIONAL SYMPOSIUM ON MULTIMEDIA WORKSHOPS, 9., 2007, Taichung. Proceedings... Washington: IEEE Computer Society, 2007. p. 207-213.

PIMENTEL, M. d. G. C.; GOULARTE, R.; CATTELAN, R. G.; SANTOS, F. S.; TEIXEIRA, C. A. C. Ubiquitous interactive video editing via multimodal annotations. In: EUROPEAN CONFERENCE ON INTERACTIVE TV, 6., 2008, Salzburg. Proceedings... Springer Berlin/Heidelberg, 2008. p. 72-81. ISBN 978-3-54069477-9. Disponível em: <http://dx.doi.org/10.1007/978-3-540-69478-6_8>. Acesso em: 18 Mai. 2010.

PIMENTEL, M. d. G. C.; PRAZERES, C.; RIBAS, H.; LOBATO, D.; TEIXEIRA, C. A. C. Documenting the pen-based interaction. In: BRAZILIAN SYMPOSIUM ON MULTIMEDIA AND THE WEB, 11., 2005, Poços de Caldas, MG. Proceedings... New York: ACM, 2005. p. 1-8. Acesso em: 18 Mai. 2010.

POUWELSE, J. A.; GARBACKI, P.; WANG, J.; BAKKER, A.; YANG, J.; IOSUP, A.; EPEMA, D. H. J.; REINDERS, M.; STEEN, M. R. van; SIPS, H. J. TRIBLER: a social-based peer-to-peer system. Concurrency and Computation: 
Practice and Experience, v. 20, n. 2, p. 127-138, 2008. Disponível em: <http://dx.doi.org/10.1002/cpe.1189>. Acesso em: 17 Mai. 2010.

PRISS, U. Formal concept analysis in information science. Annual Review of Information Science and Technology, New York, v. 40, n. 1, p. 521-543, 2006. ISSN 0066-4200.

RAIMOND, Y.; SINCLAIR, P.; HUMFREY, N. J. Programmes ontology. British Broadcasting Corporation, 2008. Disponivel em: <http://www.bbc.co.uk/ontologies/programmes/2008-02-28.shtml>. Acesso em: 18 Mai. 2010.

REISCHACH, F. von; MICHAHELLES, F.; SCHMIDT, A. The design space of ubiquitous product recommendation systems. In: INTERNATIONAL CONFERENCE ON MOBILE AND UBIQUITOUS MULTIMEDIA, 8., 2009, Cambridge. Proceedings... New York: ACM, 2009. p. 1-10. ISBN 978-1-60558-846-9. Disponível em: $<$ http://doi.acm.org/10.1145/1658550.1658552>. Acesso em: 18 Mai. 2010.

RYAN, N. ConteXtML: Exchanging Contextual Information between a Mobile Client and the FieldNote Server. Ago. 1999. 2006 p. Disponivel em: <http://www.cs.kent.ac.uk/projects/mobicomp/fnc/ConteXtML.html>. Acesso em: 17 Mai. 2010.

SALBER, D.; DEY, A. K.; ABOWD, G. D. The context toolkit: aiding the development of context-enabled applications. In: CONFERENCE ON HUMAN FACTORS IN COMPUTING SYSTEMS, 17., 1999, Pittsburgh. Proceedings... New York: ACM, 1999. p. 434-441. ISBN 0-201-48559-1. Disponível em: <http://doi.acm.org/10.1145/302979.303126>. Acesso em: 18 Mai. 2010.

SAMULOWITZ, M.; MICHAHELlES, F.; LINNHOFF-POPIEN, C. Capeus: An architecture for context-aware selection and execution of services. In: INTERNATIONAL WORKING CONFERENCE ON NEW DEVELOPMENTS IN DISTRIBUTED APPLICATIONS AND INTEROPERABLE SYSTEMS SYSTEMS, 3., 2001. Proceedings... Deventer: Kluwer, B.V., 2001. p. 23-40. ISBN 0-7923-7481-9.

SARCEVIC, A. "who's scribing?": documenting patient encounter during trauma resuscitation. In: CONFERENCE ON HUMAN FACTORS IN COMPUTING SYSTEMS, 28., 2010, Atlanta. Proceedings... New York: ACM, 2010. p. 1899-1908. ISBN 978-1-60558-929-9. Disponível em: <http://doi.acm.org/10$.1145 / 1753326.1753611>$. Acesso em: 18 Mai. 2010.

SARWAR, B.; KARYPIS, G.; KONSTAN, J.; REIDL, J. Item-based collaborative filtering recommendation algorithms. In: INTERNATIONAL CONFERENCE ON WORLD WIDE WEB, 10., 2001, Hong Kong. Proceedings... New York: ACM, 2001. p. 285-295. ISBN 1-58113-348-0. Disponivel em: <http://doi.acm.org/10.1145/371920.372071 >. Acesso em: 18 Mai. 2010. 
SCHILIT, B.; ADAMS, N.; WANT, R. Context-aware computing applications. In: WORKSHOP ON MOBILE COMPUTING SYSTEMS AND APPLICATIONS, 1994. PROCEEDINGS.,, 1994, Santa Cruz. Proceedings... Los Alamitos: IEEE Computer Society, 1994. p. 85-90. Disponível em: <http://ieeexplore.ieee.org/stamp/stamp.jsp?tp=\&arnumber=4624429 $>$. Acesso em: 18 Mai. 2010.

SCHMIDT, K.; BANNON, L. Taking CSCW seriously. Computer Supported Cooperative Work, Netherlands, v. 1, n. 1, p. 7-40, Mar. 1992. ISSN 1573-7551. Disponível em: <http://www.springerlink.com/content/p184xtj800225154/>. Acesso em: 17 Mai. 2010.

SHENG, Q. Z.; BENATALLAH, B. Contextuml: A uml-based modeling language for model-driven development of context-aware web services development. In: INTERNATIONAL CONFERENCE ON MOBILE BUSINESS, 4., 2006, Copenhagen. Proceedings... Los Alamitos: IEEE Computer Society, 2005. p. 206-212. ISBN 0-7695-2367-6. Disponivel em: <http://doi.ieeecomputersociety.org/10.1109/ICMB.2005.33>. Acesso em: 17 Mai. 2010.

SHI, Y.; XIE, W.; XU, G.; SHI, R.; CHEN, E.; MAO, Y.; LIU, F. The smart classroom: merging technologies for seamless tele-education. IEEE Pervasive Computing, Piscataway, v. 2, n. 2, p. 47-55, Abr. 2003. ISSN 1536-1268. Disponivel em: <http://dx.doi.org/10.1109/MPRV.2003.1203753>. Acesso em: 17 Mai. 2010.

SHIRKY, C. What is P2P... and what Isn't. Nov. 2000. Disponivel em: <http://openp2p.com/pub/a/p2p/2000/11/24/shirky1-whatisp2p.html >. Acesso em: 17 Mai. 2010.

SHRIMPTON-SMITH, T.; ZAMAN, B.; GEERTS, D. Coupling the users: The benefits of paired user testing for idtv. International Journal of Human-Computer Interaction, v. 24, n. 2, p. 197-213, Fev. 2008.

SKOUTAS, D.; KANTERE, V.; SIMITSIS, A.; SELLIS, T. Ontology-based data sharing in P2P databases. In: SEMANTIC WEB, ONTOLOGIES AND DATABASES, 2007, Vienna. Proceedings... Springer Berlin / Heidelberg, 2008. p. 117-137. ISBN 978-3-540-70959-6. Disponível em: <http://www.springerlink.com/content/52q84kg61827548x/>. Acesso em: 18 Mai. 2010.

STRANG, T.; POPIEN, C. L. A context modeling survey. In: INTERNATIONAL CONFERENCE ON UBIQUITOUS COMPUTING / WORKSHOP ON ADVANCED CONTEXT MODELLING, REASONING AND MANAGEMENT, 6., 2004, Nottingham. Proceedings... [S.L.: s.1.], 2004. p. 8.

TRUONG, K. N.; HAYES, G. R. Ubiquitous computing for capture and access. Foundations and Trends in Human-Computer Interaction, Hanover, v. 2, n. 2, p. 95-171, Fev. 2009. ISSN 1551-3955. Disponível em: <http://dx.doi.org/10$.1561 / 1100000014>$. Acesso em: 17 Mai. 2010. 
TULLIO, J.; HARBOE, G.; MASSEY, N. Investigating the use of voice and text chat in a social television system. In: EUROPEAN CONFERENCE ON INTERACTIVE TV, 6., 2008, Salzburg. Proceedings... Springer Berlin / Heidelberg, 2008. p. 163-167. ISBN 978-3-540-69477-9. Disponível em: $<$ http://www.springerlink.com/content/488m001630374315/>. Acesso em: 18 Mai. 2010.

WANG, J.; POUWELSE, J.; FOKKER, J.; VRIES, A. P. de; REINDERS, M. J. T. Personalization on a peer-to-peer television system. Multimedia Tools and Applications, v. 36, n. 1-2, p. 89-113, Jan. 2008. ISSN 1380-7501 (Print) 1573-7721 (Online). Disponivel em: <http://www.springerlink.com/content/lv10278q3p3090k5/>. Acesso em: 17 Mai. 2010.

WEISER, M. The computer for the 21 st century. Scientific American, v. 265, n. 3, p. 66-75, Set. 1991.

WEKA. Data Mining with Open Source Machine Learning Software in Java. 2010. Disponivel em: <http://www.cs.waikato.ac.nz/ml/weka/>. Acesso em: 15 Mai. 2010.

WIJNALDA, G.; PAUWS, S.; VIGNOLI, F.; STUCKENSCHMIDT, H. A personalized music system for motivation in sport performance. IEEE Pervasive Computing, Los Alamitos, v. 4, n. 3, p. 26-32, 2005. ISSN 1536-1268. Disponível em: $<$ http://doi.ieeecomputersociety.org/10.1109/MPRV.2005.47>. Acesso em: 17 Mai. 2010.

WITTEN, I. H.; FRANK, E. Data Mining: Practical machine learning tools and techniques. 2. ed. San Francisco: Elsevier, 2005. 524 p. ISBN 978-0-12-0884070 .

YANG, C.-S.; WANG, P.-C.; LIN, C.-L.; HOU, T.-W. Personalized idtv program in multimedia home platform. In: INTERNATIONAL CONFERENCE ON ADVANCED INFORMATION NETWORKING AND APPLICATIONS. Proceedings... [s.1.], 2008. p. 473-476. ISBN 978-0-7695-3096-3. Disponível em: <http://dx.doi.org/10.1109 /WAINA.2008.194>. Acesso em: 17 Mai. 2010.

YANG, S. J. H. Context aware ubiquitous learning environments for peer-to-peer collaborative learning. Educational Technology \& Society, v. 9, n. 1, p. 188-201, 2006. ISSN 1436-4522.

YIN, R. Case Study Research: Design and Methods. 4. ed. Thousand Oaks: Sage Publications, 2008. 240 p. ISBN 9781412960991.

ZHAI, G.; FOX, G. C.; PIERCE, M.; WU, W.; BULUT, H. esports: collaborative and synchronous video annotation system in grid computing environment. In: IEEE INTERNATIONAL SYMPOSIUM ON MULTIMEDIA, 7., 2005, Irvine. Proceedings... Los Alamitos: IEEE Computer Society, 2005. p. 9pp. Disponível 
em: <http://doi.ieeecomputersociety.org/10.1109/ISM.2005.55>. Acesso em: 18 Mai. 2010. 
APÊNDICE

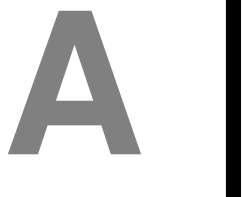

\section{Avaliações realizadas}

Este capítulo apresenta os formulários e documentos aplicados nas avaliações realizadas com os usuários.

\section{A. 1 Formulário de Percurso Cognitivo CWaCTool}

\section{Percurso Cognitivo}

\subsection{Descrição detalhada da CWACTool}

Aplicação para seleção e exibição de um vídeo, que permite ao usuário selecionar uma (ou mais) cena(s) específica(s) e solicitar compartilhamento dela(s) com outros usuários que estejam online na aplicação. Uma vez que o convite para compartilhamento de cena é aceito os usuários passam a anotar sobre as cenas de modo colaborativo, ou seja, todas as anotações feitas são visíveis por todos usuários que estejam participando da mesma sessão.

\subsection{Descrição da Tarefa a ser realizada}

\subsubsection{Escolher um video para exibir}

\subsubsection{Selecionar uma cena qualquer do vídeo}

\subsubsection{Solicitar compartilhamento da sessão}

\subsubsection{Enviar mensagem de chat}

\subsubsection{Anotar sobre o vídeo}

\subsection{Questões a serem respondidas (sobre cada tarefa acima)}


-O efeito de uma ação está de acordo com a meta do usuário?

•O usuário conseguirá identificar que uma ação está disponível?

- Guando o usuário encontra a ação disponivel, ele saberá que é a que ele precisa?

-Depois que a ação é realizada, o usuário entenderá o feedback dado pelo sistema?

\subsection{Lista Completa das Ações}

Executar o programa. Selecionar o arquivo de vídeo chamado paisagem.avi. Clicar sobre uma cena para selecioná-la. Compartilhar essa cena clicando no botão de compartilhar sessão na barra de tarefas. Enviar uma mensagem de chat. Fazer anotações quaisquer sobre a cena do vídeo.

\subsection{Descrição do perfil de usuário e experiência / conhecimentos exigidos}

Grupos de usuários: o usuário poderá ter experiência básica na área de informática, trabalhar com ou ser usuário de TV interativa. Em contextos educacionais a aplicação poderá ser usada para anotar sobre vídeos educativos em um contexto de educação a distância por exemplo. Na área de saúde pode-se utilizar para anotações em vídeos de exames (exemplo: cateterismo).

\section{A.2 Formulário Likert CWaCTool}

\begin{tabular}{|l||rllll|}
\hline Facilidade de Uso & Muito Fácil O & O & O & O & O Muito Difícil \\
\hline Estética do Sistema & Muito Boa O & O & O & O & O Muito Ruim \\
\hline Navegação do Sistema & Muito Clara O & O & O & O & O Muito Obscura \\
\hline Design dos Ícones & Muito Bom O & O & O & O & O Muito Ruim \\
\hline Funcionalidade do Sistema & Muito Útil O & O & O & O & O Sem Utilidade \\
\hline
\end{tabular}

Tabela A.1: Itens para usuário avaliar a ferramenta CWaCTool em cinco diferentes questões.

Questionário com escala de 5 pontos para avaliação dos itens. O questionário possui 5 itens:

1) Facilidade de Uso do Sistema: de modo geral se as funções estão claras, se o acesso a elas é fácil, se os termos utilizados favorecem à compreensão.

2) Estética do Sistema: de modo geral, se o contraste entre as cores usadas é ideal (os itens estão bem visíveis), se a disposição dos menus e botões favorece a utilização do sistema, se o tamanho e a posição das janelas é adequado.

3) Navegação do Sistema: se as funções que estão previstas para serem implementadas no protótipo podem ser facilmente encontradas na interface da aplicação. 
4) Design dos Ícones: se os formatos dos botões e as imagens utilizadas para os ícones torna a interpretação de suas funções claras, se é necessária uma descrição textual sobre a função do botão, ou se a imagem não é significativa para compreensão de sua utilidade no sistema.

5) Funcionalidades do Sistema: se você utilizaria funções de anotação sobre um vídeo, se essas anotações são úteis se forem realizadas em colaboração com outros usuários on-line, se você julga interessante a idéia de publicar os arquivos para serem usados em uma TV interativa (acessando os comentários de texto e áudio enquanto assiste ao vídeo.

Se julgar necessário, inclua na sua análise comentários e sugestões e críticas conforme sua avaliação. Comentários / Sugestões: 
